\title{
Untersuchungen über Lichtempfindlichkeit und Adaptierung des Vogelanges.
}

\author{
Von
}

Dr. phil. et med. Hans Honigmann.

(Aus dem Physikalischen und dem Physiologischen Institut der Universität Breslau.)

Mit 9 Textabbildungen.

(Eingegangen am 24. Januar 1921.)

Vorwort (S. 2).

\section{Inhalt.}

Einleitung. Terminologie (S. 3).

\section{Begrenzung der Aufgabe.}

1. Qualitative und quantitative Lichtwirkung (S. 5).

Unmöglichkeit einer unmittelbaren Messung der Farbwirkung.

Das Seebeck-Holmgrensche Prinzip.

Notwendigkeit der Untersuchung der quantitativen Lichtwirkung.

2. Ziele der Erforschung des Helligkeitssinnes (S. 8).

Relative Helligkeitswerte.

Relative Empfindlichkeitswerte.

Absolute Empfindlichkeitswerte.

\section{Wege zur Lösung der Aufgabe.}

1. Messung von Äquivalenten der Empfindungsstärke (S. 10). Objektive Methoden.

Handlungen des Tieres als Ausdruck der herrschenden Empfindungsstärke.

2. Messung der Reizstärke (S. 13).

Direkte Messung.

Indirekte Messung..

\section{Physikalische Versuchstechnik.}

1. Kritische Besprechung der Versuchsanordnung (S. 14).

Lichtquelle, Erzeugung vòn Licht verschiedener Brechbarkeit, Intensitätsvariation.

2. Beschreibung der Apparatur (S. 18).

3. Ermittelung der physikalischen Konstanten (S. 19).

Die Energieverteilung im Spektrum des Nernstlichtes.

Ermittelung der Dispersion im objektiven Spektrum.

Die selektive Absorption der Reiskörner.

\section{Physiologisehe Versuchstechnik.}

1. Ausgestaltung der Technik (S. 25).

2. Ausführung der Versuche (S. 27).

Untersuchung der Lichtempfindlichkeit helladaptierter Tiere.

Untersuchung der spezifischen Empfindlichkeitszunahme für Licht von verschiedener Wellenlänge während der Dunkeladaptierung. 


\section{Die Versuchsergebnisse.}

1. Chronologische Übersicht (S. 33).

2. Die graphische Darstellung der Versuchsergebnisse (S. 35).

Schwellenwerte und Empfindlichkeitswerte.

Graphische Darstellung der Adaptierung.

3. Kritik der Versuchsergebnisse (S. 39).

Vergleich der Lichtempfindlichkeit von Mensch und Huhn im Zustand der Helladaptation.

Die Grenzen des (für das helladaptierte Huhn sichtbaren) Spektrums. (S. 46). Der Unterschied zwischen der Lichtempfindlichkeit junger und geschlechtsreifer Hähne (S. 47).

Vergleich der Empfindlichkeit hell- und dunkeladaptierter Hühner (S. 49).

Der Vorgang der Dunkeladaptierung (S. 51).

Zur Theorie der Dunkeladaptierung (S. 57).

Neue Aufgaben der Forschung (S. 59).

VI. Zusammenfassung der Ergebnisse (S. 62).

Tabellen (S. 63).

Abbildungen (S. 67).

Literatur (S. 70).

\section{Vorwort.}

Der ursprüngliche Plan der vorliegenden Arbeit war eine experimentelle Untersuchung der Lichtempfindlichkeit von Vertretern aller Wirbeltierklassen. Nach einigen Vorversuchen stellte sich heraus, daß mit den mir damals zur Verfügung stehenden Hilfsmitteln nicht derjenige Grad von Genauigkeit zu erreichen war, den ich für nötig hielt. Die Versuche ruhten nun einige Zeit, bis mir Ostern 1913 Herr Professor L u m mer einen Arbeitsraum im Physikalischen Institut überließ. Die Apparate, mit denen ich jetzt arbeitete, gehörten zum großen Teil zu dem Material, das in der Experimentalvorlesung verwendet wurde. Damit war die Dauer meiner Untersuchungen natürlich von vornherein beschränkt. Ich begann die Arbeit im Mai 1913 (der Aufbau der Apparatur und die Auswertung verschiedener physikalischer Konstanten dauerte etwa einen Monat) und mußte damit rechnen, sie im Januar 1914 abzubrechen. Deshalb verzichtete ich bald auf die Untersuchung verschiedener Tierarten und beschränkte mich auf Hühner oder richtiger auf Hähne, da die von mir ganz jung gekauften Hühnchen sich später zufällig sämtlich als Hähne erwiesen.

In dem relativ kurzen Zeitraum von 8 Monaten, in dem ich gleichzeitig noch mit einer anderen, sehr zeitraubenden Arbeit beschäftigt war, konnte ich nicht alle Messungen so oft ausführen, wie es mir wünschenswert erschien. Immerhin gelangte die Arbeit zu einem gewissen Abschluß. Von einer Veröffentlichung sah ich zunächst $a b$, weil ich noch histologische Untersuchungen der Netzhaut in ganz bestimmter Richtung vornehmen wollte. Während ich noch mit dieser Arbeit beschäftigt war, brach der Krieg aus. In den ersten Kriegs- 
wochen, ehe ich ins Feld rückte, habe ich die Teile I bis $V, 1$ schriftlich fixiert und abgesehen von geringfügigen Änderungen auch jetzt in der ursprünglichen Fassung wiedergegeben. Im Juli 1916 habe ich einen kurzen Bericht über die wichtigsten Ergebnisse veröffentlicht, fand jedoch . keine Zeit zu einer ausführlichen Darstellung.

In den folgenden Jahren erschienen einige Arbeiten von anderen Autoren, die sich zum Teil mit ähnlichen Fragen beschäftigten wie meine Untersuchung und die zur Klärung mancher Probleme beitrugen. Da nun aber gewisse, von mir gefundene Tatsachen von anderer Seite bisher anscheinend noch nicht entdeckt worden sind, sehe ich mich nun doch genötigt, mein ganzes Material zu veröffentlichen.

Ich bin mir wohl bewußt, daß die große zeitliche Differenz von mehr als 6 Jahren, die zwischen der Abfassung von Teil I-V, 1 und V, 2-VI liegt, die Gleichmäßigkeit der Darstellung ungünstig beeinflußt. Aus äußeren Gründen habe ich jedoch von einer völligen Umarbeitung Abstand genommen und bitte, dies zu berücksichtigen, wenn die neuere Literatur ungleichmäßig zitiert worden ist

Zum Schlusse muß ich noch bemerken, daß diese Untersuchung ohne das alle meine Hoffnungen übertreffende Entgegenkommen von Prof. Lummer, der meine Arbeit in jeder Weise unterstützte und förderte, niemals zustande gekommen wäre. Es ist mir ein Bedürfnis, Ferrn Prof. Lummer auch hier nochmals herzlichen Dank zu sagen.

Zu großem Danke hat mich auch Herr Prof. R. F. F uchs verpflichtet, der mir immer bereitwillig ratend und helfend zur Seite stand.

Während meiner Arbeitszeit im physikalischen Institut wurde ich bei feineren, rein physikalischen Messungen von Damen und Herren, die im Institut arbeiteten, vielfach aufs freundlichste unterstützt. Ihnen allen sage ich auch hier nochmals meinen besten Dank.

\section{Einleitung.}

Am Anfang einer Untersuchung über die Lichtempfindlichkeit erscheint es zweckmäßig, den Begriff der Empfindlichkeit eng zu begrenzen. Im gewöhnlichen Sprachgebrauch dient der Begriff der Empfindlichkeit vielfach zur Bezeichnung der Reaktionsfähigkeit eines physikalischen, chemischen oder biologischen Komplexes. Andererseits versteht man darunter aber auch das Maß der Reaktionsfähigkeit. Um. diese beiden verschiedenen Begriffe sprachlich voneinander zu trennen, wollen wir die Reaktionsfähigkeit an und für sich, soweit es sich dabei um Reaktionen biologischer Komplexe handelt, nur mit dem Namen Reizbarkeit oder Erregbarkeit bezeichnen und den Begriff der Empfindlichkeit zur Bezeichnung des Maßes der Reizbarkeit aufsparen.

Die Empfindlichkeit in diesem Sinne ist das Verhältnis der Reaktionsstärke zur Reizstärke.

Wird bei gleichbleibendem Reiz die Reaktion stärker, so steigt die Empfindlichkeit. Sie steigt aber natürlich auch dann, wenn bei abnehmender Reizstärke die Reaktion unverändert bleibt. 
Der Begriff der Empfindlichkeit sagt gar nichts darüber aus, ob der empfindliche Komplex auch eine Empfindung besitzt. Wenn wir nämlich von der Empfindlichkeit einer Wage oder der Lichtempfindlichkeit einer photographischen Platte sprechen, so denken wir nicht daran, der Wage eine Druckempfindung oder der Platte eine Lichtempfindung zuzuschreiben.

Reagiert aber ein Tier auf einen Reiz, so nehmen wir in vielen Fällen an, daß dieser Reaktion auch eine Empfindung entspricht, die der betreffende Reiz ausgelöst hat, weil auch bei uns selbst die durch äußere oder innere Reize ausgelösten Reaktionen unseres Körpers von entsprechenden Empfindungen begleitet werden. $D^{*}$ e Annahme einer Existenz von Empfindungen bei höheren Tieren können wir zwar nicht entbehren, dürfen aber nicht vergessen, da $B$ sich diese Existenz mit den Methoden der Naturwissenschaft nicht beweisen läßt.

Es ist also letzten Endes nicht ganz korrekt, wenn weiter unten von der Messung der Empfindungsstärke die Rede sein wird. Streng genommen müßte man immer nur von der Messung solcher Reaktionen sprechen, denen - wie wir annehmen - die Stärke der Empfindung aus irgend welchen Gründen äquivalent ist. $\mathrm{Ob}$ diese Gründe auch wirklich überzeugend sind, ist natürlich von Fall zu Fall zu prüfen. Haben wir jedoch erst einmal geeignete Reaktionen gefunden, so können wir in unserer Definition der Empfindlichkeit den Begriff der Empfindungsstärke für den der Reaktionsstärke einsetzen. Dann ist die E $\mathbf{m p}$ findlichkeit eines Organismus für einen beliebigen Reiz das Verhältnis der Empfindungsstärke zur Reizstärke.

Nächst dem Begriff der Empfindlichkeit wird uns der Begriff der Helligkeit am häufigsten beschäftigen. Ich wende ihn ausschließlich zur Bezeichnung der Größe der Lichtempfindung an, da eine eindeutige Bezeichnung dafür bisher fehlte.

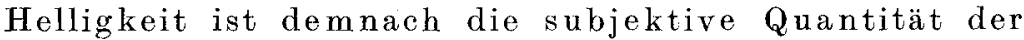
Reizwirkung a uf das lichtempfindliche Organ.

Der von Helmholtz zuweilen angewandte Ausdruck ,objektive Helligkeit" zur Bezeichnung der objektiven Energie der Strahlung ist hier nicht mehr gebraucht worden, da er nach unserer Definition eine contradictio in adjecto bedeuten würde.

Der Begriff des „Lichtes“ ist eigentlich auch rein subjektiv, hat sich aber zur Bezeichnung von objektiven Strahlungserscheinungen so eingebürgert, daß hier eine strenge Scheidung praktisch nicht mehr durchführbar ist. War eine solche Scheidung nötig, so ist hier stets die subjektive Helligkeit der objektiven Energie oder Intensität der Strahlung gegenübergestellt worden. Der Begriff der „Lichtstärke", der von manchen in subjektiven, von anderen in objektivem Sinne gebraucht wird, ist entbehrlich und daher stets vermieden worden. 
Der Begriff ,Farbe" ist ebenso wie „Helligkeit" stets in subjektivem Sinne gebraucht worden. „Farbe" bezeichnet also die Qualität der Lichtempfindung, während die objektive Verschiedenheit der Strahlungen durch Angabe ihrer Wellenlänge, Brechbarkeit oder Schwingungszahl gekennzeichnet wurde. Als ,homogenes" Licht sind hier stets Strahlungen von nahezu gleicher Wellenlänge oder Brechbarkeit bezeichnet worden, also monochromatisches, nicht gleichmäßig verteiltes licht.

Mit dem Namen ,Adaptation" wurde bisher sowohl der Vorgang der Empfindlichkeitszunahme des Sehorgans, wie auch der gerade vorhandene $Z$ ustand der Lichtem pfindlichkeit bezeichnet. Um diese beiden Begriffe zu trennen, habe ich den Vorgang ,Adaptierung" genannt und den alten Namen nur zur Bezeichnung von bestimmten Empfindlichkeitszuständen des Auges beibehalten.

\section{Begrenzung der Aufgabe.}

1. Qualitative und quantitative Lichtwirkung.

Jede Wirkung einfachen Lichtes auf das normale menschliche Auge läßt sich in zwei Komponenten zerlegen, in eine quantitative (Helligkeit) und in eine qualitative (Farbe). Erst die Untersuchung von Hellig. keitssinn und Farbensinn zusammen lehrt uns den gesamten Lichtsinn eines Organismus kennen.

Die Erforschung des Helligkeitssinnes erfolgt in der Weise, daB man feststellt, wie hell Strahlungen von bestimmter Intensität unter verschiedenen Bedingungen erscheinen. Bekanntlich besteht nämlich zwischen subjektiver Helligkeit und objektiver Strahlungsintensität durchaus keine einfache Beziehung. Einmal ist die Helligkeit von der Wellenlänge des Lichts abhängig, d. h. zwei Lichter von gleicher objektiver Intensität und verschiedener Brechbarkeit erscheinen meist ganz verschieden hell. Ferner ist die absolute Größe der Strahlung insofern von Einfluß auf die relative Stärke der Helligkeitsempfindung, als unser Auge die Fähigkeit hat, sich in weiten Grenzen der herrschenden mittleren Helligkeit anzupassen. So kann bei einem bestimmten Stande der Adaptation, wie diese Anpassungserscheinung genannt wird, eine Strahlung von sehr geringer Intensität ebenso hell erscheinen wie eine viel intensivere, die das an größere Helligkeit adaptierte Auge wahrnimmt. Zu beachten ist hierbei natürlich, da 3 diese Anpassungserscheinungen Zeit brauchen und zwar die Anpassung an geringere Helligkeit im allgemeinen mehr als die an größere. Vernachlässigt wird leider meist die Tatsache, daß auch auf den zeitlichen Verlauf der Anpassung die Wellenlänge des Lichtes einen entscheidenden Einfluß ausübt, obgleich diese Tatsache schon in dem so bekannten Purkinjeschen Phänomen implicite enthalten ist. 
Eine Reihe weiterer Faktoren kann die Untersuchung des menschlichen Helligkeitssinnes erschweren. So kann zum Bespiel der Genuß von Reizmitteln (Santonin) oder auch Ermüdung usw. das Verhältnis von Helligkeit und Intensität beeinflussen.

Alle diese Tatsachen sind natürlich in Betracht zu ziehen, wenn es sich darum handelt, Aufschluß über den tierischen Helligkeitssinn zu erhalten. Es ist freilich durchaus nicht ausgeschlossen, daß bei Tieren die Verhältnisse einfacher liegen - ebenso gut können wir hier aber auch noch weitere Schwierigkeiten finden. So ist es denkbar, daß bei irgend welchen Tieren die relative Stärke der Helligkeitsempfindung etwa rhythmischen Schwankungen unterliegt, die von der Tages- oder Jahreszeit abhängen, oder es könnten auch Unterschiede zwischen alten und jungen, männlichen und weiblichen Tieren bestehen. Jedenfalls mu $B$ man auf alle derartigen Möglichkeiten gefaßt sein und durch entsprechende Kontrollmessungen ihre Existenz nachprüfen.

Ein Punkt von grundsätzlicher Wichtigkeit ist jetzt hervorzuheben. Bei der Untersuchung des Helligkeitssinnes stehen uns - später zu besprechende - Methoden zu Gebote, die uns gestatten, die rein quantitative Wirkung verschiedener Strahlungen zu messen, ohne daß ihre qualitativ möglicherweise verschiedene Wirksamkeit (,Farbe") diese Messung störend beeinflußte.

Wie steht es nun mit dem Farbensinn? Sind wir bei seiner Erforschung in der gleich glücklichen Lage, die hier allein in Frage kommende qualitative Wirkung von der quantitativen so zu trennen, wie es im Interesse einer eindeutigen Feststellung unbedingt nötig ist?

Zur Beantwortung dieser Frage ist zunächst der Begriff des Farbensinns scharf zu begrenzen. Wir müssen hier alles Akzidentelle weglassen, wie etwa die Beziehung der Farben zueinander beim normalen menschlichen Farbensinne, oder den typischen (menschlichen) Helligkeitswert jeder Farbe bei bestimmter Intensität usw. A priori ist nämlich ein Organismus ohne weiteres denkbar, der echten Farbensinn besitzt und doch die Farben stets so hell sieht, wie sie einem total farbenblinden Menschen erscheinen würden. Das einzige wesentliche Kennzeichen eines Farbensinns ist die Fähigkeit eines Organismus, zwei Strahlungen abgesehen von ihrer subjektiven Quantität (Helligkeit), alsonurihrer Qualitätnach zu unterscheiden. Haben wir zwei Strahlungen von verschiedener Brechbarkeit und wollen wir prüfen, ob sie qualitativ verschieden wirken, so müssen wir vorher unbedingt die eventuell verschiedene quantitative Wirkung ausschalten.

Diese Forderung ist nun meist durchaus vernachlässigt worden. 
Die alten, nunmehr beinahe historisch gewordenen Graberschen „Zweikammerversuche" (1884) zeigen, zu was für abenteuerlichen Resultaten man kommt, wenn man bei Beurteilung der Wirkung einer Strahlung immer nur das postulierte Quale und nie das wirklich vorhandene Quantum berücksichtigt. Auch in einer Reihe späterer Arbeiten (B a u er 1910, Babak 1913), die sich mit der Erforschung des tierischen Farbensinnes beschäftigen, findet sich der eben genannte Fehler. Da diese Arbeiten von einer falschen Voraussetzung ausgehen, so sind ihre Resultate meist wertlos.

Einen großen Fortschritt in der experimentellen Behandlung des Problems stellen die Versuche von C. Hess dar. Dieser Forscher untersuchte den Farbensinn von Tagvögeln nach dem Seebeek-Holmgrenschen Prinzip, indem er die Tiere etwa an das Nichtfressen von gelblich-roten Körnern gewöhnte und dann feststellte, daB diese Tiere später alle vorwiegend rötlichen Körner unter verschiedenen grünen und grauen liegen ließen, also eine Unterscheidung zuwege brachten, die ein sog. rotgrünblinder Mensch in einem Kontrollversuch nicht leisten konnte.

„Für diesen Rotgrünblinden", sagt Hess (1912, S. 575), „,waren also verschieden gefärbte Körner ähnlich oder gleich, die das Huhn mit voller Sicherheit unterschied. Nur für ein Auge mit den Sehqualitäten eines normalen Mensehen haben die verschieden roten Körner das gemeinsame Merkmal der Rötlichkeit . . ."

Während also bisher die Helligkeitswirkung der Strahlungen meist ganz vernachläßigt wurde, finden wir sie hier insofern berücksichtigt, als die verschieden hellen rötlichen Körner von allen anderen., die offenbar auch ganz verschieden hell erschienen, unterschieden werden mußten.

Der große Vorteil dieser Methode, die zunächst einen völlig befriedigenden Eindruck macht, liegt darin, daß sie gestattet, den Farbensinn (oder genauer die spezifische Wirksamkeit von Licht bestimmter Brechbarkeit) eines Tieres zu untersuchen, ohne daß es nötig wäre, auch über seinen Helligkeitssinn genauere Messungen anzustellen.

In einem nicht unwesentlichen Punkte ist aber auch dieses Verfahren noch unbefriedigend. Es setzt nämlich stillschweigend voraus, daß der Helligkeitssinn der zu untersuchenden Tiere dem des normalen Menschen zum mindesten sehr ähnlich sei.

Nehmen wir nun einmal an, daß auf irgend ein Tier langwellige Strahlen ganz besonders stark einwirken oder kurz gesagt, daß es rote Farbtöne sehr hell sieht, und dressieren wir es nun auf Rot, so erreichen wir vielleicht nichts anderes, als eine Dressur auf die hellsten Strahlungen. Lassen wir jetzt auf das Tier rote, grüne und graue Lichter einwirken, so ist es ohne weiteres möglich, daß es die roten nur deshalb von allen anderen unterscheidet, weil sie ih $\mathrm{m}$ viel heller erscheinen.

Zieht man diese Möglichkeit in Betracht, so verliert die genannte Untersuchungsmethode an Wert, und ich kann jetzt schon vorausschicken, daß es sich nicht um eine Möglichkeit, sondern um eine Tatsache handelt, wie die näheren Prüfungen ergeben haben.

Wir kommen damit notwendig zu dem Schlusse, daß es unmöglich ist, über den Farbensinn eines Tieres befriedigenden Aufschluß zu erhalten, ehe wir seinen Helligkeitssinn kennen gelernt haben. 


\section{Ziele der Erforschung des Helligkeitssinnes.}

Drei grundsätzlich verschiedene Wege stehen uns zur Verfügung, um den Helligkeitssinn eines fremden Organismus zu erforschen. Einmal können wir die Stärke seiner Helligkeitsempfindungen mit unseren Helligkeitswerten vergleichen; zweitens können wir die Beziehungen zwischen Helligkeitsgraden und Strahlungsintensitäten feststellen, oder einfacher: untersuchen, in welchem Intensitätsverhältnis je zwei für das Tier gleich helle Strahlungen stehen, und drittens können wir die bestimmten Helligkeitsgraden zugrunde liegenden Intensitätswerte in absolutem Maße messen. Im.ersten Fall erhalten wir relative - auf den Menschen bezogene - Helligkeitswerte, im zweiten Fall relative Empfindlichkeitsweite, und im dritten absolute Empfindlichkeitswerte. Unter der Empfindlichkeit eines Organismus als Maß für einen beliebigen Reiz ist ja nichts anderes zu verstehen, als das Verhältnis der Empfindungsstärke zur Reizstärke, hier also der subjektiven Helligkeit zur objektiven Strahlungsintensität.

Die erste Methode, also die Ermittelung relativer Helligkeitswerte ist die einfachste, aber unvollkommenste.

Wir können mit ihrer Hilfe Aufschluß über die Empfindlichkeit eines Organismus erhalten, ohne daß es nötig wäre, unmittelbar Messungen seiner Empfindlichkeit selbst vorzunehmen.

Wirkt etwa, um ein Beispiel zu geben, die Strahlung eines Spektrums zugleich auf das menschliche Auge und auf das eines Tieres und ergibt sich aus berechtigten Analogieschlüssen, daß ein bestimmter blauer Spektralbezirk auf das Tierauge einen schwächeren Reiz ausübt als auf das menschliche, so dürfen wir natürlich schließen, daß hier die Empfindlichkeit des Tieres geringer ist als unsere, ohne daß wir auch nur eine der beiden Empfindlichkeiten selbst zu messen brauchten.

Wir können mit der gleichen Methode, also ohne jede Bestimmung der objektiven Strahlungsintensität noch eine Reihe weiterer Aufschlüsse erhalten. Wir können nämlich z. B. eine rote und eine blaue Strahlung aussuchen, die einem Tiere beide gleich hell erscheinen und können nun feststellen, wieviel heller uns das Blau als das Rot erscheint. Man erhält auf diese Weise eine Reihe von Zahlenwerten für die tierische Empfindungsstärke, d. h. für die Helligkeit, die das Tier bei einer bestimmten Strahlung empfindet. Ich betone nochmals, daß diese Werte relativ sind und sich auf menschliche Helligkeitswerte beziehen. Damit sind sie natürlich zugleich von der menschlichen Empfindlichkeit abhängig.

Die genannte Methode ist durchaus geeignet, eine Übersicht über den Lichtsinn eines Tieres zu geben und gestattet auch unter gewissen Vorsichtsmaßregeln, wie eben angedeutet wurde, die Vornahme gröberer Messungen. Handelt es sich jedoch um entscheidende Messungen, 
so darf man sich nicht mit ihr begnügen. Die Schwäche der Methode liegt in ihrer Voraussetzung; sie nimmt nämlich stillschweigend an, daB die menschliche Lichtempfindlichkeit konstant ist. Dies ist bekanntlich durchaus nicht der Fall, vielmehr schwankt gerade die menschliche Lichtempfindlickheit außerordentlich. Auch bei gleichen äußeren Bedingur gen lösen zwei Lichtreize von völlig gleicher Intensität und Qualität bei ein und demselben Beobachter oft zwei ganz verschieden starke Helligkeitsempfindungen aus.

Der konstante Punkt, auf den wir die experimentell gefundenen relativen Helligkeitswerte beziehen, existiert also garnicht, oder ist zum mindesten so schwankend, daß wir eine kaum übersehbare Fehlerquelle in unsere Methode hineintragen.

Selbst ganz abgesehen von diesem einen Grunde, der schon allein dafür spricht, bei feineren Messungen wenigstens nicht nur relative Helligkeitswerte, sondern Empfindlichkeitswerte zu bestimmen, macht ein zweiter Umstand dieses Vorgehen unbedingt erforderlich. Eine befriedigende Analyse der adaptativen Vorgänge ist nämlich ohne die Berücksichtigung von Empfindlichkeitswerten unmöglich, wie im V. Abschnitt gezeigt werden wird.

Der zweite Weg, die Ermittelung relativer Empfindlichkeitswerte, ist komplizierter, aber bedeutend exalkter als die eben besprochene Methode. Gemäß der Definition der Lichtempfindlichkeit, die wir oben gaben, stellt deren Messung eine doppelte Aufgabe dar: erstens nämlich ist die objektiv vorhandene Stärke des Reizes zu messen etwa als kinetische Energie oder als Wärmemenge -- und zweitens ist die dadurch im Organismus ausgelöste Empfindung ihrer subjektiven Intensität nach zu bestimmen. Bei der Messung der Reizstärke begnügen wir uns mit relativen Werten, $d . h$. Größen, die sämtlich einen beliebigen unbekannten, aber stets gleichen Faktor enthalten. Oder mir anderen Worten: wir messen nicht Intensitäten in absolutem Maße, sondern Intensitätsverhältnisse. Wenn wir unsere Werte nun relative Empfindlichkeitswerte nennen, so handelt es sich um die Beziehungen zu diesen einen unbekannten, aber konstanten Faktor, nicht aber etwa um eine Beziehung zu der inkonstanten menschlichen Empfindlichkeit, wie bei der vorigen Methode.

Der dritte. Weg, die Ermittelung absoluter Empfindlichkeitswette, bietet, - um es gleich vorweg zu nehmen - im Vergleich zu der eben genannten Methode keinen prinzipiellen Vorteil, denn wenn wir außer den wahren Intensitätsverhältnissen die jeweiligen Intensitätswerte selbst absolut messen, so hat das u. a. den Vorteil, daß die Ergebnisse verschiedener Untersucher ohne Umrechnung miteinander verglichen werden können. Das ist aber ein Gesichtspunkt von durchaus untergeordneter Bedeutung und das Wesentliche bleibt, daß die Unter- 
suchungsmethode selbst nicht verfeinert werden kann, wenn wir die Intensitäten der Strahlung in absolutem Maße messen. Äußerlich zeigt sich diese Tatsache sehr deutlich, wenn wir die mit Hilfe der zweiten und dritten Methode gewonnenen Resultate etwa graphisch darstellen und vergleichen: die Kurven haben zwar nicht gleiche Form, aber natürlich gleiche Maxima und gleiche relative Steilzeit des An- und Abstiegs. Das ist aber das Wesentliche, worauf es ankommt.

Wir fassen unsere bisherigen Erwägungen noch einmal kurz zusammen.

1. Untersuchungen über die spezifische Wirksamkeit von farbigen Lichtern sind wertlos, wenn die Intensität der Strahlungen nicht auch berücksichtigt wird.

2. Die Berücksichtigung der verschiedenen Helligkeitswirkung im Sinne der Seebeck-Holmgrenschen Methode ist zwar als Fortschritt zu betrachten, aber immer noch relativ ungenügend, da der Helligkeitssinn des zu untersuchenden Tieres sich möglicherweise von dem unsriğen so stark unterscheidet, daß die genannte Methode in der üblichen Anwendungsform versagen kann.

3. Erst die vorhergehende genauere Untersuchung des Helligkeitssinnes eines Tieres unter den verschiedensten Bedingungen liefert die Basis für die einwandfreie Erforsch!ng seines etwa vorhandenen Farbensinnes, der dann natürliche auch nach dem Seebeck-Holmgrenschen Prinzip untersucht werden kann.

Für die Erforschung der quantitativen Wirksamkeit verschiedener Lichter gelten wiederum drei Grundsätze:

1. Zur ersten Orientierung über den Helligkeitssinn genügen Messungen, bei denen relative, auf menschliche Empfindungsstärken bezogene Helligkeitswerte festgestellt werden.

2. Die Ermittelung der relativen Empfin lichkeitswerte ermöglicht eine wesentliche Verfeinerung der Methode. Für das Verständnis der adaptiven Vorgänge sind solche Werte unerläßlich.

3. Die Bestimmung der absoluten Empfindlichkeitswerte besitzt keinen prinzipiell neuen Wert, da die Genauigkeit der Methode dadurch nicht gesteigert werden kann.

\section{Wege zur Lösung der Aufgabe.}

1. Messung von Äquivalenten der Empfindungsstärke.

Nachdem wir unsere Aufgabe nunmehr kennen gelernt haben, wollen wir uns nach Wegen umsehen. die zu ihrer Lösung führen. Wie schon oben angedeutet, zerfällt die Messung der Empfindlichkeit erstens in die Feststellung der Empfindungsstärke des Tieres und zweitens in die Messung der Intensitäten oder der Intensitätsverhältnisse der Reize. 
Wir beginnen mit der Frage, wie beim Tier die Empfindungsstärke, hier also der Helligkeitsgrad, zu messen ist.

Wie erhalten wir nun vom Tier Aufschluß über die Stärke seiner Empfindung?

Es liegt am nächsten, nach solchen Reaktionen des Tierkörpers zu suchen, die als objektiv wahrnehmbare und damit unmittelbar meßbare Vorgänge in einer gewissen Propartionalität zur Empfindungsstärke stehen. Wir kennen eine ganze Reihe derartiger Reaktionen, von denen hier als für uns in Betracht kommend die Aktionsströme der Retina, ferner die sichtbaren Veränderungen des Netzhautgewebes und schließlich noch die Pupillarreaktion genannt seien.

Leider sind alle diese Vorgänge messend nicht sehr genau zu verfolgen und man erhält daher wenig detaillierte Resultate, wenn man sie als Maßstab der Empfindungsstärke benutzt.

Aus der Fülle von Arbeiten, die auf diese Weise eine Analyse der Lichtempfindlichkeit erstreben, sei nur eine ganz besonders klare und schöne Arbeit von Hertel erwähnt. Dieser Forscher untersuchte (1907) die Empfindlichkeit der Netzhaut des Menschen und einer Froschart und wählte als Maß für die beim Frosche anzunehmende Empfindungsstärke den Kontraktionszustand der Netzhautzapfen. Obglejch nun Hertel den Begriff der Empfindlichkeit aufs schärfste definierte und die zu ihrer Messung erforderliche Intensitätsbestimmung der Strahlung sehr exakt durchführte, so konnte er doch nur zu wenig positiven Ergebnissen gelangen, da eben die Messung der subjektiven Vorgänge mit einem viel zu groben Maßstabe vorgenommen wurde. Der Wert der auf diese Weise einmal gewonnenen Resultate wird dadurch natürlich nicht beeinträchtigt, aber ich bin überzeugt, daß man mit dem gleichen physikalischen und feinereǹ „,physiologischen" Meßmethoden bedeutend reichere Ergebnisse erhalten könnte.

Ähnlich verhält es sich mit den Netzhautströmen, die meist am enucleierten Auge untersucht wurden. Die vorhandenen Potentialdifferenzen lassen sich zwar sehr bequem und genau messen, aber die Ströme selbst konnten bisher nicht genügend konstant gehalten werden, um eindeutige Versuchsreihen von längerer Dauer anzustellen. Bis vor kurzem gelang es nicht einmal, den Ruhe- oder Dunkelstrom auch nur länger als etwa eine Viertelstunde konstant zu erhalten, und die Aktionsströme selbst sanken bei gleichbleibendem Reiz schon nach wenigen Minuten beträchtlich ab. Erst im vorigen Jahre haben Kohlra usch und Brossa (1913), einer Anregung von v. Brücke und Garten (1907) folgend, die Methodik wesentlich vervollkommnet. Sie erhielten nämlich an intakten, in situ belassenen Augen von kuraresierten Frösehen (R. esculenta) nicht nur einen fast konstanten Ruhestrom, sondern konnten auch, falls nicht allzu starke Lichtreize vorzeitig ermüdeten, die Aktionsströme etwa zwei Stunden lang konstant erhalten.

Trotz dieses schönen Fortschrittes weisen die Methoden der Aktionsstromuntersuchung noch manche Mängel auf, die vielleicht nicht alle kompensiert werden können, da sie eben in der Methode selbst begründet sind. So dürfen wir schließlich nie vergessen, daß es sich hier doch um erhebliche Eingriffe in den lebenden Organismus handelt - - andererseits ist zu hoffen, da $B$ auf diesem Weg zwar nicht die feinere quantitative, dafür aber die qualitativ verschiedene Wirkung von Lichtreizen auf die Netzhaut der experimentellen Analyse zugänglich werden wird ${ }^{1}$ ).

1) Diese Hoffnung ist inzwischen teilweise in Erfüllung gegangen, wie die Arbeiten von Kohlrausch und Brossa (1914) und Kohlrausch (1918) zeigen. 
Schließlich ist noch die Pupillarreaktion zu besprechen. Sie erscheint zunächst für unsere Zwecke wiederum sehr brauchbar, da Untersuchungen von Hess (1908) es sehr wahrscheinlich gemacht haben, daß die gleichen nervösen Elemente sowohl die optischen wie die pupillomotorischen Reize perzipieren und daß eine gewisse Proportionalität zwischen Helligkeitsempfindung und Iriskontraktion besteht, worauf Sachs schon (1892, 1893) hingewiesen hatte. (Es handelt sich hier natürlich nur um Versuche an Tieren mit intakten Reflexen von den direkten Wirkungen nach Opticusdurchschneidung [Hertel 1906] ist abzusehen, da anscheinend zwischen ihnen und der anzunehmenden Helligkeit keine unmittelbar proportionalen Beziehungen bestehen.)

Mit der genannten Methode ist schon eine Reihe schöner Resultate erzielt worden. Die Pupillenreaktion ist aber doch ein in zu engen Grenzen oder mitunter zu schwierig zu verfolgender Vorgang, als daß wir mit seiner Hilfe feinere messende Untersuchung anstellen können.

Wir verlassen deshalb diese zuweilen unersetzlichen ,objektiven" Methoden und versuchen auf einem prinzipiell durchaus anderen und theoretisch komplizierterem Wege, uns der Lösung des Problemes zu nähern, indem wir das Tier veranlassen, uns vermittelst spontaner Handlungen Aufschluß über die Stärke seiner Empfindungen zu geben.

Während wir also bisher den Organismus oder Teile davon als Objekt studierten, betrachten wir jetzt das Tier als Subjekt.

Die Schwierigkeiten einer Methodik, der dieses Prinzip zugrunde liegt, und die Beseitigung dieser Schwierigkeiten wird weiter unten ausführlich besprochen werden. Hinweisen möchte ich jedoch an dieser Stelle auf Gedanken v. Uexkülls (1912, S. 107), der die Notwendigkeit einer derartigen Auffassung öfters betonte.

Es erhebt sich nun die Frage, auf welche Weise wir vom Tier als Subjekt Auskunft darüber erhalten können, wie stark bei ihm eine Empfindung ist, wie hell ihm eine Strahlung erscheint.

Bekanntlich sind wir Menschen selbst meist ganz außerstande, quantitative Angaben über mittlere Helligkeiten zu machen. Von zwei zu vergleichenden Helligkeiten können wir nur eine als größer, die andere als kleiner bezeichnen, ohne indes auch nur annähernd ihr Größenverhältnis bestimmen zu können. Dagegen können wir mit ziemlicher Sicherheit zwei Helligkeiten bestimmen, die uns gleich erscheinen, und vermittelst Helligkeitsgleichungen wird ja auch die menschliche Lichtempfindlichkeit oft genug gemessen.

Wie steht es nun bei den Tieren? Besteht bei ihnen die Neigung, sich an einen extrem hellen oder dunklen Aufenthalt zu begeben, so kann man derartige zwar nicht immer eindeutige Reaktionen zweckmäßig zur Ermittelung von Helligkeitswerten benutzen, wobei dann freilich der Adaptationszustand der betreffenden Tiere sorgfältig berücksichtigt werden muß.

Bei der Bewertung von phototaktischen Massenansammlungen von Larvenformen, Jungtieren usw. ist übrigens auch Vorsicht geboten, da 
diese durch ganz andere als die zu prüfenden Reize zustande kommen können, wenn es erst einmal zu einer Ansammlung von wenigen Exemplaren gekommen ist. Jedenfalls ist auf die Zahl der reagierenden Tiere in solchen Fällen kein entscheidender Wert zu legen.

Bei höheren Wirbeltieren finden wir keine ,Phototaxis" mehr und können also die eben genannte Methode nicht mehr anwenden. Für ganz unmöglich halte ich es auch, etwa Vögel oder selbst Säuger darauf zu dressieren, daß sie uns irgendwie mitteilen, welche von zwei ähnlichen Strahlungen ihnen als die hellere erscheint. Hier lassen sich nur ganz grobe Helligkeitsdifferenzen feststellen, wie etwa in einer Arbeit von Laurens (1911).

Da nun die direkte eindeutige Feststellung mittlerer Helligkeitswerte versagt, so wenden wir uns zu solchen Werten, die der unteren Grenze der Wahrnehmung entsprechen, also zu Schwellenwerten, wie sie Fechner (1860; I, S. 238) genannt hat. Wir setzen natürlich voraus, daß allen Schwellenwerten auch gleiche Helligkeitswerte entsprechen, mögen die sie hervorrufenden Strahlungsintensitäten auch noch so verschieden sein.

Bei der Untersuchung der menschlichen Lichtempfindlichkeit erfreut sich die Schwellenwertmethode keiner besonderen Beliebtheit, und zwar mit vollem Recht, da die Schwellenwerte beim Menschen recht inkonstant sind: sie ,wandern", oder richtiger gesagt: sie pendeln um einen Normalwert. Bei einigen Tieren und zwar anscheinend besonders bei Vögeln sind die Schwellenwerte der Helligkeit aus teilweise wohl rein anatomischen Gründen viel besser fixiert. Wenn wir nun dafür sorgen, daß diese Werte erstens einmal konstant bleiben und ferner einwandfrei unter Anwendung sorgfältiger und kritischer Kontrolle bestimmt werden, so erhalten wir eine Methode, die für unsere Zwecke die genauesten Werte liefert. Und es gelingt wirklich, auf diesem Wege die Helligkeitsempfindungen eines Tieres genauer zu bestimmen, als dies bisher mit anderen Methoden geschehen konnte, wie weiter unten gezeigt werden wird.

\section{Messung der Reizstärke.}

Als zweite Hälfte der Aufgabe, eine Empfindlichkeit zu messen, hatten wir die exakte Messung der Reizstärke oder Reizintensität genannt. Die Intensität oder Energie einer Strahlung ist aber nichts anderes als ihr Wärmeäquivalent, d. h. diejenige Wärmemenge (,,Körperwärme" im Sprachgebrauch des Physikers), die entsteht, wenn eine „,schwarze“ Oberfläche die gesamte Strahlung absorbiert.

Ehe wir auf die spezielle Methode solcher Intensitätsmessungen eingehen, wollen wird die gerade im Hinblick auf diese Messungen praktisch sehr wichtige Frage erörtern, ob eine beliebige intensive, aber inkon- 
stante Lichtquelle einer konstanten, wenn auch schwächeren, vorzuziehen ist.

Es handelt sich hier um zwei grundsätzlich verschiedene Wege der Intensitätsmessung. Erstens nämlich können wir gleichzeitig mit der Reizung die objektive Reizintensität unmittelbar bestimmen, z. B. thermoelektrisch, und haben dabei den Vorteil, daß wir jede beliebige Lichtquelle als Reizerzeuger wählen können. Braucht man etwa sehr hohe Intensitäten zur Erreichung von Schwellenwerten - was garnicht selten der Fall ist, obgleich es zunächst paradox klingt - so stehen uns als intensivste Lichtquellen die durch einen Heliostaten in gewünschte Richtung gebrachte Strahlung der Sonne oder allenfalls auch noch Bogen- oder Zirkonlicht zur Verfügung. Daß diese Lichtquellen sämtlich mit sehr wechselnder Intensität strahlen, ist natürlich gleichgültig, wenn wir jedesmal gleichzeitig mit der Empfindungsstärke des Tieres auch die Reizstärke messen. Wir können hier natürlich auch auf jede beliebige Weise die Lichtstärke abschwächen oder wieder verstärken, etwa durch Lochbleche, Blenden oder durch lichtabsorbierende Medien, wobei wir die Gesetzlichkeit der angewandten Lichtschwächungsmethode durchaus vernachlässigen können.

Der Nachteil dieses an sich einwandfreien Vorgehens ist freilich sehr groß: müssen wir doch fortwährend die meist ziemlich komplizierten und zeitraubenden Intensitätsmessungen wiederholen. Wenn es irgend möglich ist, so verzichten wir deshalb auf die hohen Intensitäten und sehen uns nach Lichtquellen um, die zwar weniger stark, dafür aber möglichst konstant strahlen. Wir können jetzt die Energie der Strahlung ein für allemal messen - von etwaigen Kontrollmessungen abgesehen - und brauchen jetzt nur noch eine gut definierte und stets leicht zu übersehende Art der Intensitätsveränderung (Schwächung und Verstärkung) anzuwenden, um das energetische Äquivalent der gerade vorhandenen Strahlungsmenge stets indirekt feststellen zu können.

Derartige Methoden sind leicht zu finden, wann es sich um Lichter von gleicher Farbe handelt. Neue Schwierigkeiten zeigen sich erst dann, wenn Licht von verschiedener Wellenlänge in Frage kommt, da eine für verschiedene Farben gleichmäßig wirkende Änderung der Intensität nicht immer leicht zu erzielen ist. Auf diesen Punkt soll jedoch erst später eingegangen werden.

\section{Physikalische Versuchstechnik.}

\section{Kritische Besprechung der Versuchsanordnung.}

Die Frage, ob für unsere Analysen eine intensivere Strahlung einer konstanten schwächeren vorzuziehen sei, haben wir schon aus praktischen Gründen zugunsten der letzten beantwortet. Für unsere Zwecke steht uns in einer möglichst intensiven Nernstlampe eine ausgezeichnete Lichtquelle zur Verfügung, die an 
Konstanz nichts zu wünschen übrig läßt, zumal wenn die Stärke des Lampenstromes durch einen Regulierwiderstand auf gleicher Höhe erhalten wird (Boeh m 1908, Golant 1909). Daß der Nernstbrenner kein sehr ,,weißes" Licht aussendet, stört uns nicht, da wir ja die Strahlung doch wieder in ihre verschiedenen Komponenten (Farben) zerlegen müssen.

Diese Zerlegung kann auf ganz verschiedenen Wegen erreicht werden. Die Methoden der ungleichmäßigen Reflexion, also die Verwendung von farbigen Papieren, Stoffen usw. ist für unsere Zwecke deshalb wenig brauchbar, weil die Pigmentfarben meist viel zu unrein sind.

Auch die Zerlegung durch Absorption, nämlich durch farbiges Glas oder farbige Flüssigkeiten, die bei vergleichend physiologisch-optischen Untersuchungen sehr beliebt ist, hat große Nachteile, die oft nicht genügend beachtet werden. Einmal nämlich ist auch hier die Reinheit, die „Homogenität" des gewünschten farbigen Lichtes meist sehr gering. Die in der Literatur angegebenen flüssigen Strahlenfilter lassen meist, wenn man sie spektroskopisch untersucht, so breite Bänder durch, daß man die so erzeugten Lichter auch nicht einmal als praktisch homogen ansehen kann. Das nach der Angabe von Nagel (1898) hergestellte Gelbfilter läßt z. B. gewöhnlich Licht von 620 bis $570 \mu \mu$ Wellenlänge durch, also außer Gelb noch Grüngelb und Rotgelb. Natürlich brauchen wir hier nicht so reine Farben, wie sie etwa bei physikalischen Untersuchungen oft nötig sind - andererseits glaube ich doch aber, daß wir für "Gelb" eine Wellenlängendifferenz von etwa 10-15 $\mu \iota$ nicht überschreiten dürfen, d. h.: Licht von etwa 585 - 595 $\mu \mu$ können wir gerade noch als praktisch homogenes Gelb ansehen.

Die Verwendung von Lichtfiltern bedingt aber noch einen anderen, viel größeren Übelstand. Läßt nämlich ein bestimmtes Filter (Glas oder Flüssigkeit) bei einer bestimmten Intensität nur Grün durch, so kann es vorkommen, daß es bei gesteigerter Energie der Strahlung - oder geringerer Dicke oder Konzentration des Filters, was praktisch auf das Gleiche hinausläuft - plötzlich auch noch etwas Rot durchläßt.

Ich will den hier drohenden Fehler, der anscheinend nicht immer genügend berücksichtigt wurde, an einem Beispiel erläutern. Nehmen wir an, daß wir ein Tier untersuchen, das bei einem bestimmten Adaptationszustande für Rot relativ (d. h. im Vergleich zum Menschen) sehr stark, für Grün sehr schwach empfindlich ist; ein Fall, der natürlich vorkommt. Benutzen wir nun zunächst ein rotes Lichtfilter, das etwa auch Spuren von Gelb durchläßt, so werden wir annähernd richtige Werte erhalten. Untersuchen wir jedoch dann mit dem grünen Filter, das auch Rot in Spuren durchläßt, so können diese Spuren das Ergebnis der Messung absolut fälschen, indem sie eine viel zu hohe Grünempfindlichkeit vortäuschen, die gar nicht vorhanden ist. Die Gefahr einer solchen Täuschung ist, wie angedeutet, gerade dann besonders groß, wenn die Intensität des filtrierten Lichtes geändert wird, ein Verfahren, auf das wir bei unseren Messungen doch gerade meist angewiesen sind.

Als weitaus exakteste Methode der Herstellung farbigen Lichtes, kommt für unsere Zweoke spektrale Zerlegung in Betracht.

Von der Besprechung solcher Spektren, die durch Beugungsgitter erzeugt sind, können wir hier absehen, da sie für uns meist zu lichtschwach sind, und wenden uns gleich den prismatischen Spektren zu.

Von den zwei gebräuchlichen Prismenarten ist das Flüssigkeitsprisma nicht so sehr zu empfehlen, da seine Dispersion von der Temperatur abhängig ist. Ein gutes Glasprisma wird in den meisten Fällen die besten Dienste leisten.

Wir sind, um das Gesagte ganz kurz zusammenzufassen, aus praktischen Gründen für die Anwendung von durch Dispersion spektral zerlegtem Nernst. 
lichte entschlossen, das wir in bekannter Weise erhalten, indem wir die Strahlung durch einen Spalt, eine Linse und das Prisma gehen lassen. Eine bestimmte Farbe erhalten wir höchst einfach, indem wir mit einem verschiebbaren Spalte das Gewünschte aus dem Spektrum herausblenden.

Wie erzielen wir aber jetzt eine Veränderung der Strahlungsintensität? Die Spaltbreite selbst zu variieren, ist nicht angängig, da wir damit gleichzeitig die relative Reinheit des Spektrums verändern. Wir würden damit denselben Fehler begehen, in den man bei der Verwendung von Farbfiltern so leicht verfällt.

Eine Variation der Lichtstärke durch Veränderung des Abstandes der Lichtquelle vom Spalt oder des Versuchstieres vom Prisma usw. stößt natürlich sofort auf große praktische Schwierigkeiten. Es bleibt nur die Möglichkeit, im Strahlengange verstellbare Blenden so anzubringen, daß sie die einmal vorhandene Reinheit des Spektrums nicht verändern. Wo wir sie aber auch anbringen, müssen wir unbedingt dafür sorgen, daß sie auch in der von uns gewünschten Weise wirken und in der Tat Licht proportional ihrer Fläche durchlassen. Das ist aber nur dann der Fall, wenn ihre ganze Fläche gleichmäßig beleuchtet ist, eine Bedingung, der meist nur unter sehr starken Intensitätsverlusten genügt werden kann. (Gleichmäßig beleuchtete Mattscheibe vor der Blende usw.)

Wenig geeignet für messende Untersuchungen erscheinen auch die sogenannten Rauchgläser, mit deren Hilfe eine schnelle und feine Abstufung der Intensität schwer zu erreichen ist. Für unsere Zwecke kommen sie schon deshalb nicht in Betracht, weil sie - in dickeren Schichten wohl alle - selektiv absorbieren. Wir würden also die vorhin besprochene Fehlerquelle wieder einführen.

Schließlich bleiben uns noch zwei Methoden der Lichtschwächung von annähernd gleicher Brauchbarkeit. Die Verwendung eines rotierenden Sektors und als etwas prinzipiell ganz neues die Schwächung durch Polarisation.

Da die Verwendung eines rotierenden Sektors eine Reihe neuer Nebenapparate bedingt, (Elektromotor, Tachometer, Widerstand), die den Aufbau sofort wesentlich komplizieren, so entschloß ich mich zur Polarisationsmethode, bei der die Polarisationsebenen zweier Nicolscher Prismen meßbar gegeneinander gedreht werden. Bilden diese Ebenen miteinander den $<\varphi$, so wird theoretisch $-\mathrm{ab}$ gesehen von einem stets gleichen reflektierten Bruchteil - bekanntlich der Bruchteil $\operatorname{Cos}^{2} \varphi$ der gesamten Lichtmenge durchgelassen.

Die Vorteile dieser Methode sind recht erheblich. Einmal nämlich können wir sehr bequem die Lichtstärke in den weitesten Grenzen abstufen, ohne daß wir auf eine gleichmäßige Beleuchtung der Nicolschen Prismen angewiesen wären, und andererseits ist natürlich keine störende selektive (farbige) Absorption zu befürchten.

Es fragt sich jetzt nur, wo wir die beiden Polarisatoren am besten unterbringen. Ich möchte diese Frage etwas näher erörtern, weil sie einige praktische Schwierigkeiten enthält, die sich umgehen lassen.

Zunächst konnte ich feststellen, daß es unmöglich war, die beiden recht langen und sehr vollständig polarisierenden Nicols, die mir zur Verfügung standen, unmittelbar hintereinander aufzustellen, da ein entsprechend schmales und paralleles Lichtbündel ohne große Intensitätsverluste nicht zu erzielen war. Eine getrennte Aufstellung war also nötig. Am geeignetesten ersehien die Anordnung, ein Polarisationsprisma zwischen Lichtquelle and Spalt, das andere zwischen Linse und Dispersionsprisma aufzustellen.

Welches Prisma sollte nun aber feststehen und welches drehbar angebracht werden?

Zunächst versuchte ich eine Aufstellung, bei der das feste Nicolsche Prisma vor dem Spalt, das drehbare vor dem Dispersionsprisma stand. Diese Anordnung 
gab ich jedoch bald auf, da doch anzunehmen war, daß das Dispersionprisma selbst etwas polarisierte. Wenn nun stets Licht von verschiedener Polarisationsrichtung auf das Dispersionsprisma fiel, so war zu befürchten, daß es hier schon ohne das feststehende Nicolsche Prisma zu schlecht kontrollierbarenLichtverlusten kommen würde. Aus diesem Grunde wurde diese Anordnung prinzipiell verworfen und versucht, das zweite Nicolsche Prisma unbeweglich zu lassen und das erste, zwischen Lichtquelle und Spalt befindliche, zu drehen.

Zunächst schien alles gut zu gehen. Bald aber zeigte sich ein neuer Übelstand.

Um die nötige Intensität der Strahlung zu erzielen, muß̉te nämlich, wie sich herausstellte, der glühende vertikal stehende Nernstfaden selbst in der Spaltebene ziemlich scharf abgebildet werden. Vergrößerte man das Bild des Nernstfadens, so wurde die Strahlungsintensität zu gering. Selbstverständlich wurde der Faden so abgebildet, daß er den Spalt vollständig ausfüllte.

Die Schwierigkeit bestand num in folgendem: War für irgendeine Stellung des drehbaren Nicols der Faden gut auf den Spalt eingestellt, und begann man jetzt den Nicol zu drehen, so fing das Fadenbild zu wandern an, da die beiden das Nicolsche Prisma begrenzenden parallelen Flächen (wie üblich) nicht senkrecht zur optischen Achse standen. Selbstverständlich wurde dadurch das Bild des Fadens parallel verschoben, so daß es nach einer Nicoldrehung von $90^{\circ}$ den Spalt nur noch etwa zur Hälfte ausfüllte, zur anderen Hälfte jedoch rechts oder links neben den Spalt auf die Blende fiel.

Auf diese Weise wurde natürlich eine exakte Berechnung der erzielten Intensität unmöglich. $\mathrm{Zu}$ der vorhin erwähnten Anordnung mochte ich nicht zurückkehren, da auch hier erhebliche Fehlerquellen zu erwarten waren.

Die Aufgabe bestand nun darin, die parallele Verschiebung des Fadenbildes zu verhindern, ohne die einmal gewonnenen Vorteile der Versuchsanordnung aufzugeben.

Zunächst kam ich auf den Gedanken, eine dicke planparallele Glasplatte in den Strahlengang (mit dem drehbaren Nicol fest verbunden) so einzuschalten, $\mathrm{dab}$ sie die Parallelverschiebung gerade wieder eliminierte. Theoretisch war dieses Vorgehen ohne weiteres einleuchtend: die Glasplatte muBte so angebracht werden, daß ihre Flächen einmal gegen die optische (Dreh)-Achse des Systems um einen ganz bestimmten Winkel geneigt war, der eben gerade die Verschiebung wieder ausglich, und andererseits mußte die hypothetische Schnittlinie von Glas- und Prismenfläche in einer zur optischen Achse senkrechten Ebene liegen, wie wohl ohne weiteres klar ist.

Die praktische Ausführung dieses Gedankens stieß aber auch wieder auf Schwierigkeiten, da die exakte Justierung der Glasplatte nicht ohne weiteres gelang.

Hier konnte also nur ein radikales Vorgehen helfen, das das Übel zugleich mit seiner Ursache beseitigte. Mit anderen Worten: es mußte als drehbarer Polarisator ein Prisma gewählt werden, dessen Flächen senkrecht zur Drehachse standen.

Da nun damals ein derartiger Polarisator von genügender Größe im Physikalischen Institut nicht vorhanden war, bat ich den Direktor, ein solches Prisma anzuschaffen, und schon nach wenigen Tagen erhielt ich das Gewünschte.

Nunmehr war die Apparatur, soweit es sich um rein physikalische Bedingungen handelt, meinen Wünschen entsprechend. Ich lasse jetzt eine Beschreibung davon folgen, damit noch verborgene Mängel der kritischen Beurteilung zugänglich werden. 


\section{Beschreibung der Apparatur. (Vgl. Abb. 1.)}

Die Lichtquelle, eine automatisch zündende Nernstlampe (Modell H, $400 \mathrm{~K}$ ) besaß zwei senkrechte Fäden, von denen aber natürlich nur der eine zur Projektion benutzt wurde (s. o.). Die Kerzenzahl betrug demnach etwa 200. Auf den Brenner, dessen Fuß in einer breiten Schiene verschoben werden konnte, folgte zunächst eine dünne Glasscheibe, dann ein großer Doppelkondensator und in etwa $3 / 4 \mathrm{~m}$ Entfernung das (Glansche) Prisma als drehbarer Polarisator. Da dieses Prisma etwa quadratischen Querschnitt hatte und, wie schon erwähnt, der vertikale glühende Nernstfaden selbst auf dem Spalte abgebildet wurde, so kam natürlich mehr Licht durch, wenn das Prisma auf der Kante stand. Diesem Fehler wurde durch Befestigung einer kleinen schwarzen Kartonblende am Prisma abgeholfen, die sich mitdrehte und deren $\mathrm{r}$ und ausgestanzte Öffnung von $1 \mathrm{~cm}$ Durchmesser konzentrisch zur optischen Achse lag.

Da sich bei Beginn der Tierversuche bald herausstellte, daß eine Drehung des Prismas mit der Hand zu ungleichmäßig erfolgte, so wurde die Rotation durch ein Uhrwerk mit Windfangregulator betrieben, dessen Gang an Ruhe, Konstanz

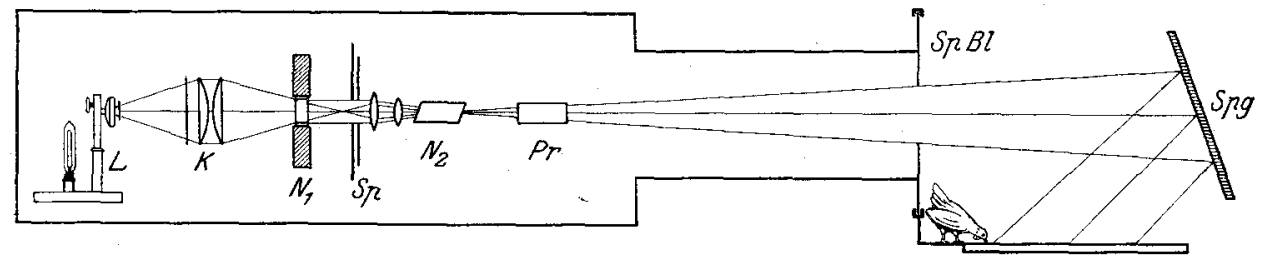

Abb. 1. $L$ Lichtquelle. $K$ Kondensor. $N_{1}$ drehbares Nicolsches Polarisationsprisma. $N_{\mathrm{a}}$ feststehendes Nicolsches Polarisationsprisma. $S p$ Spalt. Pr Dispersionsprisma. $S p B l$ verschiebbare Spaltblende. $\$ p g$ Spiegel.

und Geräuschlosigkeit nichts zu wünschen übrig ließ. Die Schnelligkeit der Drehungen konnte durch 3 Übersetzungen reguliert werden. Fast stets ließ ich den Polarisator sehr langsam laufen, so da $B$ er sich in 7 Sekunden nur um $1^{\circ}$ drehte.

Auf das genannte Prisma folgte nach ca. $10 \mathrm{~cm}$ Abstand ein guter Spalt mit scharfen Schneiden, von denen die eine vermittelst einer feinen Schraube in üblicher Weise bewegt werden konnte. Die gewöhnliche Spaltbreite betrug 1,35 mm, mußte aber zu bestimmten Zwecken (spektrale Eichung) sehr verengt werden. Natürlich wurde nach jeder Verengung der Spalt wieder auf genau die gleiche Breite gebracht, die er vorher hatte.

Dicht hinter dem Spalt befanden sich zwei bikonvexe Linsen und das feststehende Nicolsche Prisma, dann folgte wieder in einiger Entfernung ein geradsichtiges Dispersionsprisma. - Die bisher genannte Apparatur war so angeordnet, daß das scharfe Spaltbild in eine Ebene fiel, die etwa $125 \mathrm{~cm}$ vom Dispersionsprisma entfernt war. In dieser Ebene war ein Blech mit einem $8 \mathrm{~mm}$ breiten und $18 \mathrm{~cm}$ hohen vertikalen Spalt in Falzen verschiebbar und gestattete eine beliebige, praktisch homogene Farbe auszublenden und zur Untersuchung zu verwenden. Die relative Homogenität oder spektrale Einheit der ausgeblendeten. Bezirke war natürlich versehieden: im stärker zerstreuten Blau war sie größer als im Rot; gekennzeichnet wird sie durch die Angabe, daß in der Ebene, wo die Ausblendung von $8 \mathrm{~mm}$ breiten Bezirken erfolgte, der Abstand der farbigen Lichter von 720 und $440 \mu \mu$ Wellenlänge ca. $27 \mathrm{~cm}$ betrug. So bedeutet z. B. „680 $\mu \mu^{\prime \prime}$ einen Streifen von $672-688 \mu \mu$, aber, $450 \mu \mu^{\text {" }}$ nur etwa $447,5-451,5 \mu \mu$. 
Die versehiedenen Grade der Homogenität etwa dadurch gleich zu machen, daß man im Blau entsprechend breitere Bezirke ausblendete, als im Rot, wäre natürlich ein vergebliches Bemühen gewesen, da das durchgelassene Licht zur diffusen Beleuchtung verwandt wurde. Die homogen beleuchtete Fläche hätte zwar an Ausdehnung gewonnen, aber die erzielte "Flächenhelligkeit" wäre natürlich unverändert geblieben. Nur durch komplizierte Vorrichtungen hätte der genannte Erfolg erzielt werden können, der aber praktisch zu belanglos war, um seinetwegen die Apparatur noch weiter zu komplizieren.

Vervollständigt wurde der Aufbau durch einen ebenen, mit Quecksilber belegten Spiegel, der, im Mittel $85 \mathrm{~cm}$ von der verschiebbaren Spaltblende entfernt, den ausgeblendeten Lichtstreifen schräg nach unten auf eine Tischplatte reflektierte. Die Neigung der Spiegelebene gegen die Horizontale blieb immer konstant. Dagegen wurde der Spiegel nach jeder Verschiebung des davor befind. lichen Spaltes (also jedesmal, wenn eine andere Farbe zur Untersuchung benutzt wurde), um eine vertikale Achse so gedreht, daß das auffallende hohe und schmale Iichtbündel stets senkreeht reflektiert wurde. Auf diese Weise wurde erreicht, daß die Breite des auf die Tischplatte geworfenen Lichtstreifens für die verschiedenen Farben gleich blieb. Ohne diese Vorsichtsmaßregel wäre die Berechnung der relativen Flächenhelligkeiten sehr erschwert worden.

Um möglichst alle unbeabsichtigten Veränderungen der einzelnen Teile des Apparates zu verhüten, waren diese alle entweder auf der Tischplatte oder an der Zimmerwand fest angekittet und angeschraubt und teilweise auf eine schwere optische Bank montiert. Überdies war der gesamte Aufbau - von der Lampe bis zum verschiebbaren Spalt - in einem lichtdichten, fast $3 \mathrm{~m}$ langen Kasten (Holzgestell mit Pappverkleidung) eingeschlossen. Alle Stellen, wo Licht reflektiert werden konnte, waren matt geschwärzt. Besonderer Wert wurde auf die Ausmerzung des von der Vorderfläche des Dispersionsprismas reflektierten Lichte gelegt. Der Pappkasten hatte nur 3 öffuungen. Die hintere Schmalseite konnte abgeschraubt werden, um die Lampe herauszunehmen, was nur sehr selten geschah. Seitlich vom drehbaren Nicol, dem Spalt usw. befand sich eine Tür im Kasten, die nach jedem Versuch geöffnet wurde, um die durch das Uhrwerk bewirkte Drehung des Glanschen Prismas abzulesen und es wieder in die gewünschte Lage zurückzubringen. Die dritte und letzte Öffnung war von dem verschiebbaren Spalt ausgeführt. - $\mathrm{Zu}$ bemerken ist noch, daß der Strahlengang sich durchschnittlich in einer Höhe von etwa $120 \mathrm{~cm}$ über dem Fußboden befand und daß die Tischplatte, auf die das zu untersuchende Tier gesetzt wurde, etwa $1 / 2 \mathrm{~m}$ tiefer lag. Somit kam das gewünschte Licht schräg von oben, was besondere Vorteile bietet. An diesem Versuchstisch befand sich auch ein Hebel, durch den das erwähnte Uhrwerk vermittels Schnurverbindung in Gang gesetzt und arretiert werden konnte und ferner Schalter für einige mit halber Spannung brennende Glühlampen, die das zur Ablesung der gefundenen Werte nötige Licht lieferten.

\section{Ermittelung der physikalischen Konstanten.}

Die Ermittelung derjenigen Energiemengen, die unter verschiedenen Be. dingungen von dem eben beschriebenen Apparat in Form von farbigem Licht ausgesandt wurden, konnte auf zwei Wegen erfolgen. Erstens nämlich konnte man die „Endstrahlung" d. h. die Strahlung, die zum Auge des zu untersuchenden Tieres gelangte, unmittelbar messen. Ferner aber bestand die Möglichkeit, die Anfangsstrahlung $z \mathfrak{u}$ bestimmen und dann festzustellen, wieviel Licht von jeder.Wellenlänge auf dem Wege bis zum Auge verloren ginge. -- Theoretisch verdient die erste Methode den Vorzug. Leider war sie aber trotz aller Bemühungen nicht anwendbar, da die als Endstrahlung austretende Lichtmenge zu gering 
war, um mit dem mir damals zur Verfügung stehenden Hilfsmitteln gemessen werden zu können.

Am nächsten lag natürlich der Versuch einer thermoelektrischen Messung, vermittels Thermosäule and Galvanometer. Da jedoch mit einem Drehspulengalvanometer überhaupt keine konstanten Ausschläge erzielt werden konnten, so wurde von Versuchen mit einem empfindlicheren Galvanometer als voraussichtlich aussichtslos abgesehen.

Die sehr heikle bolometrische Messung hätte vielleicht zum Ziele geführt, jedoch war die zur Verfügung stehende Zeit viel zu kurz, um die Messung korrekt auszuführen.

Nur aus prinzipiellem Interesse erwähne ich den Versuch, die ,Endstrahlung“" mit einem Quecksilberthermometer zu messen. Das zu diesem Zwecke angefertigte Instrument besa B eine derartige Empfindlichkeit, daB z. B. die maximale Strahlung eines roten Bezirkes stets ein deutliches Steigen des Quecksilbers bewirkte. Natürlich waren größere Zeiträume erforderlich, um einen vollständigen Wärmeausgleich zu erzielen. Leider versagte das Thermometer schon im Grün, wo das Wärmeäquivalent der Strahlung nicht mehr genügte, um ein deutliches Steigen zu veranlassen, so daß an Messungen im Blau und Violett überhaupt nicht zu denken war.

So blieb mir denn nichts anderes übrig, als zur indirekten Feststellung der Intensität der Endstrahlung überzugehen.

\section{Die Energieverteilung im Spektrum des Nernstlichtes.}

Unter den einzelnen Faktoren, welche die Intensität der verschiedenen Bezirke der Endstrahlung bestimmen, steht die Lichtquelle an erster Stelle.

Bekanntlich sind nun die Intensitätsverhältnisse einer Strahlung theoretisch dann ohne weiteres za berechnen, wenn es sich um eine sogenannte ,schwarze Strahlung " handelt, d. h. eine Strahlung, die von einem theoretisch schwarzen, alle auffallende Strahlungsenergie stets absorbierenden Körper ausgeht. Die Intensität und die Qualität (das ist das Verhältnis der Intensitäten des verschiedenen welligen Lichtes) einer solchen Strahlung hängt einzig und allein von der Temperatur desstrahlenden Körpers ab.

Haben wir nun einen strahlenden Körper, der den Gesetzen der schwarzen Strahlung genügt, so können wir ohne weiteres mit diesem jede andere (,grau“" oder farbig strahlende) Lichtquelle durch Photometrie vergleichen und dessen Intensitätsverhältnis ermitteln, indem wir gleichfarbige und gleichbreite Spektralbezirke der beiden. Lichtquellen in einem Spektrophotometer durch meßbares Abschwächen der einen Strahlung für uns gleich hell machen.

An dieser Stelle möchte ich auf einen prinzipiellen Irrtum aufmerksam machen, der sich übrigens auch in den besten Lehrbüchern der Physik findet. Es wird nämlich oft behauptet, daß für ei ne bestimmte Wellenlänge das Energieverhältnis mit dem (menschlichen) Helligkeitsverhältnis identisch sei, und das ist natürlich durchaus nicht richtig. Jedenfalls gilt diese Beziehung nur innerhalb relativ enger Grenzen.

Richtig ist nur das eine, daß ceteris paribus gleich hellen Strahlungen von gleicher Wellenlänge auch gleiche Intensitäten entsprechen, oder um es ganz deutlich zu machen: ist $H_{a}=H_{b}$, so ist auch $I_{b}=I_{a}$, wenn wir mit $H_{a}$ die der Intensität $I_{a}$ zugrunde liegende Helligkeitsempfindung bezeichnen; ist aber $\frac{H_{x}}{\bar{H}_{y}}=c$, so braucht $\frac{I_{x}}{I_{y}}$ durchaus nicht $=c$ zu sein. Begründet sind diese Verhältnisse natürlich nur in der Funktion des Sehorganes. 
Eine Lichtquelle, die den von der Theorie geforderten Bedingungen der schwarzen Strahlung praktiseh genügt, ist der von Lummer und Kurlbaum (1901) konstruierte elektrisch zu heizende schwarze Hohlkörper. Ist nun dessen Temperatur durch ein im Inneren des Hohlraumes befindliches Thermoelement als elektromotorisches Äquivalent bestimmt, so können wir die Energieverteilung seiner Strahlung nach der Wien-Planckschen Formel berechnen. Aus dem einfachen spektrophotometrischen Vergleiche dieser Strahlung mit einer beliebigen anderen erhalten wir nun aber sofort die Energieverteilung der letzteren. Auf diese Weise kann also z. B. ein Nernstbrenner durch wenige photometrische, also sehr einfache Messungen, einwandfrei geeicht werden. Dabei erhalten wir Werte, die von der Dispersion der verwandten Prismensubstanz ganz unabhängig sind, da die Wien-Plancksche Formel sich auf Normalspektra bezieht.

Hat man erst einmal eine geeichte Lichtquelle, so kann man damit natürlich durch einfache Spektrophotometrie wieder neue Lichtquellen eichen. Es hat sich übrigens herausgestellt, daß die Energieverteilung im Spektrum von Nernstbrennern - selbst ganz verschiedener Modelle -- bei entsprechender Belastung praktisch gleich ist. Die Tabelle I gibt die interpolierten Werte einer Kurve wieder, die Fräulein Dr. Kohn (1913, Abb. 11) aufgenommen und mir freundlichst zur Verfügung gestellt hatte.

Der zu meinen Untersuchungen benutzte Nernstbrenner brannte bei der Eichung mit einer Spannung von 210 Voit. Auch bei den Tierversuchen wurde eine Reihe von Messungen mit konstant gehaltenem Strom angestellt. Da sich jedoch durch Kontrollversuche bald zeigte, daß die vorkommenden Schwankungen - im Laufe von Stunden nur 2 bis höchstens 4 Volt - keinen praktisch bemerkbaren Wechsel der Helligkeit verursachten, so wurde die dauernde Regulierung der Lampenstromstärke nach einiger Zeit wieder aufgegeben.

\section{Ermittelung der Dispersion im objektiven Spektrum.}

Haben wir die Energieverteilung einer Lichtquelle im Normalspektrum gemessen, in einem Spektrum also, wo das Licht nicht nach der Brechbarkeit, sondern nach der Wellenlänge angeordnet ist so erhalten wir durch eine einfache Umrechnung sofort die Energieverteilung für jedes Dispersionsspektrum dieser Lichtquelle. Wir brauchen nur die Dispersion des benutzten Prismas zu messen, und multiplizieren jetzt die Lichtmenge eines jeden kleinen ausgeblendeten Spektralbezirkes mit einem der Brechbarkeit der betreffenden Farbe proportionalen Faktor. Dadurch wird die relativ (d. h. im Verhältnis zum Normalspektrum) geringere Flächenhelligkeit oder Flächenintensität der breiter auseinander gebrochenen kurzwelligen Lichter wieder entsprechend rechnerisch vergrößert.

Die Dispersionsbestimmung stieß zunächst auf Schwierigkeiten. Als Methode wurde natürlich die Erzeugung von bekannten Spektrallinien in der Ebene des verschiebbaren Spaltes gewählt. Die gebräuchlichen Lichtquellen dafür (gefärbte Flammen oder Geisslersche Röhren) versagten aber vollständig, da ihre Intensität bei weitem nicht ausreichte. Ebensowenig gelang es, Absorptionsstreifen im kontinuierlichen Spektrum zu erzeugen.

Erst mit Hilfe einer sehr intensiven Quecksilberdampflampe (von Heraeus) konnte ein Linienspektrum von genügender Helligkeit erzeugt werden. Es handelte sich um eine Quarzlampe mit Quecksilberamalgam, die außer den Quecksilberlinien auch die von Cadmium und Zink aussandte.

Die Eichung wurde nun in der Weise ausgeführt, daß an Stelle der Nernstlampe die Quecksilberlampe gesetzt wurde, die zunächst mit (durch einen Regulierwiderstand) verringerter Spannung brannte und ein scharfes Linienspektrum auf einer Mattscheibe entwarf, die in der Ebene der verschiebbaren Spaltblende 
angebracht war. Nunmehr wurde der erste, zwischen Lichtquelle und Dispersionsprisma befindliche Spalt so verengt, daß die Linien auf der Mattscheibe ganz schmal und gerade noch sichtbar waren. Diese Linien (die drei hellsten Hg-Linien: die gelbe Doppellinie 577-579 $\mu$, die grüne $546 \mu \mu$, die violetten $435-436 \mu \mu$ ) konnten ohne Schwierigkeit markiert werden. Bei längerem Brennen $(1 / 2$ bis $3 / 4$ Stunden) mit allmählich erhöhter Spannung traten neue Linien auf, die jedoch nicht mehr ohne weiteres angezeichnet werden konnten. Deshalb wurden jetzt bei verschiedener Expositionsdauer Filmaufnahmen des Spektrums gemacht und da die Möglichkeit bestand, daß die Films beim Entwickeln oder Trocknen nicht die ursprüngliche Länge behielten, noch Kontrollaufnahmen auf besonders empfindlichem Papier hergestellt, die jedoch dieselben Abstände der Linien ergaben. Anf diese Weise erhielt ich etwa 15 Linien, die genügten, um eine ausreichende Interpolation vorzunehmen.

Die Interpolation der einzelnen Wellenlängen wurde nicht direkt rechnerisch vorgenommen, sondern auf graphischem Wege mit Hilfe des Hartmannschen Dispersionsnetzes (zu beziehen von Schleicher \& Schüll, Düren, Rheinland) ermittelt, wodurch die Bestimmung außerordentlich einfach wurde. Die Abszissenachse dieses Netzes ist nämlich so geteilt, daß eine Dispersionskurve eine gerade Linie wird. Als in die Ordinatenachse einzutragende Funktionswerte der Wellen. längen benutzt man natürlich einfach die Abstände der photographierten Spektrallinien von einem beliebigen Punkte (z. B. derjenigen Linie, welcher Licht von der geringsten Wellenlänge entspricht). Legt man nun diesen Punkt auf die Abszissenachse, so erhält man durch weitere Eintragung eine fast geradlinige, schwach gekrümmte Kurve. Die Krümmung beruht in unserem Falle darauf, daB das Spektrum nicht auf einer Kugelfläche, sondern in einer Ebene gemessen wurde.

Diese Kurve genügte durchaus, um die von der Dispersion abhängigen Werte mit einer für unsere Zwecke vollständig ausreichenden Genauigkeit interpolicren zu können. ('Tabelle II.)

\section{Die selektive Absorption der Reiskörner.}

Unsere bisherigen Ermittelungen ließen uns erstens die absolute, von der Art der Zerlegung unabhängige Energieverteilung unserer Lichtquelle bestimmen und haben dann gezeigt, wie intensiv die Strahlung von bestimmten stets gleich breiten Bezirken ist, die wir aus einem beliebigen Dispersionsspektrum ausblenden,

Wir kennen also die Lichtmengen, die bei verschiedenen Stellungen der verschiebbaren Spaltblende aus dieser austreten, da wir wissen, daß die sonst noch benutzten im Strahlengang vor dem Dispersionsprisma liegenden Gläser (Prismen und Linsen) die verschiedenwelligen - hier noch nicht getrennten - Strahlungen gleichmäßig durchlassen. Sie absorbieren natürlich etwas, aber von allen Farben praktisch gleiche Mengen, so da $\beta$ an den Intensitäts verhältnisse n nichts geändert wird, solange wir uns im sichtbaren Spektrum befinden. Wollten wir auch im Infrarot oder Ultraviolett Messungen ausführen, so müßte die für diese Strahlungen stark selektive Absorption gewöhnlicher Gläser natürlich berücksichtigt werden.

Nachdem die Strahlung die Spaltblende unseres Apparates passiert hat, tritt sie noch nicht unmittelbar ins Auge des zu untersuchenden Tieres ein, sondern erleidet noch zwei Reflexionen. Die eine reflektierende Fläche ist der schon erwähnte Spiegel, der die Lichtstrahlen schräg nach unten zurückwirft. Die zweite und letzte reflektierende Fläche wurde bisher noch nicht genannt. Es handelt sich, wie hier im voraus bemerkt sei, um die Oberfläche von Reiskörnern, die mit den verschiedenen Farben bestrahlt wurden und die den Tieren als Sehobjekte dienten. 
Es wurde eine Reissorte gewählt, deren Körner besonders groß und weiß waren (das bedeutet in diesem Fall wenig glasig und durchscheinend) und die stets in gleicher Qualität erhältlich war. Bei den Versuchen wurden, von wenigen Vorversuchen abgesehen, stets ungekochte Körner verwandt.

Es war nicht zu befürchten, daß die Reflexion am Spiegel ungleichmäßige Lichtverluste verusachen würde, dagegen hielt ich es von vornherein nicht für ganz ausgeschlossen, - wenn auch für wenig wahrscheinlich - daß die Reiskörner selektiv reflektierten. Hätten sie als weißer Körper oder auch nur grau reflektiert, $d$. h. von allen Farben gleiche Bruchteile absorbiert, so wären unsere relativen Berechnungen natürlich unverändert geblieben.

$\mathrm{Zu}$ meiner Überraschung stellte es sich aber heraus, daß die scheinbar durchaus weißen Reiskörner gemischtes Licht recht ungleichmäßig reflektierten, und zwar wurden - um das Ergebnis der Messung vorweg zu nehmen - die Enden des sichtbaren Spektrums stark absorbiert, Grün dagegen besonders gat reflektiert.

Als es sich darum handelte, diese Tatsachen zu ermitteln, hatte ich zuerst den Plan, eine Reisfläche mit einem Nernstbrenner zu bestrahlen und nun die Intensität der einzelnen reflektierten Spektralfarben mit denen eines bekannten Vergleichslichtes zu eichen. Hierbei hätte freilich die Berücksichtigung der Selektivität des Vergl sichslichtes wiederum eine umfangreiche Rechnung bedingt, und um dies zu umgehen wählte ich einen Weg, der seiner relativen Einfachheit halber hier auch erwähnt werden soll.

Im Prinzip handelte es sich darum, nur ei ne Lichtquelle zu benutzen und damit sowohl die zu prüfende Fläche (Reiskörner) wie auch zugleich eine weiße Fläche zu bestrahlen und das von diesen beiden reflektierte Licht unmittelbar spektrophotometrisch zu vergleichen. Der große Vorteil der Methode liegt darin, daß man natürlich sofort das Reflexionsvermögen für jede Farbe ohne weiteres, z. B. prozentuell, angeben kann, wenn man das der weißen Fläche gleich 100 setzt. Angenehm ist ferner, daß man von der Art der Lampenstrahlung in weiten Grenzen unabhängig ist, da doch beide Flächen stets im gleichen Momente miteinander verglichen werden und es hier nur darauf ankommt, wieviel die Reisoberfläche mehr absorbiert als die als Norm anzusehende weiße Fläche. Man kann also theoretisch jede beliebige Lichtquelle zu der Eichung benutzen. Freilich ist zu beachten, daß eine konstant brennende gewisse praktische Vorteile bietet.

Die Messung wird in folgender Weise ausgeführt: die Lichtquelle (zunächst eine handregulierte Bogenlampe) beleuchtete zugleich eine matte Gipsplatte, wie sie als weiße Flächen in Photometern Verwendung finden, und ferner eine mattschwarze Holztafel, auf deren Mitte ich eine Anzahl von Reiskörnern dicht nebeneinander aufgeklebt hatte. Ein seitliches Hervortreten des glänzenden Klebstoffes vor den Reiskörnern, das eine Spiegelung hätte bewirken können, wurde vermieden. Beide Flächen - die Gipsfläche und die Tafel mit Reis - standen vertikal und nahe vor den Enden der beiden Spaltrohre eines Lummer-Brodhunschen Spektrophotometers, gegen deren Längsachsen sie um $45^{\circ}$ geneigt waren. Etwa unter dem gleichen Winkel fielen auch auf beide die Strahlen der gemeinsamen Lichtquelle. (Abb. 2). Genau nachgemessen wurden diese Winkel nicht, da es sich ja um diffuse Reflexion handelte und schließlich auch die Stellung der beiden Flächen während der Messung unverändert blieb.

Die Intensitätsänderung wurde hier - da die Anwendung eines sonst üblichen rotierenden Sektors unnötig schien - einfach dádurch erzielt, daß an einem Kollimatorrohre die Breite des Spaltes geändert wurde. Die Berechtigung dieses Vorgehens wurde noch geprüft, indem festgestellt wurde, bis zu welcher Spaltbreite bei sonst unveränderten Bedingungen Proportionalität zwischen den Messungen herrschte. Es zeigte sich, daß die Spalte etwa $0,15 \mathrm{~mm}$ breit gemacht werden 
konnte, ohne daß sich der Quotient der Ablesung änderte. Oder mit anderen Worten: ergab sich eine Helligkeitsgleichung mit den Werten $0,05 \mathrm{~mm}$ Breite für den einen und z. B. $0,06 \mathrm{~mm}$ für den zweiten (verstellbaren) Spalt, so ergab sich gleichfalls eine Helligkeitsgleichung, wenn der eine Spalt die Breite 0,10 mm,

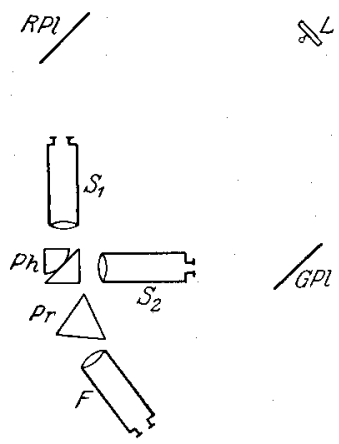

Abb. 2.

$L$ Lichtquelle. $S_{1} S_{2}$ Spaltrohre. $F$ Fernrohr. GPl Gipsplatte. RPl Reisplatte. $P h$ Photometerwürfel. . Pr Prisma. der zweite die von $0,12 \mathrm{~mm}$ besaß. Dagegen hörte diese Proportionalität auf, wenn eine Spaltbreite von $0,15 \mathrm{~mm}$ überschritten wurde. Bei den eigentlichen Messungen wurde daher der feste Spalt meist auf $0,1 \mathrm{~mm}$, seltener auf $0,5 \mathrm{~mm}$ und nur im Notfalle (Lichtsehwäche im Violett) auf $0,15 \mathrm{~mm}$ Breite eingestellt. Diese Spaltbreite wurde nicht überschritten. Der Abstand des Brenners von den beiden Flächen wurde so gewählt, daß sie im Mittel etwa gleiche lichtmengen reflektierten.

Variiert wurde bei der Messung der Spalt vor der Gipsplatte. Da nun die Spaltbreite der Helligkeit (und hier bei gleichen Farben auch der Intensität) umgekehrt proportional ist, so gaben die Einstellungen dieses Spaltes die von der Reisfläche reflektierte Lichtmenge prozentuell an, wenn der Spalt vor der Reisfläche selbst konstant auf einer mit 100 bezeichneten Breite $(0,1 \mathrm{~mm})$ erhalten wurde. Es gilt nämlich für jede einzelne Farbe folgende Gleichung:

Breite des Spalt I (vor der Gipsfläche) $=$ von der Reisfläche reflektierte Lichtmenge

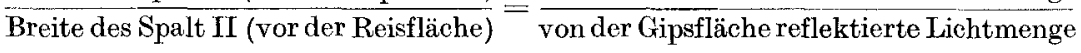
oder, wenn die Breite des Spaltes II gleich 100, die von der Gipsplatte reflektierte Lichtmenge gleich 1 gesetzt wird:

Von der Reisfläche refl. Lichtmenge $=\frac{\text { Breite des Spaltes I (vor der Gipsfläche) }}{100}$

Die zuerst verwandte Bogenlampe lieferte schwankende Werte - wahrscheinlich deshalb, weil der natürlich immer etwas bewegte Lichtbogen (abgesehen von der hier natürlich unschädlichen Inkonstanz seiner Intensität) bald die eine, bald die andere Fläche stärker beleuchtete. Die Verwendung einer Nernstlampe (Modell GA) half diesem Fehler ab und lieferte Werte von ausreichender Übereinstimmung.

Die Frage, ob durch Umsetzung von kurzwelligem in längerwelliges Licht (Fluorescenz) eine weitere Änderung der Energieverhältnisse stattgefunden hätte, wurde geprüft, indem bei einigen Kontrollmessungen Glasscheiben zwischen Lichtquelle und Reisbrett gestellt wurden, die etwa fluorescenzerzeugendes kurzwelliges Licht absorbiert hätten. Es wurden jedoch innerhalb der mittleren Fehler keine abweichenden Werte gefunden.

Die für 8 verschiedene Farben $(700,660,620,580,540,500,480$ und $465 \mu u)$ gewonnenen Werte ergaben eine Kurve, der die Interpolationen der Tabelle III zugrunde liegen.

Wenn wir rückschauend noch einmal unsere Versuchsanordnung überblicken, so zeigt sich, daß der scheinbar so komplizierte Aufbau außerordentlich leicht zu handhaben ist. Nur zweier Bestimmungen bedarf es, um jederzeit die herrschende relative Intensität genau zu ermitteln: der Ablesung der benutzten Wellenlänge und der Ablesung am Teilkreise des drehbaren Polarisationsprismas. Der Spalt vor dem Dispersionsprisma blieb bei den Versuchen selbst natürlich unverändert und deshalb außerhalb der Berechnungen. 
Die für jede einzelne Farbe geltende Grundintensität ergibt sich aus der Kombination von je 3 Werten. (Energieverteilung im Normalspektrum der Lichtquelle, Dispersion des Zerstreuungsprismas und selektive Reisabsorption.)

Die Tabelle IV gibt eine Übersicht über die Logarithmen dieser Werte. Multiplizieren wir nun einen dieser Grundwerte mit dem. Cosinusquadrat des ab. gelesenen Drehungswinkels, so erhalten wir den gewünschten Endwert der Intensität. Aufs deutlichste zeigt die Tabelle die sehr starken Verschiedenheiten der Intensität in den einzelnen Abschnitten eines prismatischen Spektrums. Wir sehen z. B., daß die Energie einer roten Strahlung von $660 \mu \mu$ Wellenlänge etwa 100 mal größer ist als die einer blauen von der Wellenlänge $450 \mu \mu$.

\section{Physiologische Versuchstechnik.}

\section{Ausgestaltung der Technik.}

Für die Ausgestaltung der Methodik des eigentlichen Tierversuches war der Grundsatz maßgebend, die Messung der Empfindungsstärke zunächst so fein als irgend möglich auszuführen und dann erst diejenigen Faktoren der rein physikalischen Messung aufzugeben, die auf die erstere keinen Einfluß mehr hatten. So wurde z. B., wie schon erwähnt, die Lampenstromstärke nicht mehr gemessen, nachdem sich herausgestellt hatte, daß die geringen Schwankungen des Stroms die Versuchsresultate nicht merklich beeinflußten.

Prinzipiell hatten wir uns für die Anwendung einer Schwellenwertmethode entschieden, um die Empfindungsstärke zu messen, und zwar wollten wir Handlungen des Tieres als Merkmal dafür benützen, daß gerade ein Minimum der Helligkeit für das zu untersuchende Tier bestünde. Das Ziel der Methode war die Erreichung konstanter Werte.

Da es sich bei unseren Versuchen um Warmblüter handelte, bei denen der Hunger eine ungleich wichtigere Rolle spielt, als bei Poikilothermen, so erschien es aussichtsvoll, die Sichtbarkeit von Futter als Maß der anzunehmenden Helligkeit zu wählen. Hühner waren ihrer Gefräßigkeit und relativen „Hemmungslosigkeit" wegen ganz besonders gut geeignet. Ich beleuchtete eine mit Körnern oder dergl. bestreute Fläche niemals gleichzeitig mit einem ganzen Spektrum, wie dies Hess (1912) etwa tat. Man kann auf diese Weise mit Sicherheit nur das Helligkeitsmaximum im Spektrum feststellen. Ist etwa alles Futter der Gegend des Helligkeitsmaximums - es sei z. B. Gelb - gefressen, und steigert man nun die Intensität, so werden jetzt die heller gewordenen Stellen rechts und links vom Maximum auch wahrgenommen, aber wahrscheinlich relativ zu spät, da das nunmelir noch heller gewordene Gelb die Empfindlichkeit der Netzhaut inzwischen herabgedrückt hat. Ganz besonders gilt dies, wenn man schwarzes Futter auf weißem Grunde benutzt, was noch aus mehreren anderen Gründen zu verwerfen ist. So stört z. B. der Schatten des Tieres selbst sehr, und der Schatten der Futterkörner gibt Anlaß zu Täuschungen über deren Lage. Ich benutzte deshalb nur weißes Futter auf mattschwarzem Grunde.

Als möglichst weißes Futter wählte ich, wie schon oben erwähnt wurde, Reiskörner und zwar eine recht weiße, großkörnige und undurchsichtige Sorte, die ungekocht verfüttert und sehr gern gefressen wurde,

Beleuchtet wurde nun aus den eben erwähnten Gründen immer nur ein schmaler Streifen mit einer einzigen, praktisch homogenen Farbe. Fraßen die Hühner nun unter all den Körnern gerade den beleuchteten Streifen heraus, so war es 
zunächst einmal ganz sicher, $d a ß$ bei dieser Leistung nur der Gesichts. sinn, nicht aber der Tast-oder gar Geruchssinn in Frage kam.

Die Versuche begannen damit, daß eine Anzahl junger Hühner an die immerhin etwas ungewöhnliche Arbeit gewöhnt wurde, im Dunkeln einen schmalen beleuchteten Streifen Körner zu fressen. Als dies gar nicht gelingen wollte, nahm ich schließlich den verschiebbaren Spalt einmal ganz weg, worauf dann die meisten Tiere sofort zu fressen begannen, da nunmehr die ganze breite Fläche - wenn auch verschiedenfarbig - beleuchtet war. Dann wurde die Öffnung wieder allmählich verkleinert, bis das normale Maß von $8 \mathrm{~mm}$ Spaltbreite erreicht war.

Jetzt fraßen also die Hühner den beleuchteten schmalen Streifen, aber die Resultate waren noch sehr schwankend. Sehr störend war nämlich, daß die Tiere binnen kurzer Zeit sich an die Versuche so gewöhnten, daß sie sofort zu picken begannen, sobald sie im Dunkeln auf den Versuchstisch gesetzt worden waren, da sie wohl gelernt hatten, mit den Füßen zu tasten und dann entsprechend zu picken. Es geschah also zuweilen, daß man das Tier im Dunkeln picken hörte, ehe noch an eine Kontrolle mit dem menschlichen Auge zu denken war, und machte man dann wieder hell, so hatte es entweder ganz regellos, bald hier, bald da, Körner aufgepickt oder freilich auch gar nichts getroffen.

Unhaltbar wurde das Verfahren aber erst, als die Versuchsergebnisse ihre Eindeutigkeit dadurch verloren, daß die Hühner anfingen, im Dunkeln zu scharren, was sie zuerst nicht getan hatten. So war der Streifen vielleicht schon manchmal hell genug und sauber ausgefressen, und das Resultat wurde erst nachträglich wieder verwischt oder richtiger, "verscharrt".

Dieser Übelstand mußte beseitigt werden. Der Versuch, durch jedesmalige sofortige Strafen nach einem Scharrversuche diese den Hühnern abzugewöhnen. blieb zwar nicht ganz ohne Erfolg, aber allmählich fielen die Tiere immer wieder in ihren Fehler zurück. Nunmehr versuchte ich, ihnen das Scharren unmöglich zu machen und setzte sie im Dunkeln auf eine Stange, von der aus sie picken sollten. Hatten sie sich jedoch erst einmal von der natürlich geringen Distanz zwischen Stange und Tischplatte überzeugt, so sprangen sie einfach - auch im absolut Dunklen, wo sie in der Regel still sitzen - von der Stange herunter. Auch die Maßnahme, die Tiere durch ein weitmaschiges Drahtnetz hindurch fressen zu lassen, bewährte sich nicht.

Da sich nun die Unmöglichkeit herausstellte, die Tiere am Scharren zu hindern, so suchte ich ein Mittel, das zwar das unvermeidliche Scharren an sich nicht unmöglich machen, aber seine störende Wirkung aufheben sollte. Ich bohrte zu diesem Zweck in ein Holzbrett in ziemlich regelloser Anordnung halbkugelige Vertiefungen, in welche die Reiskörner einzeln gelegt wurden. Diese Löcher waren so tief, daß die Hühner beim Scharren die Körner nicht erreichten und so weit, daß sie sie immerhin bequem herauspicken konnten (Abb. 3).

Damit waren alle bisherigen Störungen beseitigt.

Die Befürchtung, daß die Hühner auch jetzt mit Hilfe ihrer Füße oder des Schnabels die Vertiefung abtasten würden, erwies sich als völlig unbegründet. Im Dunkeln machte es den Tieren zunächst sogar Schwierigkeiten, die Körner aufzupicken. Da sie hier natürlich nur die Körner selbst bcleuchtet sahen - das Brett war natürlich überall matt schwarz - ohne die halbkugeligen Vertiefungen wahrzunehmen, so öffneten sie den Schnabel meist zu zeitig, so daß nicht beide Schnabelspitzen in die Vertiefung gelangen konnten und das Picken erfolglos blieb. Erst nach einiger Übung im Hellen, wo ihnen das Aufpicken keine Schwierigkeiten machte, lernten die Tiere, auch im Dunklen vom „Lochbrett" zu fressen.

Als die Hühner nunmehr allmählich merkten, daß das Scharren stets erfolglos blieb, stellten sie es jetzt ganz von selber ein. Jedenfalls zeigte es sich nur noch 
ganz vereinzelt, wenn die Tiere etwa aufgeregt oder zu hungrig waren. Die Versuchsresultate wurden jetzt freilich dadurch nicht mehr beeinflußt.

Damit war ein Zustand erreicht, der die Vornahme exakter Versuchsreihen möglich machte, denn die sich ergebenden Werte zeigten nunmehr eine gute Übereinstimmung.

\section{Ausführung der Versuche.}

Die ersten systematischen Versuche, die ich vornahm, sollten die relative Empfindlichkeit von helladaptierten Hühnern für Licht von verschiedener Brechbarkeit ermitteln.

Zu diesem Zwecke wurden meist je zwei Hühner abwechselnd untersucht. Während der Untersuchung des einen Tieres wurde das andere wieder der Wirkung des Tageslichts ausgesetzt. Damit wurde erstens die Zeit gespart, die man, wenn immer nur ein Tier untersucht worden wäre, zu dessen Helladaptierung nach dem Versuche benötigt hätte. Dadurch, daß stets zwei verschiedene Individuen unmittelbar nacheinander untersucht wurden, ergab sich die auch Möglichkeit, etwaige rein individuelle Schwankungen der Empfindlichkeit festzustellen und ausschalten zu können.

Die einzelnen Versuche wurden folgendermaßen ausgeführt: die Nernstlampe wurde angezündet, das Reisbrett gefüllt, d. h. in jede Vertiefung ein Reiskorn gelegt, die Spaltblende so eingestellt, daß die gewünschte Farbe erschien (zuerst stets Grün von $540 \mu \mu$ Wellenlänge) und das Uhrwerk aufgezogen, das zur Drehung des Polarisationsprisma diente. Dieses drehbare Prisma wurde jetzt auf den Nullpunkt eingestellt (die Ablesung erfolgte sehr bequem an einem großen Teilkreise von $35 \mathrm{~cm}$ Durchmesser, auf dem nur die Grade angegeben waren), sodaß also das Maximum der Absorption erreicht war. Nunmehr wurde eins von den beiden Hühnern, mit denen gerade experimentiert wurde, nach einem Aufenthalt im Hellen von zunächst mindestens 5 Minuten Dauer in das absolut dunkle Versuchszimmer gebracht und auf den Versuchstisch gesetzt. Gleichzeitig wurde durch Bewegung des Hebels an diesem Tische das Uhrwerk in Bewegung gesetzt, worauf die Drehung des Prismas begann und die Intensität der Strahlung sich nun ganz allmählich steigerte. Da der Vorgang der Dunkeladaptierung (siehe unten) bei Hühnern weit langsamer verläuft, als bei uns, so sah der Beobachter - wenn es sich etwa um Grün oder noch stärker brechbares Licht handelte - bald einen weißlichen Streifen, der allerdings zunächst nur beim indirekten, extrafovealen Sehen sichtbar war. Bald aber nahm die Helligkeit zu, und zwar immer schneller, da die Helligkeit einmal mit der objektiv wachsenden Intensität, ferner aber mit der im Dunkeln wachsenden Empfindlichkeit - also doppelt - zunahm. So wurden bald einzelne Körner sichtbar; der Farbton erschien und wurde immer ausgesprochener. Sobald jetzt das Huhn zu picken begann, 
wurde das Uhrwerk zum Stehen gebracht, so daß das Tier den ganzen Streifen bei derjenigen Lichtintensität ausfressen konnte, die als Reizschwelle auzusehen war. Wir wollen ganz exakt sein und müssen deshalb bekennen, daß während des Fressens die Helligkeit freilich noch insofern zunahm, als die Lichtempfindlichkeit im Dunkeln doch noch etwas größer wurde. Diese Zunahme ist aber sicher ganz unbedeutend, da das Fressen des Streifens kaum länger als etwa $1 / 2$ Minute dauerte.

War der Versuch beendet, so wurde vom Versuchstische aus eine der nur mit halber Spannung brennenden oder richtiger glimmenden Glühlampen entzündet und das Tier schnell wieder ins Helle gesetzt, nämlich in handliche aber durchaus genügend starke und große Kartonkästen, die oben mit sehr weitmaschigen Drahtgeflecht verschlossen waren. Diese Kästen wurden vor das Fenster auf einen Sims'gestellt, wo die Hühner ausgiebig helladaptieren konnten, ohne jemals der direkten Sonnenstrahlung ausgesetzt zu sein.

Notiert wurde vor jedem Versuch Datum und Tageszeit, die Nummer des Tieres, die benutzte Wellenlänge und die Dauer des vorangegangenen Hell- und Dunkelaufenthaltes.

Nach dem Versuch wurde zunächst die Güte der Leistung geprüft und kurz mit den Bezeichnungen ,deutlich", ,gut", „, fehlerlos" bei positivem, ,undeutlich" oder ,nichts gefressen" bei negativem Ergebnisse gekennzeichnet. Auf diese Feststellungen ist insofern oft entscheidender Wert zu legen, als durch sie erst hervorgeht, ob die benutzte Intensität auch wirklich einem Schwellenwerte der Helligkeit entsprach. Wenn nämlich durch irgend einen Umstand dieser Wert überschritten wurde und das Tier zu spät zu fressen abfing, so dokumentierte sich diese Tatsache fast stets dadurch, daß die Tiere $\mathrm{z} \mathbf{u}$ deutlich oder fehlerlos fraßen. Die Abb. 3 zeigt die Reistafel, auf der ein Streifen bei richtiger Helligkeit (Schwellenwert), ein zweiter Streifen bei überschwelliger Helligkeit ausgefressen wurde. Im ersten Falle fehlen nur sieben Körner, die nicht einmal alle aufgepickt zu sein brauchen; einige scheinen nur zur Seite geschleudert. Im merhin ist es ganz de utlich, daß die leeren Löcher alle in einer Geraden liegen, und zwar auf der Geraden, a uf die der Lichtstreifen hinfiel. - Im zweiten Falle sieht man sofort, daß die Helligkeit schon viel zu groß war und daß das Tier seine Aufgabe mühelos löste.

Erst nachdem also die Qualität des Versuchsergebnisses, wenn ich so sagen darf, fixiert war, wurde die Seitentür des den Apparat umschließenden Kastens geöffnet und die Gradstellung des Polarisationsprismas abgelesen und notiert. Damit war jede Selbsttäuschung oder Beeinflussung des Resultats unmöglich gemacht. Aufgeschrieben wurde übrigens nicht nur der Endwert der Prismastellung, sondern auch der Anfangswert, da sich aus diesen beiden Daten sofort genau die Frist 
ergibt, die das Tier seit Beginn des Versuches bis zum Moment des ersten Pickens im Dunkeln zugebracht hat. So bedeutet die Bemerkung: von $0^{\circ}$ bis $29^{\circ}$, daß der Dunkelaufenthalt $29 \cdot 7$ Sekungen $=$ etwa $31_{2}$ Minuten gedauert hatte, da wie oben gesagt wurde, $1^{\circ}$ in 7 Sekunden durchlaufen wurde. Waren übrigens, wie bei diesem Beispiele, die Tiere über $3 \mathrm{Mi}$ nuten im Dunkeln gewesen, so wurden die gefundenen Zahlen natürlich nicht mehr als Schwellenwerte für an mittlere Tageshelligkeit gewöhnte Tiere betrachtet. Am nächsten lag es wohl, als Schwellenwerte für helladaptierte Tiere diejenigen Helligkeiten anzusprechen, die bewirken, daß das ins Dunkle gesetzte Tier s of ort zu fressen begann. Derartige Helligkeitswerte lassen sich natürlich ermitteln; sie sind aber schwankend und meines Erachtens auch relativ zu hoch, und die gefundene Empfindlichkeit ist zu gering. Es ist nämlich sehr wahrscheinlich, daß wie beim Menschen der plötzliche Übergang ins Dunkle stark wirkende rein subjektive Nebenerscheinun. gen auslöst, welche die gleichzeitig beginnende Empfindlichkeitszunahme zwar nicht stören, aber äußerlich

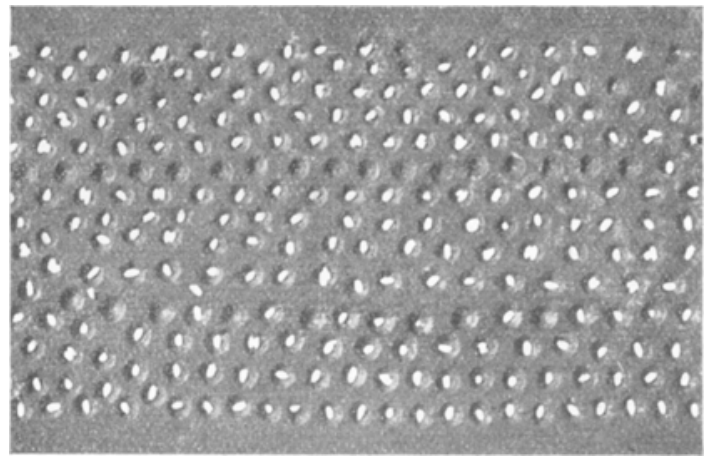

Abb. 3. Teilansicht des Lochbrettes mit Reiskörnern. verdecken (z. B. Nach-

bilder). Es ergaben sich nämlich viel konstantere Werte, sobald etwa wenigstens eine Minute Dunkelaufenthalt bis zum Beginn der Messung eingeschaltet wurde. Wenn also nach der vorhergehenden Messung (z. B. $0^{\circ}-29^{\circ}$ ) der Schwellenwert annähernd bekannt war, so wurde als Ausgangspunkt der Prismenstellung für die nächsten Versuche etwa die Stellung von $20^{\circ}$ gewählt. Ergab sich dann als gültiges Resultat $\left[20^{\circ}-\right] 31^{\circ}$, so wurde dieser Wert - der einen vorhergehenden Dunkelaufenthalt von nur etwa einer Minute anzeigt - als Schwellenwert des helladaptierten Tieres angesehen. Die Berechtigung dieses Vorgehens ergibt sich aus den unten mitgeteilten Adaptierungskurven.

Ich muß jetzt noch einige Tatsachen erwähnen, die vielleicht imstande sind, zur Verschleierung der Ergebnisse beizutragen. Erwähnt wurde schon, daß schließlich nach Ausschaltung der oben genannten Übelstände die Resultate befriedigend übereinstimmten. Voraussetzung dafür war freilich einmal, daß die Tiere seit dem yorhergehenden Abend nichts zu fressen erhalten hatten. Waren die Tiere auch nur wenig 
gefüttert, so sank die Empfindlichkeit scheinbar sehr stark. Es handelt sich hier keineswegs etwa um völlig satte Tiere; im Gegenteil: im Hellen fraßen sie gierig, aber der Hunger war doch zu schwach, um die Leistung des Fressens im Dunkeln auszulösen, wobei doch schließlich starke Hemmungen überwunden werden müssen.

Diese Fehlerquelle war natürlich, nachdem sie erkannt war, leicht zu beseitigen.

Um eine wirkliche Abnahme der Empfindlichkeit handelte es sich hier sicher nicht, wie aus dem Folgenden noch hervorgehen wird. Man könnte hier von einem,,peri pheren" und einem,,zentralen"Schwellenwerte sprechen, zwei Ausdrücke, die nichts präjudizieren, sondern nur andeuten sollen, daß der Reiz für das Sinnesorgan überschwellig ist, ohne den vom Zentralorgan abhängigen komplizierten Vorgang auszulösen, der sonst bei gleicher Reizstärke auftritt. Insofern sind die beiden genannten termini freilich nicht ganz korrekt, als wir ja durchaus gewohnt sind, gerade die Netzhaut anatomisch als Bestandteil des Zentralnervensystems anzusehen. Trotzdem glaube ich die beiden Ausdrücke ihrer Anschaulichkeit wegen beibehalten zu dürfen.

Eine weitere Fehlerquelle bestand darin, daß die Tiere keine guten Werte lieferten, wenn sie a ufgeregt waren. Besonders reizbar waren die Hähne während der Geschlechtsreife. Eine befriedigende Versuchsreihe mußte oft vorzeitig abgebrochen werden, weil etwa in der Nachbarschaft ein fremder Hahn krähte, ein Vorgang, der das Versuchstier sofort zum Antworten veranlaßte und seine ganze Aufmerksamkeit in Anspruch nahm. Diesem Übelstand war nicht abzuhelfen, da die akustische Isolierung nie vollständig gelang.

Endlich bestand noch eine dritte Möglichkeit der Schwellenverschiebung. Hatte nämlich das Tier trotz aller Anstrengungen keinen Erfolg, so war es bei den nächsten Versuchen von vornherein entmutigt und zeigte eine scheinbar zu geringe Lichtempfindlichkeit. Dem Vorwurfe, diese Vorgänge allzu anthropomorphistisch darzustellen, ist entgegenzuhalten, daß die normale Empfindlichkeit sofort wieder hergestellt werden konnte, wenn man in eine derartige schlechte Versuchsreihe eine ,Ermunterungsfütterung" einschob. Diese Ermunterung bestand einfach darin, daß ich die Tiere (im Dunkeln) den Streifen Körner bei einer etwas - wenn auch nicht viel - überschwelligen Helligkeit fressen ließ.

Da sich eine derartige Unsicherheit immer wieder bei den ersten Versuchen zeigte, die am Tage angestellt wurden, so begann ich später regelmäßig mit zwei Versuchen, bei denen der Körnerstreifen eine überschwellige Helligkeit zeigte.

Es bleibt uns noch übrig die Versuchsreihen zu beschreiben, die zur Ermittelung des Verlaufs der Dunkeladaptierung angestellt 
wurden. Es erschien mit außerordentlich wichtig, den zeitlichen Verlauf der Empfindlichkeitszunahme nicht nur für gemischte Strahlungen (,farbloses Licht") sondern auch für homogene Strahlungen zu ermitteln: War es doch von vornherein mehr als wahrscheinlich, daß sich starke Verschiedenheiten für verschiedenfarbige Lichter ergeben würden. Ich betone nochmals die auffallende Tatsache, daß bisher systematische Untersuchungen über die typische Verschiedenheit des Verlaufs der Empfindlichkeitszunahme für homogene Lichter verschiedener Wellenlänge nicht einmal beim Menschen, geschweige denn bei Tieren angestellt worden sind.

Die Versuche wurden zunächst ganz ebenso angestellt, wie die bisherigen. Nach zwei Ermunterungsversuchen wurde festgestellt, ob die normale ,Zentral"empfindlichkeit für Licht von irgend einer Wellenlänge bestünde. War das, wie fast immer, der Fall, so wurde das Tier wieder 5 Minuten ins Helle gesetzt, dann aber, nachdem es wieder im absolut Dunkeln auf dem Versuchstische saß, noch z. B. 3 Minuten ohne jede Belichtung gelassen. Erst nach Ablauf dieser Frist wurde das Uhrwerk in Gang gesetzt und die Intensität der Beleuchtung allmählich vergrößert. Alles übrige wurde ebenso gehandhabt wie bei den bisher beschriebenen Versuchen. Das Huhn wurde nun wieder 5 Minuten ins Helle gesetzt, blieb dann z. B. 6 Minuten im Dunkeln, worauf wieder eine Messung erfolgte usw. Die Zeit vom Beginn der eigentlichen Messung bis zum ersten Picken des Tieres wurde hier natürlich zu der Zeit des vorhergehenden Dunkelaufenthaltes hinzuaddiert.

Der Nachteil dieses Vorgehens war die sehr lange Dauer jedes einzelnen Versuches. Um diesem Überstande abzuhelfen, versuchte ich die dazwischen liegenden Hellaufenthalte auszuschalten. Zu diesem Zwecke baute ich mir einen absolut lichtdichten Doppelkasten aus Holz, in dessen beiden Kammern 2 Hühner bequem sitzen konnten. Die Versuche gestalteten sich nunmehr folgendermaßen: nach den täglichen ersten Vorversuchen am helladaptierten Tiere wurde z. B. eine Messung mit 3 Minuten Dunkelaufenthalt angestellt. Der Versuch selbst dauerte nun ungefähr 1 Minute, darauf wurde das Tier im Dunkeln in den lichtdichten Kasten gesetzt und jetzt erst das Zimmer erleuchtet, um das Resultat zu kontrollieren. Damit und mit den Vorbereitungen zum nächsten Versuche (Aufschreiben des Ergebnisses, Verteilung neuer Körner auf das Reisbrett, Aufziehen des Uhrwerks usw.) waren wiederum $2 \mathrm{Min}$. vergangen. Bei Beginn des nächsten Versuches war also das Tier insgesamt $3+1+2=6$ Min. im Dunkeln. 4 Min. später wurde z. B. wieder eine Messung gemacht, die die Empfindlichkeit bei einem Dunkelaufenthalt von 10 Min. zeigte usw. Der Versuch ergab innerhalb der Fehlergrenzen denselben Wert, wie wenn das Tier nach dem Hellaufenthalt ununterbrochen 6 bzw. 10 Min. Iang im Dunkeln zugebracht hätte. 
Nachdem sich auf diese Weise gezeigt hatte, daß die minimale Helligkeit, die beim Versuche selbst auf das Tier einwirkt, die im Dunkeln einmal gewonnene Empfindlichkeit nicht herabsetzte, war die Berechtigung des eben beschriebenen Verfahrens nachgewiesen. Bei Adaptationsmessungen wurde es nunmehr ausschließlich angewandt.

Wollen wir z. B. die Empfindlichkeiten nach einem Dunkelaufenthalt von je 3,6, 10, 20, 30, 45 und 60 Minuten messen, so brauchen wir bei Anwendung der ersten Methode und einem jedesmaligem Hellaufenthalt von 5 Minuten zu diesem 7 Messungen mehr als $3^{1} / 2$ Stunde, während wir jetzt nur noch 1 Stunde dazu benötigen. Schon im Interesse des Versuches selber ist diese Abkürzung dringend geboten. Die Leistungsfähigkeit gut eingewöhnterTiere ist zwar nach 8-10 Stunden noch durchaus befriedigend, aber größere Pausen in den Messungen bedingen eben meist ein Sinken der zentralen Schwelle, die dann erst durch Ermunterungsfütterungen wieder auf ihre normale Höhe gebracht werden muß.

Innerhalb der ersten Stunde wiederholten sich die Versuche oft genug, selbst wenn - wie es fast stets der Fall war - immer zwei Tiere abwechselnd untersucht wurden. Nach einem längeren Dunkelaufenthalte nahm die Empfindlichkeit für die meisten Lichter natürlich immer langsamer zu, so daß die Messungen auch in immer größeren Zwischenräumen erfolgten. War nun ein Versuch nach 2 Stunden Dunkelaufenthalt gemacht, so ergab der nächste, z. B. nach 3 Stunden Dunkelaufenthalt, zunächst fast regelmäßig zu niedrige Empfindilichkeitswerte. Der Versuch wurde dann sofort wiederholt und ergab meist einen höheren Wert der Empfindlichkeit. (Natürlich wurden nur solche Resultate in Betracht gezogen, die sich bei einem bestimmten Dunkelaufenthalt als konstant und maximal ergaben.) Wir haben hier ein vollständiges Analogon zu der oben erwähnten Schwellenverschiebung. Auch hier ist Ermüdung als Ursache der Verschiebung natürlich ausgeschlossen.

Schließlich sind noch einige Kontrollmessungen zu erwähnen, die zur Ermittlung menschlicher Schwellenwerte angestellt wurden, um einen Anhalt für die Vergleiche zwischen Tier und Mensch zu liefern. Ganz entsprechend den Tierversuchen wurde auch hier eine Kombination von Schwellenwert- und Sehschärfemethode angewandt. Mehrere kleine schwarze Holztafeln, auf die je 3 Reiskörner in dieser Form Igeklebt waren, lagen in der Lichtlinie. Als Schwellenwert wurde diejenige Helligkeit angesehen, die nicht nur das Wahrnehmen der einzelnen Körner, sondern auch das Erkennen der Lage der Öffnung gestattete, die natürlich nach jedem Versuche variiert wurde. Eine Kopfstütze sorgte dafür, daß der Abstand des Auges von den Sehproben konstant blieb.

Für 2 Farben $(620$ und $540 \mu \mu)$ wurde auch der Verlauf der Dunkeladaptierung festgestellt. Auch hier wurden die Hellaufenthalte ausgeschaltet und nach jedem Versuche der Kopf des zu Untersuchenden bis zum Beginn des nächsten Versuches mit einem vollkommen lichtdichten schwarzen Tuche verhüllt.

Alle diese Messungen hatten natürlich, wie gesagt, nur den Zweck, eine Vergleichsbasis für den Tierversuch zu schaffen. Für eine spezielle Untersuchuing menschlicher Empfindlichkeitswerte ist ja die 
Methode wenig geeignet und liefert deshalb auch nicht sehr konstante Werte. Aber es lag mir daran, unter genau den gleichen Bedingungen Messungen der tierischen und menschlichen Empfindlichkeit anzustellen, die einen unmittelbaren Vergleich der Ergebnisse gestatten.

\section{Die Versuchsergebnisse.}

\section{Chronologische Übersicht.}

Die Ergebnisse der mehr als 2000 Messungen, die nach den bisher beschriebenen Methoden angestellt wurden, sind in den Tab. V-XVIII niedergelegt. Thnen entsprechen die Kurven auf Abb. 4-9b.

Ehe wir jedoch auf die Besprechung von Einzelheiten eingehen, möchte ich chronologisch ganz kurz berichten, wie schon im Verlauf der Messungen einige überraschende Tatsachen festgestellt werden konnten.

Gleich in den ersten Tagen der. Untersuchung helladaptierter Tiere (Anfang Juni 1913) trat ein völlig unerwartetes Versuchsergebnis zutage. Bei den ersten Versuchen waren die Reiskörner mit grünem Licht beleuchtet gewesen, daß uns Menschen - ceteris paribus - viel heller erscheint als Hühnern, wie dies ja schon bekannt war. Die nächste Farbe, deren Helligkeit untersucht wurde, war ein Rot $(640 \mu \mu)$. Der Versuch begann in gewohnter Weise; plötzlich aber, als für mich noch nicht das geringste zu erkennen war, begann das Tier schnell hintereinander zu picken. Ich glaubte bestimmt, das es sich um eine resultatlose Messung handelte, und war nicht wenig erstaunt, als sich zeigte, daß der Streifen völlig fehlerlos ausgefressen war. Häufige Wiederholungen des Versuches zeigten die Tatsache, das für (helladaptierte) Hühner Rot viel heller ist, als für (gleichfalls helladaptierte) Menschen, sodaß die Strahlung für das Tier schon erheblich überschwellig sein kann, wenn wir noch nicht das geringste sehen.

Zunächst möchte es scheinen, als ob wir hier ein vollständiges Gegenstück zu der schon bekannten Tatsache vor uns hätten, daß Tagvögeln der kurzwellige Teil des Spektrums relativ dunkler erscheint als uns. Aber es handelt sich doch bei unserer Feststellung um etwas prinzipiell Neues, worauf wir unten noch eingehen müssen.

Eine weitere Überraschung zeigte sich bei der ersten Untersuchung von Tieren, die längere Zeit im Dunkeln zugebracht hatten (Sept. 1913). Während nämlich die Untersuchung helladaptierter Tiere leider schon im Blaugrün $(500 \mu \mu)$ ihre Grenze erreichte, da selbst die maximale Intensität (d. h. Nicolstellung $90^{\circ}$ ) der noch mehr brechbaren Lichter zu gering war, um Schwellenwerte festzustellen, so zeigten dunkeladaptierte Tiere eine (relativ) so außerordentlich hohe Empfindlichkeit 
für blaugrüne und blaue Strahlungen, da $\beta$ die Messungen bis tief ins Blau $(450 \mu \mu)$ ausgedehnt werden konnten. Aus dieser einen Tatsache ergibt sich schon der enorme Unterschied in der Empfindlichkeitszunahme für lang- und kurzwelliges Licht, da für jede einzelne Farbe die Nicolstellungen allein den jeweiligen Intensitätsverhältnissen entsprechen.

Eine ganz eigenartige Tatsache, die wohl bisher in der gesamten Sinnesphysiologie der Wirbeltiere ohne Beispiel dasteht ${ }^{1}$ ), konnte festgestellt werden, als die erste Serie von Hähnen, die zur Untersuchung dienten, geschlechtsreif geworden war. Die Ende Mai 1913 gekauften Tiere waren im Oktober 1913 ausgewachsen und lieferten seitdem viel niedrigere Empfindlichkeitswerte als vorher. Sie waren jetzt auch - wie schon erwähnt wurde - oft sehr erregt, so daß die Empfindlichkeitsabnahme durch zentrale Hemmungen bedingt sein konnte. Freilich wurde es mir damals schon wahrscheinlich, daß mit der Geschlechtsreife eine Änderung der ,,peripheren“ Lichtempfindlichkeit einträte, und zwar um so mehr, als die Empfindlichkeit besonders für kurzwellige Lichter abzunehmen schien.

Ende November brach num eines Tages ganz plötzlich ein heftiger Kampf zwisehen den beiden größten und kräftigsten Hähnen aus, mit denen ich bisher fast ausschließlich experimentiert hatte. Beide Tiere waren mit mehreren anderen Tieren zusammen aufgewachsen und hatten sich früher vorzüglich miteinander vertragen. Nach dem Zweikampf waren beide so zugerichtet, daß zunächst nicht daran zu denken war, sie zu weiteren Untersuchungen zu verwenden.

Ich begann deshalb mit der Eingewöhnung von neu erworbenen jungen Hähnen. Schon nach etwa 14 Tagen lieferten diese gute Werte, die mit den Resultaten der früheren Versuche (mit den damals jungen, nunmehr ausgewachsenen Tieren) übereinstimmten. Damit war zunächst einmal ganz zweifellos festgestellt, daß sich an der Apparatur nichts geändert hatte, und daß diese Änderung der Werte durch den Organismus der geschlechtsreif gewordenen Hähne bedingt sein mußte. Immerhin bestand noch immer die zwar wenig wahrscheinliche Möglichkeit einer vorübergehenden Abnahme der Empfindlichkeit älterer Hähne für gewisse Lichter. Um diese Frage klarzustellen, wurden zu den Versuchen später wieder die alten Tiere herangezogen, die inzwischen in Einzelhaft, von den übrigen Hühnern völlig getrennt, untergebracht gewesen waren. Es war nun bemerkenswert, daß die Tiere, obwohl seit $21 / 2$ Monaten mit ihnen kein einziger Versuch gemacht worden war,

1) Die Vergrößerung der Augen bei AaIen nach Eintritt der Geschlechtsreife ist eine Tatsache, die ganz anders zu bewerten ist. Die reifen Aale wandern vom Fluß in die Tiefsee, kommen also in ein ganz neues biologisches Medium, was bei den Hühnern nicht der Fall ist. 
doch sofort wieder im Dunkeln fraßen. - Nur wenige Tage waren die Werte schwankend, was infolge der Aufregung beim Transport und beim Wiedersehen mit den anderen Hühnern nicht verwunderlich erschien, dann aber waren die Ergebnisse befriedigend, d. h. wenigstens einigermaßen konstant.

Wenn man jetzt je einen alten und einen jungen Hahn abwechselnd nacheinander unter genau den gleichen äußeren Bedingungen untersuchte; so zeigte sich aufs allerdeutlichste die Abnahme der Empfindlichkeit der älteren-Tiere. Die Differenz beginnt etwa bei $640 \mu \mu$ und wird für kurzwellige Lichter immer bedeutender.

Diese letzten Messungen gestalteten sich übrigens sehr schwierig und zeitraubend, da der ständige Wechsel von Hell und Dunkel die a usgewachsenen Tiere beunruhigte. Einige Versuchsreihen mit lange (8-10 Stunden) d unkeladaptierten jungen und alten Tieren gelangen ohne Schwierigkeit, da auch die ausgewachsenen Tiere, wenn sie ununterbrochen im Dunkel blieben, sich sehr ruhig verhielten.

\section{Die graphische Darstellung der Versuchsergebnisse.}

Wenn wir unsere Ergebnisse nicht nur zahlenmäßig, sondern auch graphisch darstellen wollen, so müssen wir Kurven konstruieren, deren Verlauf uns ein Bild von den wechselnden Beziehungen zwischen Empfindungsstärke und Reizstärke gibt. Wir können dieses Ziel auf zwei Wegen erreichen: einmal nämlich können wir die gefundenen Schwellenwerte selbst (die Minima der Strahlungsintensität), andererseits aber auch die sich daraus ergebenden Empfindlichkeitswerte als Ordinaten in ein Koordinatensystem eintragen. Da nun bei gleichbleibender Empfindungsstärke die Reizempfindlichkeit der Reizstärke immer umgekehrt proportional ist, so erhalten wir im letzten Falle Kurven der Lichtempfindlichkeit selbst, im ersten dagegen Kurven mit den reziproken Werten der Lichtempfindlichkeit.

Zunächst könnte man denken, daß es gleichgültig ist, ob wir den einen oder den anderen Weg beschreiten, und es scheint so, als ob der Unterschied der beiden Kurvensysteme nur darin bestünde, daß das Empfindlichkeitsmaximum einmal unten liegt (niedrige Schwelle, geringe objektive Strahlungsintensität), im anderen Falle oben (hohe Empfindlichkeit). Und doch besteht ein prinzipieller Unterschied zwischen beiden Arten der Darstellung, den wir uns jetzt ganz klar machen müssen.

Betrachten wir zunächst einmal als Beispiele die Abb. 4 und 5. Abb. 4 enthält in 3 Kurven die Schwellenwerte helladaptierter Hühner (junger and geschlechtsreifer Hahn) und des Menschen für Licht von $660-480 \mu \mu$ Wellenlänge. Abb. 5 enthält entsprechend 3 Kurven der mit 1000 multiplizierten Empfindlichkeitswerte. 
Die beiden Kurvensysteme stimmen nun natürlich in einer Reihe wesentlicher Momente überein. So geht schon aus der Definition der Reizempfindlichkeit hervor, da 3 man die (im Zustande der Helladaptation herrschende) maximale Empfindlichkeit für Licht von einer ganz bestimmten Wellenlänge aus beiden Kurvensystemen ohne weiteres ablesen kann. So erscheint z. B. bei gleicher objektiver Intensität der verschiedenwelligen Strahlungen dem helladaptierten Menschen Licht von $530 \mu \mu$ Wellenlänge am hellsten ${ }^{1}$ ), dem jungen Tiere Licht von $550 \mu \mu$ und dem geschlechtsreifen Huhn Licht von $580 \mu \mu$ Wellenlänge. Die Maxima der 3 Empfindlichkeitskurven liegen nun natürlich genau bei denselben Wellenlängen wie die Minima der Schwellenwertskurven.

Selbstverständlich können wir uns auch mit Hilfe beider Kurvensysteme äber den Unterschied der Empfindlichkeit junger und alter Hühner orientieren. Die Kurven gabeln sich in beiden Abb. bei $640 \mu \mu$ Wellenlänge und entsprechend der niedrigeren Kurve der Schwellenwerte für das junge Huhn auf Abb. 4 finden wir eine höhere Empfindlichkeitskurve für das junge Tier auf Abb. 5. Ganz entsprechend beginnt die absolute Überlegenheit der Lichtempfindlichkeit von Hühnern gegenüber dem Menschen für langwellige Strahlungen in Abb. 4 wie auf Abb. 5 jedesmal bei einer Wellenlänge von $582 \mu \mu$, wie ein Blick auf die Abbildungen zeigt.

Etwas ganz anderes aber ergibt der Vergleich der Schwellenwerts- und Empfindlichkeitswerte auf Abb. 6 und 7 . Hier sind diejenigen Werte graphisch dargestellt, die sich bei der Untersuchung (junger und geschlechtsreifer) Hühner einerseits im Zustande der Helladaptation, andererseits nach einer Dunkeladaptierung von 8 Stunden ergeben haben.

Das Neue besteht hier darin, daß jetzt Werte miteinander verglichen werden, die ganz erheblich voneinander abweichen. Während nämlich die Schwellenwerte bzw. Empfindlichkeitswerte bisher höchstens um das 5 fache voneinander diffe. rierten, finden wir hier Werte, die sich um das 150 fache unterscheiden. Diese ungewöhnlich großen Differenzen beruhen eben auf den so enorm gesteigerten Empfindlichkeitswerten (bzw. den außerordentlich niedrigen Schwellenwerten der Strahlungsintensität), die nach einer langen Dunkeladaptierung auftreten.

Betrachten wir Abb. 6 allein, so sehen wir, daß die Schwellenwerte für junge und ausgewachsene Tiere im Zustand der Helladaptation zwar erheblich voneinander abweichen, während die Kurven für die dunkeladaptierten Tiere fast zusammenfallen.

Auf Abb. 7, wo die reziproken Werte der Kurven von Abb. 6, also die Empfindlichkeitswerte eingetragen sind, finden wir nun genau das Umgekehrte: hier differieren die Kurven der dunkeladaptierten Tiere, während die der helladaptierten Hühner beinahe zusammenliegen.

Diese zunächst so merkwürdig erscheinende Tatsache beruht einfach darauf, daß bei sehr geringen Strahlungsintensitäten auch relativ große Empfindlichkeitsdifferenzen praktisch kaum eine Rolle spielen. Verdoppelt sich nämlich unter solchen Umständen der Empfindlichkeitswert, so brauchen wir jetzt auch nur noch die Hälfte der Strahlungsintensität, aber diese Hälfte ist bei der so außerordentlich geringen Energie der Strahlung praktisch kaum von der zuerst gemessenen ganzen Strahlungsintensität zu unterscheiden.

Gerade das Entgegengesetzte gilt, wie gesagt, für die Empfindlichkeits kurve auf $\mathrm{Abb}$. 7. Hier gehen die Kurven für die dunkeladaptierten Tiere (junges und ausgewachsenes) weit auseinander und sind außerordentlich spitz-

1) Der Wert von $530 \mu \mu$ Wellenlänge als Maximum gilt beim Menschen erst nach ca. 30 Sekunden Dunkeladaptierung. Für den völlig ,helladaptierten“ Menschen ist er gleich 540-550 $\mu \mu$ Wellenlänge. (Bender 1913.) 
gipfelig, wobei noch zu berücksichtigen ist, daß auf Abb. 7 der Ordinatenmaßstab um $1 / 10$ kleiner ist als auf Abb. 5, während die Kurven auf Abb. 4 und 6 in zwei identische Koordinatensysteme eingezeichnet sind. Ohne diese Verkleinerung des Ordinatenmaßstabes wären die Kurven der dunkeladaptierten Tiere auf Abb. 6 noch 10 mal höher.

Es bestehen also in der Tat ganz erhebliche Differenzen in der Lichtempfindlichkeit junger und ausgewachsener Hühner im Zustand der Dunkeladaptation, aber diese starken Unterschiede verlieren praktisch sehr an Bedeutung, wenn wir uns klarmachen, daß sie nur ganz winzigen Intensitätsänderungen entsprechen.

Das eine steht jedenfalls fest: weder die Schwellenwertskurven, noch die Empfindlichkeitskurven geben jede allein für sich ein deutliches Bild von den Beziehungen zwischen Reizstärke und Empfindungsstärke, sondern erst die vergleichende Betrachtung beider Kurvensysteme zusammen gibt genügenden Aufschluß über die hier zu analysierenden Verhältnisse.

An dieser Stelle sei es mir gestattet, noch etwas über die graphische Darstellung der Adaptierung zu sagen. Wir gehen von der alten Methode von Charpentier (1886) aus, nämlich der Eintragung der gefundenen Zahlenwerte als Kurve in ein Koordinatensystem, wo als Abszissen die Zeit des Dunkelaufenthaltes, als Ordinaten die Schwellenwerte der Strahlungsintensität aufgetragen werden.

Will man sich nur eine Übersicht über den Verlauf der Adaptierung bei Untersuchung mit farblosem (gemischtem) Licht oder mit Licht von einer einzigen Farbe verschaffen, so genügen bei unserer Versuchsanordnung diejenigen Werte, die sich aus der Nicolstellung allein ergeben. Wir können also zunächst, wenn wir nur Licht von einer bestimmten Wellenlänge benutzen, die Tatsache vernachlässigen, daß gleiche „Nicolwerte“ im Rot einer viel höheren Intensität entsprechen als im Blau. Konstruieren wir auf Grund dieser Werte Kurven, so können wir sagen, daß die Form jeder einzelnen $K$ urve für sich ein richtiges Bild von dem zeitlich verschieden starken Absinken der Schwellenwerte gibt.

Sobald wir jedoch einen Vergleich der Schwellenwerte für Licht von verschiedener Wellenlänge vornehmen wollen, so müssen wir das bisherige Verfahren unbedingt verlassen. Wir müssen nunmehr die Schwellenwerte, die sich für langwelliges Licht ergeben haben, mit entsprechend größeren Faktoren multiplizieren, als die für kurzwelliges Licht erzielten; kurz, wir müssen die tatsächlich im Spektrum vorhandenen Energieverschiedenheiten rechnerisch ausgleichen genau ebenso, wie wir das bei den einfachen Empfindlichkeitsmessungen von vornherein tun mußten (III, 3). Nehmen wir diese Umrechnung vor, so kommt es zu einigen Änderungen an den Kurven. Einmal wird natürlich die Lage der Kurven geändert, da ja die Schwellenwerte für kurzwelliges Licht nunmehr erheblich kleiner werden, wenn dessen im Vergleich zn langwelligen Bezirken tatsächlich viel geringere Intensität beriücksichtigt wird.

Auch die Form der Kurven ändert sich insofern, als zwar das gegenseitige Verhältnis der Anstiegssteilheit von Abschnitten einer Kurve nach wie vor unverändert bleibt, während sich das Verhältnis der Anstiegssteilheit zweier verschiedener Kurven (für verschiedene Wellenlängen) natürlich ändert. Nehmen wir z. B. der Einfachheit halber an, daß für je eine rote und eine blaue Strahlung (von verschiedener Intensität) die Kurven der absinkenden Sehwellen. werte innerhalb der ersten beiden halben Stunden geradlinig und parallel verlaufen (beides ist in Wirklichkeit nicht der Fall) und haben wir nun, unseren Energiemessungen zufolge, alle Werte für "Rot" mit 2, alle Werte für „Blau“ mit 3 zu multiplizieren, so bleiben sich bejde Kurven insofern gleich, als sie beide gerad- 
linig verbleiben, aber die Kurve für Blau wird jetzt natürlich rascher ansteigen, als die für Rot. Waren die beiden Kurven also bisher parallel, so konvergieren sie jetzt, d. h. es gibt nun einen vorher nicht vorhandenen Schnittpunkt. Das gleiche gilt natürlich mutatis mutandis für alle Kurven beliebiger Form.

Macht man sich die eben besprochenen Tatsachen klar, so sieht man, daß eine vergleichende Analyse des Vorganges der Dunkeladaptierung nur möglich ist, wenn wir die wahren Intensitätsverhältnisse in Rechnung ziehen, die bei den betreffenden Versuchen geherrscht haben. Während des experimentellen Teiles der Untersuchung hatte ich auch nur jede "Tarbe" einzeln für sich betrachtet. Die sich ergebenden Adaptierungskurven, d. h. Kurven der Schwellenwerte für homogene Lichter, wurden zunächst alle in das gleiche Koordinatennetz eingetragen, aber es zeigte sich keine Ordnung, kin System - die Kurve, liefen anscheinend regellos durcheinander. Erst nach Abschluß der Tierexperimente nahm ich die eben erwähnte Umreehnung vor, die sofort eine befriedigend harmonische Gruppierung der Kurven ergab. Die Gesetzmäßigkeit dieser Gruppierung wird im Abschnitt V, 3 besprochen werden.

Auch hier bei der Darstellung der Adaptierung kann man statt der Schwellenwerte wieder die Empfindlichkeitswerte selbst in den Kreis der Betrachtung ziehen. In diesem Fall gilt natürlich auch all das, was eben erörtert wurde. Andererseits ist aber auch das zu berücksichtigen, was auf S. 36-37 über die Darstellung von Schwellenwerten and Empfindlichkeitswerten geaagt worden ist. Denn entwerfen wir Adaptierungskurven, die als Ordinaten die zunehmende Empfind. lichkeit selbst haben, so ergeben sich naturgemäß wieder prinzipiell die gleichen Unterschiede, wie wir sie oben besprochen haben. Hier ist es noch viel einleuchtender, daß wir mit Hilfe der Empfindlichkeitskurven allein nur ein verzerrtes Bild der wirklichen Vorgänge erhalten. Denn wenn bei zunehmender Dunkeladaptierung die Schwellenwerte der Intensität immer kleiner und kleiner werden, so ergeben sich für die geringsten Intensitätsänderungen wieder ungeheler große Variationen der Empfindlichkeit. Die Folge davon ist ein enorm steiler Anstieg bei den Kurven für diejenigen Wellenlängen, für die eine hohe Empfindlichkeit besteht, und ein auffallend flacher Verlauf der Kurven im entgegengesetzten Falle.

Auf $A b b .9 a$ und $b$ finden wir solche Adaptierungskurven, aus denen man ohne weiteres ablesen kann, wie groß die Empfindlichkeit für Licht von 7 verschiedenen Wellenlängen nach einer beliebig langen Dunkeladaptierung geworden ist. - Beim Vergleich der Kurven auf Abb. 9 mit denen auf Abb. 8 gilt natürlich wieder ganz das entsprechende, was wir oben gesagt haben. Auch hier ermöglicht erst die gemeinsame vergleichende Betrachtung beider Kurvensysteme ein ausreichendes Verständnis des so verwickelten Vorgangs der Empfindlichkeitszunahme.

In einer sehr lesenswerten Arbeit hat Best (1910) eine klare Kritik der früher üblichen Darstellungsmethoden der Adaptierung gegeben und kommt dabei zu dem Schluß, daß die graphische Darstellung der Empfindlichkeitswerte selbst, wie sie z. B. Pi per (1903) veröffentlicht hat, ein falsches Bild von der ,Variation der Empfindlichkeit" gibt. Sie sei durch die Form der Kurve im Anfang zu gering, zum Schlusse übermäßig zum Ausdruck gebracht. Best schlägt daher vor, nicht die Empfindlichkeit selbst, sondern die jeweils im Laufe der Zeit aufgetretene Empfindlichkeitssteigerung darzustellen und rechnet die Pipersche Kurve entsprechend um. Einen ganz ähnlichen Gedanken findet man auch in Hel mholtz' Handbuch der Physiologischen Optik (1911, Bd. II, S. 270), wo bei der Darstellung der Adaptierung des Menschen in Abb. 60 die Empfindlichkeitswerte selbst, in Abb. 61 die Logarithmen dieser Werte als Ordinaten verwendet sind. Damit ist 
natïrlich auch, genau so wie es Best vorschlug, der relative Empfindlichkeitszuwachs zur Darstellung gebracht.

Wenn auch die Darlegungen von Best durchaus zutreffend sind, so kann ich mich doch seinen praktischen Folgerungen nicht anschließen. Ich kann keinen Vorteil in der Darstellung des relativen Empfindlichkeitszuwachses (d. h. des Logarithmus der Empfindlichkeit) sehen, vielmehr finde ich, daß die tatsächlich vorhandenen Verhältnisse dadurch eher verschleiert als geklärt werden. Denn eine bestimmte Energiemenge der Strahlung (die Schwellenwerte selbst) kann man sich ohne weiteres vorstellen, schwerer schon deren reziproke Werte (also die Empfindlichkeitswerte) - der Logarithmus dieser reziproken Werte ist aber schließlich ein so komplizierter Begriff, daß ich in seiner Einführung als Ordinate keinen Fortschritt erblicken kann. Die graphische Darstellung ist aber meines Erachtens nicht dazu da, dem weniger Erfahrenen einen vagen bild mäBigen Begriff von einem bestimmten Vorgang z u geben, sondern soll vor allem das experimentell gewonnene Zahlen material interpolieren und dadurch unser Verständnis ergänzen. Zum Ver. ständnis einer Kurve gehört aber eine klare Vorstellung von der Bedeutung jedes einzelnen Kurvenpunktes. Es ist daher wünschenswert, möglichst einfache Begriffe als Abszisse und Ordinate einzuführen. Wir haben oben nachgewiesen, daß wir sowohl den Begriff des Schwellenwertes, wie den Begriff der Empfindlichkeit für unsere Untersuchung unbedingt brauchen, haben aber auch gezeigt, daß man mit diesen beiden Begriffen vollkommen auskommen kann. Die Einführung neuer, noch komplizierterer Begriffe ist daher überflüssig.

\section{Kritik der Versuchsergebnisse.}

Vergleich der Lichtempfindlichkeit von Mensch und Huhn im Zustand der Helladaptation.

Wir beginnen mit dem Vergleich der Empfindlichkeit des helladaptierten Menschen und gleichfalls helladaptierter junger Hühner für Licht von verschiedener Wellenlänge (Tab. V und VII, Abb. 4 und 5). Es zeigt sich zunächst die schon von Hess und von A belsdorff $(1900,1907)$ entdeckte größere Empfindlichkeit des Menschen für kurzwelliges Licht. Wir finden, daß die Überlegenheit etwa bei Licht von $582 \mu \mu$ Wellenlänge beginnt. Hier ist sie zunächst unerheblich, aber für grünes Licht von $540 \mu \mu$ Wellenlänge ist der Mensch schon fünfmal empfindlicher, für blaugrünes ticht von $500 \mu \mu$ Wellenlänge fast sechsmal empfindlicher als das junge Huhn. Im Vergleich zu ausgewachsenen Tieren ist die Empfindlickeit des Menschen noch größer, nämlich etwa siebenmal so groß für Licht von $540 \mu \mu$ Wellenlänge. Für blaue und violette Strahlungen ist der Unterschied sicher noch beträchtlicher. Ihrer geringen Energie wegen konnte jedoch ihre Reizwirkung hier leider nicht mehr mit untersucht werden. - Bei den eben genannten Werten ist zu berücksichtigen, daß wir die Empfindlichkeit des Menschen und des Huhns nicht ganz gleich beurteilen dürfen. Die Versuche erfolgten, wie oben beschrieben, zwar unter möglichst gleichen äußeren Bedingungen - eine halbe Minute Dunkeladaptation - aber die halbe Minute, die Mensch und Huhn im Dunkeln zubrachten, bis die Körner 
erkannt wurden, verschaffte dem Menschen schon eine gewisse Empfindlichkeitszunahme. Für das Huhn dagegen, das - wie unten gezeigt werden wird - ungleich langsamer adaptiert, ist die Empfindlichkeit nach einer halben Minute Dunkeladaptierung kaum merklich größer als im Zustand der Helladaptation. Wenn wir diesen Unterschied in Betracht ziehen, so wird die Ửberlegenheit des helladaptierten Menschen zwar etwas geringer, bleibt aber natürlich bestehen.

Unsere Messungen zeigen aber noch eine zweite, bisher noch nicht entdeckte Tatsache, nämlich die Überlegenheit der Hühner bei der Wahrnehmung langwelliger Strahlungen (orangegelb und rot). Für diese Strahlungen ist das helladaptierte Huhn viel empfindlicher als der helladaptierte Mensch, nämlich schon doppelt so empfindlich für Licht von $620 \mu \mu$, dreimal empfindlicher für Licht von $640 \mu \mu$ und viermal empfindlicher für Licht von $660 \mu \mu$ Wellenlänge. Ziehen wir hier wieder die halbe Minute Dunkeladaptierung in Betracht, während der (allerdings in geringerem Grade als bei kurzwelligen Strahlen) die menschliche Empfindlichkeit schon schneller zugenommen hat, als die des Huhns, so werden die Unterschiede zwischen Huhn und Mensch noch etwas größer. Mit anderen Worten können wir sagen: unter den Bedingungen des Tagessehens sehen Hühner das, was wir rote Farben nennen, bedeutend heller als wir.

Es ist auffallend, daß diese Tatsache, von der sich jeder leicht überzeugen kann, bei den so zahlreichen optisehen Versuchen mit Hühnern bisher noch nicht gefunden worden ist. Wenn wir uns aber die Versuchsanordnung in den früheren Arbeiten ansehen, so ergibt sich, daß sie mit ihrer Hilfe gar nicht gefunden werden konnte, da man offenbar an die Möglichkeit einer größeren Empfindlichkeit des Tieres für bestimmte Strahlungen kaum gedacht und sie deshalb auch nicht experimentell nachgeprüft hat. Merkwürdig erscheint es zunächst, daß Hess auch bei seinen pupilloskopischen Messungen die Überempfindlichkeit der Hühner für langwellige Strahlungen nicht gefunden hat, denn er schreibt noch 1915 (S. 387): „Bei Tagvögeln sind die pupillomotorischen Reizwerte für Rot jenen beim normalen Menschen ähnlich oder gleich..." Aber das erklärt sich sofort, wenn wir hören, was Hess schon 1913 über die Untersuchung des Pupillenspiels sagte (S. 572): „Bei meinen photographischen Beobachtungen mußte ich mich auf dunkeladaptierte Tiere beschränken, da die Helladaptation das Pupillenspiel der von mir untersuchten Arten störend beeinflußte: Tagvögel wie Nachtvögel, die einige Stunden in einem genügend hellen Raum oder etwa im Freien gesessen hatten, zeigen, ins Dunkle gebracht, selbst in ziemlich lichtstarken Spektren zunächst keine Spur von Pupillenverengerung, die Pupille ist für solche Lichter weit und starr, die mit dem Lidschlag synergische Pupillenreaktion aber sehr deutlich vorhanden."

Es handelte sich also bei den früheren Hessschen Versuchen offenbar gar nicht um helladaptierte Tiere und Menschen, und wir werden weiter unten sehen, daß die Überlegenheit der Hühner bei gemeinsamer Dunkeladaptierung sich bald ins Gegenteil umkehrt. Denn für Licht von $620 \mu u$. Wellenlänge sind zwar Hühner mehr als doppelt so empfindlich wie Menschen, wenn beide helladaptiert sind; nach 5 Minuten gemeinsamer Dunkeladaptierung ist die Empfindlichkeit des Menschen aber schon gleich der des Huhnes und wird bei noch längerem Dunkelaufenthalt sogar größer als jene, 
In seiner letzten Arbeit über den Farbensinn der Vögel (1917) hat Hess seine Angaben in diesem Punkt etwas geändert. Er schreibt diesmal (S. 395): „,Die roten und gelben Lichter haben für die Tagvogelpupille ähnlichen (bzw. nur um ein geringes größeren) motorischen Wert als für die in gleichem Adaptationszustand befindliche Menschenpupille." Hier finden wir also zum erstenmal eine Andeutung davon, daß rote (und gelbe) Strahlungen für das Tier größeren Reizwert haben als für den Menschen.

Leider erfahren wir aber von Hess nichts über den Adaptationszustand, in welchem dieses Resultat erhalten wurde. Wir hören zwar, daß der Adaptationszustand von Menschen- und Vogelauge gleich war, was offenbar bedeutet, daß sich beide eine gleich lange Zeit hindurch dunkeladaptiert hatten - aber wie lange diese Zeit gedauert hat, ist leider nicht zu ersehen; und gerade das ist nach dem oben Gesagten von größtem Interesse. Es ist möglich, daß es sich um 15 Minuten Dunkelaufenthalt gehandelt hat, es können aber auch nur 3-4 Minuten gewesen sein, und in diesem letzten Falle würde das Hesssche Resultat mit den Ergebnissen unserer Messungen gut übereinstimmen.

Um sich von der Überlegenheit der Lichtempfindlichkeit der Hühner für rote Strahlungen zu überzeugen, braucht man gar keine komplizierte Apparatur. Man entwirft einfach ein genügend breites und reines objektives Spektrum und blendet aus diesem einen schmalen Streifen roten Lichtes heraus. Beleuchtet man nun - selbstverständlich unter peinlicher Vermeidung alles falschen Lichtes - mit diesem roten Lichtstreifen ein Lochbrett mit Reis und verringert jetzt schnell die Intensität der Lichtquelle, so wird bald ein Zustand erreicht, bei dem der helladaptierte Mensch nichts mehr sieht, das Huhn aber noch ohne Schwierigkeit den beleuchteten Körnerstreifen auspickt. Ich habe diesen Versuch, dessen Ergebnis einen überzeugenden Beweis unserer Behauptung darstellt, häufig vorgeführt und empfehle ihn seiner Einfachheit halber als Vorlesungsdemonstration.

Die Tatsache, daß Hühner im Zustand der Helladaptation rotes Licht bedeutend heller sehen als wir, macht die Nachprüfung der Versuche nötig, durch die Hess beweisen wollte, daß Hühner rote Strablungen ihrer Farbe wegen von anderen Strahlungen unterscheiden können. Hess wandte sich damals (1911) mit berechtigter Schärfe gegen die Versuche von Katz und Révész (1908), die mit Hilfe einer an sich sehr geistvollen Methode den Farbensinn der Hühner beweisen wollten. Sie dressierten nämlich Hühner auf das Nichtfressen von Reiskörnern, die in einer bestimmten Sättigungsstufe gefärbt waren, indem sie gerade diese Körner festklebten, alle anderen aber lose aufstreuten. Die Hühner lernten nun bald, daß sie Körner gerade von dieser bestimmten Sättigung der Farbe nicht aufpicken konnten und ließen sie nun auch dann liegen, wenn sie lose aufgestreut waren.

Hess bemerkte dagegen (1911, S. 445) mit vollem Recht, daß bei dem hier festgestellten Unterscheidungsvermögen die Körner gar nicht ihrer Farbe, sondern ihrer Helligkeit nach unterschieden wurden, und daß infolgedessen von einer Prüfung des Farbensinnes gar nicht die Rede sein kann.

Um nun zum gewünschten Ziele zu gelangen, verfuhr Hess folgendermaßen. Er färbte (nach dem Prinzip der Seebeck-Holmgrenschen Wollprobe) größere Mengen von Reiskörnern mit verschiedenen Pigmenten so, daß ihm ,insbesondere gelblichrote, angenähert rein rote und bläulichrote, sowie gelblichgrüne, angenähert 
rein grüne und bläulichgrüne Körner teils in mehr oder weniger stark mit weiß, grau oder schwarz verhüllten Farben, ferner gelblichgraue, rein graue und bläulichgrave Körner reichlich zur Verfügung standen."

Hess klebte nun die leicht gelblichroten Körner fest, so daB nur die anderen Körner gefressen werden konnten, was das untersuchte Huhn bald lernte. Es pickte also nur die grauen und grünen Körner auf. Wurden später alle Körnersorten, also auch die roten, lose aufgestreut, so wurden diese auch jetzt nicht gefressen, woraus hervorgeht, daß das Huhn sie von den andersfarbigen unterscheiden konnte, was einem sogenannten rotgrünblinden Menschen nicht gelang.

"Nur für ein Auge mit den Sehqualitäten eines normalen Menschenauges", schließt Hess (1911, S. 446) seine Ausführungen, ,haben die verschieden roten Körner das gemeinsame Merkmal der vorwiegenden Rötlichkeit. Meine Versuche schließen die Möglichkeit einer Rotgrünblindheit bei den untersuchten Hühnern aus" u. s.f.

Demgegenüber ist jetzt zu betonen, daß der Hesssche Beweis nur gültig wäre, wenn die Hühner rote Strahlungen ebenso hell sähen, wie der Mensch. Da sie den Hühnern aber beim Tagessehen viel heller erscheinen als dem Menschen, so besteht die Möglichkeit, daß auch hier wieder nicht die Farbe, sondern die für Hühner größere Hellig keit ausschlaggebend war, wenn die roten, gelbroten und bläulichroten Körner von den anderen Körnern unterechieden wurden. Wir müssen also den Einwand, den Hess mit Recht gegen Katz'und $\mathbf{R}$ évész geltend machte, jetzt gegen ihn selbst erheben.

Auch in seiner zusammenfassenden Arbeit über den Farbensinn der Vögel (1917) hat Hess wieder erklärt, daß die gelbroten, bläulichroten und rein roten Körner, d. h. die vorwiegend roten Körner für das Huhn das ,gemeinsame Merkmal der vorwiegenden Rötlichkeit" haben müßten. - Das gemeinsame Merkmal kann aber, wie nochmals betont werden muß, für das Huhn in der vorwiegenden Helligkeit bestanden haben.

Um kein Mißverständnis aufkommen zu lassen, will ich gleich von vornhercin bemerken, daß ich nicht etwa der Meinung bin, die Hühner wären tatsächlich Rotgrünverwechsler. Dagegen muß festgestellt werden, daß das Gegenteil experimentell noch nicht erwiesen ist, donn die Methodo von Hess hat nach dem eben Gesagten nunmehr ihre Beweiskraft verloren.

Das gleiche gilt natürlich auch von den entsprechenden Versuchen, die Hoss mit spektralen Lichtern angestellt hat.

Soll der Versuch beweisend sein, so muß er folgendermaßen angestellt werden: man ermittelt zunächst eine ,rote" und eine ,grüne" Strahlung, die dem Huhn gleich hell erscheinen. Mit diesen beiden Strahlungen beleuchtet man nun weiße Körner. Kann das Tier nunmehr (nach vorheriger Dressur auf Körner von einer bestimmten ,Farbe ") die beiden Strahlungen voneinander unterscheiden, so ist in der Tat bewiesen, daß jetzt nicht die Helligkeit, sondern die Farbe dabei ausschlaggebend gewesen ist. Will man den entsprechenden Versuch bei Tageslicht mit buntgefärbten Körnern ausführen, so muß verlangt werden, daß das Huhn die roten Körner nicht nur von solchen grünen und grauen unterscheidet, die dem normalen farbentüchtigen Menschenauge ungefähr gleich hell erscheinen, sondern es muB auch hier berücksichtigt werden, daß das helladaptierte Huhn die kurzwelligen violetten, blauen und grünen Strahlungen zwar dunkler, die langwelligen gelbroten und roten aber heller sieht als der Mensch. -

Um ein Bild vom Empfindlichkeitsunterschied zwischen Mensch und Tagrogel zu geben, gebraucht Hess wiederholt den anschaulichen Vergleich, Hühner sähen die Welt der Farben so wie ein normaler Mensch, 
der sich ein rötlich-gelbes Glas vors Auge hält. Der Vergleich ist vollkommen richtig, soweit es sich um die Unterschiede der Empfindlichkeit für blaue und grüne Lichter handelt, die dem Menschen durch ein rötlichgelbes Glas gesehen dunkler und ungesättigter vorkommen als sonst. Aber der Vergleich ist insofern doch unvollkommen, da er die Überlegenheit des Vogelauges für langwellige Strahlen nicht zum Ausdruck bringt. Denn die rotgelbe Brille läßt im besten Falle diese Stralungen ungeschwächt passieren, so daß sie höchstens ebenso hell, aber niemals heller erscheinen können, als sie das unbewaffnete menschliche Auge sieht.

Die Frage, worauf die überlegene Empfindlichkeit der Hühner für langwelliges Licht beruht, ist vorläufig noch nicht mit Sicherheit zu beantworten. Es bestehen drei Möglichkeiten: entweder ist das helladaptierte Sehorgan der Hühner an und für sich empfindlicher für alle Strahlungen, aber die roten und gelben Ölkugeln der Netzhaut absorbieren so viel kurzwelliges Licht, daß dieses den Hühnern nicht nur nicht heller, sondern sogar dunkler erscheint als dem Menschen, so daß sich die Überlegenheit nur noch bei langwelligen Lichtern zeigt, die von den Ölkugeln wenig oder gar nicht absorbiert werden. Ob diese hypothe. tische Überlegenheit nun darauf beruht, daß jedes einzelne Netzhaut. element bei Hühnern empfindlicher ist als bei Menschen, oder ob die relativ größere Anzahl der Zapfen in der Vogelretina dabei eine Rolle spielt, läßt sich gleichfalls vorläufig nicht entscheiden. -

Zweitens besteht die Möglichkeit, daß die Netzhaut der helladaptierten Hühner in ihrer Gesamtheit zwar nicht lichtempfindlicher ist als die des helladaptierten Menschen, aber durch gewisse Einrichtungen gerade für die langwelligen Strahlungen erst em pfindlicher ge macht wird.

In ihrer Eigenschaft als Lichtfilter können die Ölkugeln diese Empfindlichkeitssteigerung natürlich nicht bewirken, aber die Ölkugeln sind noch mehr als Lichtfilter: sie wirken nämlich auch als Sammellinsen, die den schmalen Zapfenaußengliedern eine vergrößerte Licht. menge zuführen. Den Nachweis dieser überaus wichtigen Tatsache verdanken wir Hess, der sich (1917, S. 401) folgendermaßen darüber ausapricht: „Dieses Bedürfnis" (nämlich das Bedürfnis nach Kompensation des Verlustes an kurzwelligen Lichtern) ,,muß sich um so mehr geltend machen, als die Zapfenaußenglieder bei den Tagvögeln außerordentlich dünn sind - ihr Durchmesser ist beträchtlich kleiner als jener der fovealen Zapfenaußenglieder des Menschen — so daß ohne besondere optische Hilfsmittel zu jedem einzelnen Außengliede nur eine verhältnismäßig sehr kleine Lichtmenge gelangen kann. Die ihnen vorgelagerten stark lichtbrechenden Ölkugeln haben nun einen beträchtlich größeren Durchmesser als die Zapfenaußenglieder: sie sammeln nach Art einer 
Kugellinse das Licht so, daß annähernd die ganze auf sie auffallende Lichtmenge zu dem zugehörigen feinen Außengliede gelangen kann, das also auf diese Weise viel mehr Licht erhält, als ohne die Kugellinse möglich wäre." - Es ist ohne weiteres klar, daß die Empfindlichkeitsüberlegenheit für langwellige Strahlen wenigstens zum Teil auf diesen von Hess angegebenen dioptrischen Verhältnissen beruhen kann. Denn bekanntlich enthält zwar durchaus nicht jeder Zapfen eine rote oder gelbe Ölkugel; ist aber eine solche vorhanden, so wird von den von ihr hauptsächlich durchgelassenen langwelligen Strahlen nunmehr auch eine ganz besonders große Menge ins Zapfenaußenglied geleitet.

Das ist eine zweite Hypothese, durch die wir die Úberlegenheit des helladaptierten Vogelauges für langwellige Strahlungen (im Vergleich zum helladaptierten Menschen) erklären können.

Drittens besteht die Möglichkeit, daß die Annahmen sowohl der ersten wie der zweiten Hypothese zu Recht bestehen, daß also die helladaptierte Hühnernetzhaut für Strahlungen aller Wellenlängen etwas empfindlicher ist als die helladaptierte menschliche Retina, und daß sie a ußerdem noch für langwellige Strahlen dadurch empfindlicher wird, daß die ölkugeln gerade diese Strahlen besonders konzentriert in die Zapfenaußenglieder lenken.

An dieser Stelle sei kurz einer Arbeit von Henning (1920) gedacht, der von einem ganz neuen Gesichtspunkt aus die Funktion der roten Ölkugeln betrachtet. Er stellt nämlich die Behauptung auf, daß die Tagvögel und Schildkröten mit Hilfe der roten Ölkugeln besser als andere Tiere durch Dunst, trübe Medien, Nebel und Flüssigkeiten hindurchsehen können. Henning geht dabei von dem Gedanken aus, daß Iangwellige Strahlen am besten durch die neblige und dunstige Atmosphäre dringen. Das ist vollkommen richtig und übrigens eine längst bekannte Tatsache. Die weitere Beweisführung von Henning ist nicht gerade glücklich. Er schreibt nämlich (1920, S. 101): ,, Wir betrachten mit unbewaffnetem Auge eine Landschaft im Nebel, der unseren Blick etwa $300 \mathrm{~m}$ tief dringen läßt. Nun halten wir rotes oder rotgelbes Glas vor unser Auge und jetzt werden nicht lediglich alle Einzelheiten in der Nähe viel deutlicher, als vorher, sondern unser Blick geht etwa $2000 \mathrm{~m}$ weiter in die Tiefe. Das liegt nur daran, daß langwellige Strahlen den Nebel eher durchdringen." - Wie glücklich wäre jeder Seemann, wenn die Behauptung von Henning zutreffend wäre! Er brauchte nur, wenn ihn der Nebel überrascht, eine rote Brille aufzusetzen und sähe dann sofort ungefähr 7 mal weiter durch den Nebel, als mit unbewaffnetem Auge.

Eine einfache Überlegung wird uns aber zeigen, daß die Behauptung Hennings unmöglich richtig sein kann. Nach seiner eigenen Aussage gehen langwellige Strahlen besser durch Dunst und Nebel hindurch als kurzwellige. Infolgedessen gelangen an einem nebligen Tage schon an und für sich weniger kurzwellige Strahlen ins Auge, als an klaren Tagen. Setzen wir nun noch ein rotes oder rotgelbes Glas vor unser Auge, so gehen die langwelligen Strahlen bestenfalls ungeschwächt hindurch, während die kurzwelligen noch mehr vermindert werden. Henning scheint jedoch zu meinen, daß nach dem. Vorsetzen des roten Glases objektiv mehr rotes Licht vorhanden wäre, wovon natürlich nicht die Rede sein kann. 
Man könnte nun einwenden, daß die rote Brille insofern ein besseres Sehen durch Nebel usw. ermögliche, als sie die durch ihre chromatische Aberration störenden kurzwelligen Strahlungen ausschaltet. Ein ähnlicher Gedanke ist auch von Garte n (1908) ausgesprochen worden. Aber auch dieser Einwand läßt sich leicht widerlegen. Wäre nämlich wirklich die chromatische Aberration beim Sehen unter den genannten Bedingungen störend, so müßte sich diese Störung ja bei klarem Wetter - wo relativ und absolut mehr kurzwellige Lichter zum Auge gelangen - noch viel unangenehmer bemerkbar machen, als an trüben, nebligen Tagen. Mit anderen Worten: man müßto durch dunstige, neblige Luft besser und schärfer sehen als durch klare!

Die einfachsten physikalischen Ưberlegungen zeigen also dio völlige Unhaltbarkeit der Henningschen Hypothese. Es erübrigt sich daher, auf die Arbeit dieses Autors ausführlich einzugehen. -

Betrachten wir nun noch einmal die Werte der Lichtempfindlichkeit ron Mensch und Huhn, wie sie Tab. V-VII und Abb. 5 zeigen, nicht nur vom Gesichtspunkt des Vergleichs von Mensch und Tier, sondern in Hinsicht auf die absolute Größe der Werte, so ergeben sich noch einige bemerkenswerte Tatsachen. Wir müssen dabei berücksichtigen, daß unsere Kurven in ein ideales Spektrum eingezeichnet sind, in dem nicht nur die Abstände von Licht verschiedenerer Wellenlänge gleichmäBig sind, sondern in dem auch überall gleiche Energie herrscht. Ein solches Spektrum erleichtert aber besonders das Loskommen von einem hier nur störenden anthropozentrischen Standpunkt.

So sehen wir (Abb. 5), daß die Empfindlichkeitswerte helladaptierter Hühner für verschiedene Strahlungen viel gleichmäßiger im Spektrum verteilt sind als die des Menschen. Sie sind nach unseren Messungen für rotgelbes Licht von $620 \mu \mu$ Wellenlänge fast genau so groß wie für blaugrünes von $500 \mu \mu$ Wellenlänge. Die Empfindlichkeit für Licht von mittlerer Wellenlänge (orange, gelb, gelbgrün, grün) ist auch nur wenig, nämlich höchstens um die Hälfte größer als die für die beiden eben genannten Strahlen.

Ganz anders ist es beim helladaptierten Menschen: innerhalb eines gleich großen Spektralbezirks variiert hier die Empfindlichkeit um das 14 fache, denn für grüne und blaugrüne Strahlungen ist sie erheblich größer als für rote und gelbe. Dem Anschein nach ist also die Verteilung der Empfindlichkeitswerte der Hühner ,natürlicher", d. h. in diesem. Falle der Energieverteilung im Sonnenspektrum gleichmäßiger angepaßt.

Berücksichtigt man aber, daß die im Vergleich zum Menschen geringe Empfindlichkeit des Vogelauges für kurzwellige Strahlungen offenbar lediglich auf der rein physikalischen Filterwirkung der Ölkugeln beruht und in letzter Linie nicht von der Lichtempfindlichkeit der Netzhaut abhängt, so kommt man doch notgedrungen zu dem Schluß, daß die Empfindlichkeitsverhältnisse des Vogelauges als eine sekundäre Anpassung aufzufassen sind. -

Auf die Frage, wie und warum diese Anpassung zustande gekommen ist, lassen sich zur Zeit kaum begründete Vermutungen äußern. 
Die Grenzen des (für das helladaptierte Huhn sichtbaren) Spektrums.

Bei der Bestimmung der Grenzen der Sichtbarkeit des Spektrums für das helladaptierte Vogelauge war die geringe Energie der kurzwelligen Strahlungen natürlich sehr störend. Während das rote Ende des Spektrums praktisch genügend weit erforscht werden konnte, war dies für die violette Ende des Spektrums nicht möglich, da in unserer Versuchsanordnung die an und für sich schon wenig intensiven kurzwelligen Strahlungen infolge ihrer größeren Brechbarkeit bei der prismatischen Zerlegung noch über eine viel größere Fläche ausgebreitet wurden, als die langwelligen Strahlungen, wodurch ihre Intensität noch mehr verringert wurde.

Am roten Ende des Spektrums konnte die Lichtempfindlichkeit der. Hühner bis zur Wellenlänge $\lambda=700 \mu \mu$ gemessen werden. Aus der Form der Kurve auf Abb. 5 ergibt sich aber mit größter Wahrscheinlichkeit, daß die Hühner das rote Ende des Spektrums mindestens ebenso weit sehen wir farbentüchtige Menschen - wahrscheinlich sogar noch etwas weiter. Für die äußersten roten Strahlen, die dem Menschen eben noch sichtbar sind, hat Hel mholtz (1860, S. 231; 1911, II. Bd., S. 58) die Wellenlänge $\lambda=810 \mu \mu$ gefunden. Wir können also schließen, daß Hühner solche Strahlungen gleichfalls noch wahrnehmen, dürfen jedoch dabei nicht vergessen, daß der experimentelle Beweis für diese Annahme noch nicht erbracht worden ist. -

Wie steht es nun aber mit dem kurzwelligen Ende des Spektrums? Helladaptierte Tiere konnte ich nur mit Licht bis zur Wellenlänge $\lambda=500 \mu \mu$ untersuchen (ausgewachsene Hühner sogar nur bis zur Wellen]änge $\lambda=520 \mu \mu$ ), aber immerhin zeigt die Form unserer Kurven, da $\beta$ die absolute Sichtbarkeitsgrenze am kurzwelligen Ende des Spektrums für Hühner sicher noch nicht bei Licht von den eben genannten Wellenlängen, sondern weiter violettwärts liegt. Es ist möglich, daß helladaptierte Hühner das kurzwellige Ende des Spektrums bei genügend hoher Intensität der Strahlung ebenso weit sehen wie der normale helladaptierte Mensch - freilich viel dunkler als dieser -, es ist aber andererseits auch möglich, daß das kurzwellige Ende des für uns sichtbaren Spektrums für helladaptierte Hühner völlig unsichtbar ist - so unsichtbar, wie für uns etwa ultrarote Wärmestrahlen. Bewiesen ist aber eine solche absolute Verkürzung des Spektrums am kurzwelligen Ende für Hühner bisher noch nicht, sondern lediglich eine relative Verkürzung im Vergleich zum Menschen bei bestimmten geringen Graden der Intensität. (Umgekehrt besteht für die helladaptierten Hühner nach meinen Feststellungen eine relative Verlängerung am roten Ende des Spektrums). Unter diesen Umständen erscheint es aber irreführend und zum mindesten verfrüht, ohne weiteres von einer Verkürzung des Spektrums am kurzweiligen Ende für das 
Sehen der Tagvögel zu sprechen, denn Hess hat wiederholt (schon 1907) darauf hingewiesen, daß kurzwellige blaue Glaslichter von den Hühnern ohne weiteres gesehen werden, wenn man sie nur genügend ,,lichtstark "* macht. Diese Angabe gilt nach meiner Erfahrung auch für homogene spektrale Strahlungen.

Der Unterschied zuischen der Lichtempfindlichkeit junger und geschlechtsreifer Hähne.

Wie oben mitgeteilt wurde, ergab sich bei unseren Messungen ein Unterschied in der Lichtempfindlichkeit junger und ausgewachsener Hähne in dem Sinne, daß bald nach Eintritt der Geschlechtsreife zwar die Empfindlichkeit für langwellige Strahlungen sich kaum änderte, jedoch für kurzwellige erheblich abnahm. Von einer ,Alterserscheinung“ kann hier natürlich nicht die Rede sein. Häufige Kontrollmessungen an mehreren jungen und ausgewachsenen Hähnen bewiesen die Gesetzmäßigkeit dieser Empfindlichkeitsabnahme. Die Schwellenwerte für gelbe Strahlungen $(\lambda=580 \mu \mu)$ stiegen etwa um $1 / 4$, die für grüne Strahlungen $(\hat{\lambda}=540 \mu \mu)$ um mehr als die Hälfte der bisherigen Werte. Unter diesen Umständen war der Gedanke sehr naheliegend, daß auch hier wieder die Ölkugeln eine Rolle spielten. Am wahrscheinlichsten erschien mir, daß mit Eintritt der Geschlechtsreife die Anzahl der kurzwelliges Licht absorbierenden Ölkugeln vermehrt würde. Ich untersuchte deshalb die Netzhäute von etwa 50 Hähnen, um zu sehen, ob sich hier ein Unterschied in der Zahl oder Anordnung der Ölkugeln zwischen jungen und ausgewachsenen Tieren feststellen ließe. Die Bulbi wurden wenige Minuten nach dem Tode der Tiere enucleiert, sofort in warme physiologische Kochsalzlösung gebracht und innerhalb 1-2 Stunden nach dem Tode untersucht, da sich zeigte, daß es später mitunter zu Schrumpfungen der Retina kam. Nur völlig unverletzte Bulbi waren zur Untersuchung geeignet, da die geringste Verletzung, die Glaskörperausfluß zur Folge hatte, meist auch eine Ablösung und Faltung der Netzhaut verursachte. Die unverletzten Bulbi wurden durch vorsichtige Scherenschnitte äquatorial halbiert, worauf sich der Glaskörper meist im ganzen herausnehmen ließ. Nun wurde mit einem scharfen Locheisen ein kreisförmiges Stück Netzhaut von $3 \mathrm{~mm}$ Durchmesser ausgestanzt und mit Kochsalzlösung vorsichtig auf einem Objektträger gespült. Da es sich nun darum handelte, die Ölkugeln zu zählen, mußte jeder Druck auf die Netzhaut unbedingt vermieden werden, um den Abstand der Ölkugeln voneinander nicht zu vergrößern. Ich untersuchte sie daher mit einem Wasserimmersionssystem (ohne Deckglas) und führte die Zählung mit einem Okularnetz aus, da die Anwendung einer Zählkammer (nach Art der bei der Zählung von Blutkörperchen usw. üblichen) an der Undurchsichtigkeit der Retina scheiterte. 
Natürlich wurden bei jungen und alten Tieren möglichst gleich lokalisierte Netzhautstücke ausgestanzt, da die Zahl und Anordnung der Ölkugeln in verschiedenen Teilen der Netzhaut stark variiert, was schon Waelchi (1883) festgestellt hatte. Die ersten Zählungen ergaben nun in der Tat eine größere Anzahl von Ölkugeln bei den ausgewachsenen Tieren. Weitere Untersuchungen zeigten aber, daß diese Differenz nur zufällig und nicht konstant war. Dagegen fiel mir öfter auf, daß die Ölkugeln bei den ausgewachsenen Hähnen dunkler und anscheinend auch größer waren als bei jungen Tieren. Eine Bestimmung der Absorption der einzelnen Olkugeln erschien aussichtslos; daher hielt ich es für das zweckmäßigste, genaue Größenmessungen vorzunehmen, um festzustellen, ob der Durchmesser der Ölkugeln bei alten Tieren zunimmt. Da nun die Größe der: Ölkugeln aber auch in ein und derselben Netzhaut erheblich schwankt, mußte ein relativ großes Netzhautmaterial untersucht werden.

Mitten in diese Untersuchung fiel der Ausbruch des Krieges, der mir ihre Weiterführung unmöglich machte. -

So kann ich es nur als wahrscheinlich, nicht als sicher bezeichnen, daß das Größer- und damit auch Dunklerwerden der Ölkugeln die Empfindlichkeitsabnahme der ausgewachsenen Hähne bedingt, indem die Ölkugeln jetzt natürlich noch mehr kurzwellige Strahlen absorbieren als vorher. Mit dieser Annahme ist auch ohne weiteres erklärt, daß die Empfindlichkeit für langwellige rote Strahlungen bei helladaptierten jungen und alten Tieren gleich bleibt.

Ich betone nochmals, daß diese hier gegebene Erklärung nur eine Hypothese ist, die noch weiterer Untersuchung bedarf, während die Tatsache der Empfindlichkeitsänderung nach Eintritt der Geschlechtsreife-selbst feststeht.

Spätere Untersuchungen werden zu entscheiden haben, ob die Empfindlichkeitsabnahme nicht nur bei geschlechtsreifen Hähnen, sondern auch bei ausgewachsenen Hennen auftritt. Sollte die Empfindlichkeitsabnahme nur bei männlichen Tieren vorhanden sein, so erscheint es aussichtsvoll, die Netzhäute von gleich großen, ausgewachsenen Hähnen und Hennen miteinander zu vergleichen, da die vergleichende Untersuchung von verschieden großen Augäpfeln naturgemäß immer gewisse Schwierigkeiten bietet.

Die sorgfältigen histologisehen Untersuchungen von Erna Hahn (1916), die sich vor allem mit der Entstehung der Ölkugeln während der Embryonalzeit beschäftigen, haben keine Geschlechts- oder Altersunterschiede ergeben. Die Verfasserin hat aber offenbar nur die Netzhäute von Embryonen mit denen von jungen Hühnchen der ersten Lebensmonate verglichen, die sie dann als ,erwachsen " den Embryonen und den eben ausgekrochenen Küken gegenübergestellt. Wirklich ausgewachsene, geschlechtsreife Tiere sind anscheinend gar nicht von ihr untersucht worden. Jedenfalls wird es von Interesse sein, das hier behandelte Problem, das sich aus physiologischen Tatsachen ergeben hat, durch anatomische Untersuchungen weiter zu verfolgen. 


\section{Vergleich der Empfindlichkeit hell- und dunkeladaptierter Hïhner.}

Beim Vergleich der Empfindlichkeit hell- und dunkeladaptierter Hühner wollen wir uns nicht lange aufhalten, da es - wie wir zeigen werden - einen konstanten Zustand der Dunkeladaptation kaum gibt. Wir dürfen nicht vergessen, daß zwar im Zustand der Helladaptation (etwa bei Tageslicht) ziemlich konstante Lichtempfindlichkeitswerte vorhanden sind, daß diese Werte aber während der Dunkeladaptierung einer steten und für Licht verschiedenen Wellenlänge ungleichmäßigen Änderung unterworfen sind. Wir können nun zwar bestimmte Momente der Dunkeladaptierung herausgreifen und die Empfindlichkeit etwa nach 1, 2 oder mehr Stunden Dunkelaufenthalt messen. Wir erhalten jedoch auf diese Weise (die bisher allein übliche) nur unvollkommenen Aufschluß über das Wesen der Emapindlichkeitszunahme. Es ist so - um ein modernes Bild zu gebrauchen - als ob wir aus einem Filmstreifen nur den Anfang und das Ende herausschnitten und betrachteten. Wir können uns zwar aus diesen Stücken ein Bild von Anfang und Ende der dargestellten Handlung machen - es fehlt uns aber jeder Einblick in die Entwicklung der Handlung und wir wissen vor allem nicht, auf welche Weise sich das Ende aus dem Anfang ableiten läßt.

Genau so ist es beim Vorgang der Adaptierung. Auch hier können wir den endlich erreichten Zustand nur verstehen, wenn wir den wechselnden Vorgang der Adaptierung messend verfolgen, wie wir es im letzten Abschnitt tun werden. -

Hier wollen wir uns lediglich darauf beschränken, die Empfindlichkeitswerte zu betrachten, wie sie sich nach einer Dunkeladaptierung von 8 Stunden ergeben. Auf Abb. 6 und 7 sind nun sowohl die Empfindlichkeitswerte helladaptierter Hühner, als auch die Empfindlichkeitswerte 8 Stunden lang dunkeladaptierter Hühner dargestellt. Da die beiden Gruppen von Werten ganz erheblich differieren (bis um das 74 fache), so ist eine gemeinsame Darstellung in einem Koordinatennetz nur möglich, wenn man den Ordinatenmaßstab relativ klein wählt. Darauf beruht - wie immer wieder beťnt werden muß - die Flachheit der Schwellenwertskurven dunkeladaptierter Tiere auf Abb. 6 und die Flachheit der Empfindlichkeitskurven helladaptierter Tiere auf Abb. 7. Man muß dabei im Auge behalten, daß beide Tafeln von verschiedenen Gesichtspunkten aus dasselbe darstellen.

Das Auffallendste an den Werten dunkeladaptierter Tiere ist die enorme Zunahme der Empfindlichkeit für kurzwellige Strahlen. Diese Empfindlichkeitszunahme gestattete erfreulicherweise, die Messung diesmal bis tief ins Blau $(\lambda=450 \mu \mu)$ hinein auszudehnen. Ein weiteres Vordringen nach dem violetten Ende des Spektrums wäre ohne weiteres mit den dunkeladaptierten Tieren möglich gewesen, doch sah ich von solchen Messungen ab, da die physikalischen 
Konstanten der Strahlung nur bis zur Wellenlänge $\lambda=450 \mu \mu$ gemessen waren und ich nicht extrapolieren wollte. Immerhin zeigt Abb. 6 ohne weiteres schon den fundamentalen Unterschied zwischen „Hellnetzhaut" und „Dunkelnetzhaut" der Hühner. Wir sehen, daß die Empfindlichkeit für Licht von $660 \mu \mu$ Wellenlänge nach 8 Stunden Dunkelaufenthalt sich verdoppelt, für Licht von $640 \mu \mu$ Wellenlänge sich verdreifacht, für Licht von $620 \mu \mu$ Wellenlänge sich verfünffacht usw. Im einzelnen ergeben sich aus Tab. V und VIII folgende Werte der Empfindlichkeitszunahme:

$$
\begin{aligned}
& \text { Für Licht von der Wellenlänge } 680 \mu \mu \quad 1,5 \\
& 660,2 \\
& 640,3 \\
& 620,, \quad 5 \\
& 600,, \quad 11 \\
& 580 \quad, \quad 19 \\
& 560,31 \\
& 540, \quad 49 \\
& \text { (Maximum) } 520,, \quad 74 \\
& 500 \text { " } 68 \text { fache Empfindlichkeitszunahme } \\
& \text { nach } 8 \text { Std. Dunkelaufenthalt. }
\end{aligned}
$$

Diese Werte gelten für junge Hühnor. Für ausgewachsene sind sie etwas geringer, wie ein Vergleich der Tabellen VI und IX ergibt. Das Maximum liegt für beide bei Licht von der Wellenlänge $\lambda=520 \mu \mu$.

Betrachten wir jetzt noch einmal Abb. 6, um zu sehen, wie sich die Schwellenwerte junger und ausgewachsener Hühner zueinander verhalten, wenn beide dunkeladaptiert sind, so ergibt sich im Vergleich zu helladaptierten Tieren ein bemerkenswerter Unterschied. Es zeigt sich nämlich, daß die beiden Kurven der dunkeladaptierten Tiere einander sehr ähnlich sind; sie zeigen einigermaßen gleiche Form und vor allem haben beide ihr Maximum bei ein und derselben Wellenlänge, nämlich bei $520 \mu \mu$. Die Kurven der helladaptierten Tiere dagegen zeigen verschiedene Maxima der Empfindlichkeit, nämlich das junge Tier bei $550 \mu \mu$, das alte bei $580 \mu \mu$ Wellenlänge, wie Abb. 6 zeigt. Diese Tatsachen erklären sich ohne weiteres, wenn man annimmt, daß im helladaptierten Auge andere Reizempfänger vorhanden sind, als im dunkeladaptierten. Nach der vorhin von uns aufgestellten Hypothese zur Erklärung der Empfindlichkeitsabnahme nach der Geschlechtsreife müßten die qualitativen Unterschiede der EmpfindJichkeit zwischen jungen und alten Tieren aufhören, sobald der allein ölkugelbesitzende Zapfenapparat außer Funktion tritt. Wie wir jetzt sehen, ist das wirklich der Fall.

Der Komplex Stäbchen und Sehpurpur, der jetzt vorherrscht, ist natürlich frei von der Einwirkung der (bei jungen und alten Tieren verschieden stark) absorbierenden Ölkugeln, so daß im Zustand der 
Dunkeladaptation junge und alte Tiere keine qualitativ verschiedene Empfindlichkeit mehr zeigen.

Wenn wir also jetzt experimentell gefunden haben, daß sowohl für junge wie für alte Tiere - sobald sie dunkeladaptiert sind - Licht von gleicher Wellenlänge maximalen Reizwert besitzt, so dürfen wir dieses Ergebnis als einen neuen Beweis für die funktionelle Verschiedenheit von Zapfen und Stäbchen im Sinne der Duplizitätstheorie auffassen.

\section{Der Vorgang der Dunkeladaptierung.}

Die Analyse des Vorganges der Empfindlichkeitsänderung des Auges, den wir seit den Untersuchungen von A ubert $(1861,1865)$ Adaptation nennen, gehört mit zu den schwierigsten Problemen der physiologischen Optik. Einige theoretische Vorbemerkungen sind daher unerläßlich.

Schon in der Einleitung habe ich darauf hingewiesen, daß mit dem Begriff der Adaptation sowohl der Vorgang der Empfindlichkeitsänderung, als auch der jeweils bestehende Zustand der Empfindlichkeit bezeichnet wird. Um diese verschiedenen Begriffe auch sprachlich zu trennen, habe ich den alten Begriff ,Adaptation" nur auf den bestehenden Zustand der Empfindlichkeit angewandt, den Vorgang der Empfindlichkeitsänderung aber ,Adaptierung“ genannt.

Wenn wir jetzt weiter die beiden Richtungen der Adaptierung als Hell- und Dunkeladaptierung bezeichnen (was durchaus berechtigt ist, denn das Sehorgan paßt sich wirklich an Helligkeitsgrade an, nicht etwa an verschiedene Werte der Strahlungsenergie), so dürfen wir nicht vergessen, daß wir damit nicht 2 , sondern 4 funktionell grundverschiedene Vorgänge kennzeichnen. Wir müssen uns nämlich klar darüber sein, daß wir unter den Bedingungen des Tagessehens durchaus anders adaptieren als unter den Bedingungen des Dämmerungssehens. Daß überhaupt beim Tagessehen erhebliche Schwankungen der Adaptation vorkommen, ergibt sich aus folgenden Betrachtungen. Als Tagessehen im Gegensatz zum Dämmerungssehen bezeichnen wir, dem herrschenden Sprachgebrauch folgend, diejenige Art des Sehens, bei der Farben unter schiedən werden können. Nun unterssheiden wir aber Farben nicht nur bei strahlendem Sonnenschein, sondern auch bei trübem Wetter, ferner aber auch sowohl bei Beleuchtung mit einer hundertkerzigen Lampe, wie auch bei einfachem Kerzenlicht. Wir sehen also, daß die Bedingungen des ,Tagessehens" auch nicht ganz rein - bei ungeheuer verschiedenen Größen der objektiven Strahlungsintensität bestehen, woraus folgt, daß auch dabei sehr erhebliche Änderungen der Empfindlichkeit vorkommen müssen. Diese Änderungen vollziehen sich im allgemeinen so schnell, daß wir meist kaum etwas von ihnen merken. Wir müssen sie aber in Betracht ziehen, wenn wir Adaptierungskurven betrachten, die scheinbar lediglich die 
Adaptierung während des Dämmerungssehens darstellen. Es ist nach dem eben Gesagten nur natürlich, daß der Tagesapparat durch seine Adaptierungsfähigkeit unter bestimmten Umständen mit dem Dämmerungsapparat sich in Wettstreit befindet.

Die Dauer dieses Wettstreits hängt nun offenbar ceteris paribus von der Schnelligkeit ab, mit welcher der Dämmerungsapparat über den Tagesapparat siegt und ist daher von dem Zahlenverhältnis von Stäbchen und Zapfen in der Netzhaut abhängig. Darauf folgt weiter, daß beim Menschen die Überlegenheit der Stäbchen früher in der Peripherie als in zentralen Netzhautteilen auftreten muß und daß andererseits - wenn wir von lokalen Bedingungen der Netzhaut absehen beim stäbchenarmen Tagvogelauge die Überlegenheit der Stäbchen viel später auftreten wird als beim menschlichen Sehorgan unter gleichen Bedingungen.

Daß wir bei der Darstellung des Verlaufs der Adaptierung die bisher üblichen Methoden verlassen und aus theoretischen Gründen die Zunahme der Empfindlichkeit nicht für gemischtes Licht, sondern für verschiedene homogene Lichter bestimmt haben, wirde bereits mehrfach hervorgehoben. Es ist ja ohne weiteres klar, daß die Empfindlichkeitsänderung des Sehorgans nicht nur vom zeitlichen Ablauf der Adaptierung und der Intensität, sondern auch von der Brechbarkeit der verwandten Strahlung abhängt. Daraus ergibt sich die Notwendigkeit, die Empfindlichkeitszunahme für Lichter von verschiedener Qellenlänge gesondert zu untersuchen; eine Notwendigkeit, auf die ich (1916) zum ersten Male hingewiesen habe.

Damals habe ich in der Literatur vergebens nach Messungen gesucht, die dieser Forderung entsprachen ${ }^{1}$ ). Inzwischen sind (1918) zwei Arbeiten von Best erschienen, in denen diese Forderung gleichfalls erhoben wird. Best untersuchte nämlich den Gang der Dunkeladaptierung beim Menschen nicht mit gemischtem Licht, sondern einmal mit den Strahlen, die von sogenannter „Leuchtfarbe“ ausgingen (also vorzugsweise kurzwelligem Licht) und zum Vergleich mit langwelligem roten Licht, um festzustellen, worin die Adaptierungsstörung bei Hemeralopen besteht. „Unsere bisherigen Adaptometer", sagt Best (1918, I, S. 168), ,berücksichtigen nicht, daß die Anpassung im Bereiche verschiedener Wellenlängen ganz verschieden verläuft."

Leider hat Best nur diese beiden extrem lang- und kurzwelligen Strahlungen zur Untersuchung verwandt, deren Brechbarkeit noch dazu sich schwer in genauen Werten angeben läßt. Da $\beta$ es erwünscht wäre, nicht nur zwei, sondern mehr verschiedenwellige Strahlungen zu verwenden, hat Best selbst mit folgenden Worten ausgedrückt: „Eine noch genauere Trennung der Anpassungskurven je nach Wellenlängen muß allerdings eine Forderung der Zukunft bleiben". -- Soweit es sich um die Untersuchung von Hühnern handelt, hatte ich diese sehr berechtigte Forderung schon 4 Jahre vorher erfüllt.

1) Eine ältere Arbeit von Peschel (1880) ist für unsere Zweeke leider so gut wie wertlos, da weder die Dauer der Adaptierung, noch das Intensitätsverhältnis der farbigen Strahlungen gemessen wurde. 
Ein Nachteil der Methode von Best besteht darin, daB die Intensitäten der angewandten Strablungen keinen zahlenmäßigen Vergleich gestatten. So sind denn die beiden Kurven für lang- und kurzwellige Strahlungen an sich einwandfrei gemessen, können aber leider nicht miteinander verglichen werden oder mit anderen Worten: wir kennen die Form der beiden Kurven, wissen aber nicht, wie sie zueinander liegen, ob sie sich schneiden usw. Über diese letzten sehr wichtigen Fragen können wir eben nur Aufschluß erhalten, wenn wir die wirklichen energetischen Verhältnisse der Strahlung in Rechnung ziehen, wie es bei unseren Messungen geschehen ist.

Nach diesen Vorbemerkungen wenden wir uns jetzt zur Betrachtung unserer Adaptierungskurven. Auf $A b b .8 a$ and $b$ and $9 a$ und $b$ sehen wir zunächst einmal, wie wechselnd die Empfindlichkeit für Licht von verschiedener Wellenlänge im Laufe mehrerer Stunden Dunkelaufenthalt zunimmt. Die maximale Empfindlichkeit besteht immer für grünes Licht von $540 \mu \mu$ Wellenlänge. Das absolute Maximum liegt, wie die Abb. 6 und 7 zeigen, bei der Wellenlänge $\lambda=520 \mu \mu$. Diese Tatsache wurde erst nach Abschluß der Tierexperimente bei Berechnung der wahren Empfindlichkeitswerte festgestellt, als eine Messung der Adaptierung für Licht von dieser Wellenlänge nicht mehr möglich war. Die Kurve der Empfindlichkeit für diese Strahlung würde also - abgesehen von den ersten Minuten der Dunkeladaptierung - in Abb. 9 a und $\mathrm{b}$ immer über allen anderen Kurven liegen.

Betrachten wir jetzt zunächst $\mathrm{Abb} .8$ a allein, so sehen wir, daß die Schwellenwerte verschiedenwelligen Lichts während der Dunkeladaiptierung mit vollkommener Gesetzmäßigkeit absinken. Am schnellsten erreicht die Kurve für Licht von $540 \mu \mu$ Wellenlänge ihr Minimum, die für Licht von $560 \mu \mu$ Wellenlänge fällt flacher ab, noch flacher die für Licht von $580 \mu \mu$ und $620 \mu \mu$ Wellenlänge. Noch viel langsamer vollzieht sich das Absinken der Schwellenwerte für Licht von $660 \mu \mu$ Wellenlänge. (Das starke Absinken dieser Kurve in ihrem Beginn darf uns nicht zu der Annahme führen, daB hier etwa eine starke Empfindlichkeitszunahme bestände; vgl. die entsprechende Kurve auf Abb. 9 a).

Ein praktisches Minimum erreichen diese Kurven also nach sehr verschiedener Zeit. Die Schwellenwerte für grünes Licht erreichen es etwa nach einer Stunde Dunkelaufenthalt, die für gelblichgrünes nur wenig später, die für gelbes erst nach $3^{3} / 4$ Stunden Dunkelaufenthalt. Für rotgelbes Licht $(620 \mu \mu)$ und für rotes $(660 \mu \mu)$ ist auch nach 10 Stunden Dunkelaufenthalt kein ausgesprochenes Minimum feststellbar.

Ganz anders verhalten sich die Kurven der Schwellenwerte kurzwelliger Strahlungen. Sie sinken schnell ab, wie wir es auf $A b$ b. 8 b sehen. Der Anfangsteil der Kurve für Licht von $460 \mu \mu$ Wellenlänge konnte aus den wiederholt genannten Gründen nicht gemessen werden und ist daher nur angedeutet worden. 
Auf den Abb. $9 \mathrm{a}$ und $\mathrm{b}$ sind nun nicht die Schwellenwerte, sondern die Empfindlichkeitswerte eingetragen, die sich für verschiedenwelliges Licht während der Dunkeladaptierung ergaben. Auch hier finden wir wieder das verschieden rasche Ansteigen: für rotes Licht $(660 \mu \mu)$ nimmt die Empfindlichkeit ganz allmählich und sehr wenig zu, für rotgelbes Licht $(620 \mu \mu)$ etwas schneller und mehr - und so fort, bis wieder für grünes Licht von $540 \mu \mu$ Wellenlänge das schnellste und stärkste Ansteigen der Empfindlichkeit erreicht wird (Abb. 9a). Andererseits finden wir bei Betrachtung der Empfindlichkeitszunahme für kurzwelliges Licht (Abb.9 b), daß die Empfindlichkeit zunächst langsam zunimmt, nachher aber um so rascher ansteigt. Prinzipiell finden wir also auf Abb. 8 a und $9 \mathrm{a}$ sowie $8 \mathrm{~b}$ und $9 \mathrm{~b}$ die gleichen Verhältnisse. (Das unaufhörliche Steigen der Empfindlichkeitskurven auf Abb. 9 ist natürlich praktisch bedeutungslos, da den hohen Empfindlichkeitswerten nur minimale Intensitäten der Strahlungen entsprechen; vgl. Abb 8).

Wir haben also bisher experimentell folgende Gesetzmäßigkeiten gefunden:

I. Die Empfindlichkeit bleibt während der ganzen Dunkeladaptierung maximal für Licht von einer bestimmten Wellenlänge $\hat{\lambda}_{m}$.

II. Im ganzen zeitlichen Verlauf der Dunkeladaptierung ist die Empfindlichkeit $E$ für Licht von größerer Wellenlänge als $\lambda_{m}$, also für Licht von der Wellenlänge $\lambda_{(m+x)}$ zwar geringer als die Empfindlichkeit für $\lambda_{m}$, aber größer als die Empfindlichkeit für Licht von noch größerer Wellenlänge $\lambda_{(m+a x)}$, wobei $a$ größer als 1 ist.

Für Lichter, die noch stärker brechbar sind als das Licht von maximaler Reizwirkung, gelten folgende Sütze:

Die Empfindlichkeit $E \lambda_{(m-x)}$ ist auch kleiner als $E \lambda_{m}$, aber größer als $E \lambda_{(m-a x)}$, wie ein Blick auf die Abb. $8 \mathrm{~b}$ und $9 \mathrm{~b}$ zeigt.

Zusammenfassend können wir die hier vorliegende Gesetzmäßigkeit folgendermaßen ausdrüeken :

ferner

$$
E \lambda_{m}>E \lambda_{(m+x)}>E \lambda_{(m+a x)}
$$

$$
E \lambda_{m}>E \lambda_{(m-x)}>E \lambda_{(m-a x)} .
$$

Diese Formeln zeigen aber nưr die gesetzmäßigen Beziehungen in nerhalb der beiden Gruppen von Adaptierungskurven für kurz- und langwelliges Licht.

Betrachten wir jetzt aber alle Kurven zusammen vergleichend, so zeigen sich nicht mehr so einfache Beziehungen. Wir sehen, daß die Empfindlichkeit für blaugrünes Licht von $500 \mu \mu$ Wellenlänge, die zunächst geringer ist als die für rotgelbe, gelbe und gelbgrüne Strahlungen zwischen der 15. und 25. Minute der Dunkeladaptierung größer als diese wird. Und wịr sehen ferner, daß auch die Empfindlichkeit für noch kürzer- 
welliges blaues Licht von $460 \mu \mu$ Wellenlänge größer wird, als die Empfindlichkeit für rotgelbes und gelbes Licht, allerdings erst nach einem Dunkelaufenthalt von etwa 45 Minuten.

Wir können also ohne weiteres aus unseren Kurven das Helligkeitsverhältnis ablesen, das zu irgend einer beliebigen Zeit der Dunkeladaptierung zwischen zwei bestimmten Strahlungen von gleicher Energie besteht. Betrachten wir etwa den Gang der Empfindlichkeitszunahme für Licht von $500 \mu \mu$ (Blaugrün) und $580 \mu \mu$ Wellenlänge (gelb), so ergibt sich, da 3 in den ersten 20 Minuten der Dunkeladaptierung eine gelbe Strahlung heller, nachher aber dunkler erscheint, als eine blaugrüne von gleicher Intensität. Nun bleibt das Helligkeitsverhältnis eine Zeit lang annähernd konstant, um sich dann wieder umzukehren: jetzt wird die gelbe Strahlung wieder relativ heller als die blaugrüne, bleibt aber natürlich absolut dunkler als diese.

Unsere Kurvensysteme ermöglichen also aufs einfachste eine sofortige zahlenmäßige Analyse dessen, was man Purkinjesches Phänomen nennt. Darunter ist ja nach Purkinjes eigener Definition (1825, S. 109) nichts anderes zu verstehen, als das wechselnde Helligkeitsverhältnis zweier Farben bei wechselnder Intensität der Gesa mtbeleuchtung. Ändert sich das Helligkeitsverhältnis so, daß bei ab. nehmender Gesamtbeleuchtung die zunächst hellere Farbe schneller an Helligkeit abnimmt, als die ursprünglich dunklere, so können wir von einem relativen Purkinejschen Phänomen reden, denn die Empfindlichkeit für die ursprünglich dunklere Farbe wird jetzt relativ größer. Wird dagegen die ursprünglich dunklere Farbe sogar heller als die zuerst hellere, so können wir das als ein absolutes Purkinjesches Phänomen bezeichnen. Nennen wir das Phänomen „normal“", wenn (bei abnehmender Helligkeit) die kurzwellige Strahlung weniger an Helligkeit verliert als die langwellige und im entgegengesetzten Falle ,,umgekehrt" - natürlich immer unter der Voraussetzung gleicher objektiver Intensitätsabnahmen beider Strahlungen - so können wir sagen, daß bei Hühnern für die obengenannten Strahlungen (580 und $500 \mu \mu$ Wellenlänge) während der ersten halben Stunde der Dunkeladaptierung ein absolutes normales, in den nächsten 10 Stunden aber ein relatives umgekehrtes Purkinjesches Phämonen auftritt.

Eine Umkehrung des Purkinjeschen Phänomens bei langer Dauer des Dämmerungssehens hatte v. Kries $(1900,1901)$ auf Grund theoretischer Erwägungen als wahrscheinlich bezeichnet. Die durch Stegmann (1900) ausgeführte experimentelle Nachprüfung am Menschen ergab die Richtigkeit dieser Annahme, und die jetzt bei Hühnern gefundenen ganz entsprechenden Empfindlichkeitsänderungen im Laufe der Dunkeladaptierung können als ein weiterer Beweis für ihre Richtigkeit gelten. 
An dieser Stelle muß ich noch einmal darauf hinweisen, daß man vom Purkinjeschen Phänomen und vom umgekehrten Purkinjeschen Phänomen natürlich nur dann reden kann, wenn das objektive Intensitätsverhältnis der beiden Farben, deren Helligkeitsverhältnis sich ändert, immer gleich bleibt. Das Wesentliche des Purkinjeschen Phänomens ist ja gerade sein r ein s ubjektiver Charakter. Infolgedessen muß es als eine vollständige Verkennung des Problems bezeichnet werden, wenn Hen ning (1920, S. 113) folgendes schreibt : „Setzen wir uns eine den Ölkugeln äs Schildkrötenauges entsprechende orangefarbene Brille auf, welche alles schädliche Seitenlicht abschließt, so erleben wir das umgekehrte Purkinjesche Phänomen: die langwelligen Lichter hellen sich auf, die kurzwelligen werden dunkler". - Hier haben wir also einen einfachen phy sikalischen Vorgang vor uns, da die kurzwelligen Lichter objektiv geschwächt werden. Es ist natürlich sinnlos, diescn Vorgang als ,,umgekehrtes Purkinjesches Phänomen " zu bezeichnen. -

Unsere Kurven gestatten noch eine weitere Orientierung. Wir können aus ihnen ohne weiteres ablesen, nach welcher Zeit des Dunkelaufenthaltes Licht von einer bestimmten Intensität und Wellenlänge für das Huhn überhaupt sichtbar wird. So entnehmen wir den Kurven auf $\mathrm{Abb} .8 \mathrm{a}$ und $\mathrm{b}$ beispielsweise, daß Licht von 50 Intensitätseinheiten schon etwa nach 10 Minuten wahrgenommen wird, wenn es die Wellenlänge $540 \mu \mu$ hat, dagegen erst, nach 22 Minuten, wenn es die Wellenlänge $500 \mu \mu$ hat - Licht von gleicher Intensität und der Wellenlänge $580 \mu \mu$ erst nach 55 Minuten und Licht nach $620 \mu \mu$ Wellenlänge sogar erst nach 6 Stunden.

Ganz entsprechend können wir aus Abb. 9 a und b sofort ablesen, nach wie langem Dunkelaufenthalt die Empfindlichkeit für Licht einer bestimmten Wellenlänge gleich der Empfindlichkeit für Licht einer anderen Wellenlänge geworden ist. Auch hier ergeben sich zahllose Möglichkeiten von verschiedenen Empfindlichkeitsverhältnissen, aber alle diese verwickelten Beziehungen lassen sich mit Hilfe unserer graphischen Darstellung leicht entwirren.

Schließlich sind auf Abb. 8 und 9 noch zum Vergleich 2 Kurven eingetragen, welche die Empfindlichkeitszunahme des Menschen für rotgelbes Licht von $620 \mu \mu$ und für grünes Licht von $540 \mu \mu$ Wellenlänge während der Dunkeladaptierung zum Ausdruck bringen (besonders deutlich auf Abb. 8). Wir sehen, daß die beim Tagessehen vorhandene Empfindlichkeitsüberlegenheit der Hühner für rotgelbes Licht schon in den ersten 4 Minuten des Dunkelaufenthaltes verloren geht. Von der 4. Minute ab wird die menschliche Empfindlichkeit für dieselbe Strahlung sogar größer als die des Huhns. Wir finden hier also eine völlige Umkehrung des Helligkeitsverhältnisses, in dem Mensch und Tier ein und dieselbe Strahlung unter jedesmal gleichen äuBeren Bedingungen wahrnehmen eine Tatsache von fundamentaler Bedeutung, die uns manchen Widerspruch in den Angaben der vergleichenden physiologisch - optischen Literatur erklärt. 
Für den Menschen ist nur noch die Empfindlichkeitszunahme für Licht von $540 \mu \mu$ Wellenlänge gemessen worden. Hier ist die Empfindlichkeit des Menschen immer - wie man sieht - weit größer als die des Huhns. Im übrigen zeigen aber schon diese zwei Adaptierungskurven des Menschen für verschiedenwellige Lichter, die lediglich zur vorläufigen Orientierung und zum Vergleich mit den Empfindlichkeitsverhältnissen der Hühner angestellt sind, daß beim Menschen prinzipiell durchaus ähnliche Verhältnisse bestehen, wie beim Huhn. Auch hier vollzieht sich die Empfindlichkeitszunahme für Licht von verschiedener Wellenlänge in ganz verschiedener, aber gesetzmäßiger Weise.

\section{Zur Theorie der Dunkeladaptierung.}

Die Tatsache, daß die stäbchen- und sehpurpurarmen Tagvögel im Dunkeln eine starke Zunahme der Lichtempfindlichkeit zeigen, hatte Hess $(1907,1913)$ als einen Beweis gegen die Duplizitätstheorie angesehen. Meine Messungen bestätigen die Angaben von Hess insofern, als auch ich eine erhebliche Empfindlichkeitszunahme bei Hühnern festgestellt habe, die allerdings nicht so schnell erfolgt, wie beim Menschen, und die auch die hohen menschlichen Endwerte nie ganz erreicht. Aber gerade die qualitative Analsye des Vorganges der Empfindlichkeitszunahme, die hier zum erstenmal vorgenommen wurde, ergibt eine Reihe von Tatsachen, die sich meines Erachtens nur durch die Duplizitätstheorie erklären lassen. Die Annahme Pipers (1905, S. 176), daß die Stäbchen die alleinigen Träger der Adaptierungsfähigkeit wären, ist freilich heute nicht mehr haltbar, wie die Arbeiten von $\mathrm{Nagel}$ und Schäfer (1904), Hess (1907), Dittler und Koike (1912) zeigen. Aber ebenso unmöglich ist es, die Vorgänge bei der Adaptierung der Hühner allein aus der Funktion der Zapfen zu erklären.

Wenn wir davon ausgehen, da $\beta$ im Zustand der Helladaptation die Hühnerretina für langwelliges Licht (z. B. $\lambda=620 \mu, \mu$ ) empfindlicher ist als für kurzwelliges $(\lambda=500 \mu \mu)$ und wir diese Tatsache mit der selektiven Absorption der Ölkugeln erklären konnten, so ist ohne weiteres verständlich, wenn zunächst - etwa bis zur 16. Minute des Dunkelaufenthaltes - die Empfindlichkeit für beide Strahlungen in gleichem Maße ansteigt. Wir können diese Tatsache einfach durch die Zunahme der Zapfenempfindlichkeit erklären.

Wir können aber nicht mehr erklären, warum jetzt auf einmal die Empfindlichkeit für die kurzwelligen Lichter viel größer wird und die für langwellige Lichter weit überflügelt. Denn die absolute Intensität der Strahlungen wird immer geringer, und in keiner Weise ist $\mathrm{zu}$ verstehen, wie jetzt plötzlich die Zapfen für kurzwellige Lichter empfindlicher werden sollten als für langwellige, da doch geringere Mengen kurzwelligen Lichts von dem ölkugelfilter relativ noch stärker ab- 
sorbiert werden, als größere Mengen. Denkbar wäre ja nun, daß die Wirkung der Ölkugeln während der Dunkeladaptierung in irgend einer Weise ausgeschaltet würde, aber wir haben nicht den geringsten Anhaltspunkt dafür, daß ein solcher Vorgang wirklich stattfindet.

So bleibt denn vorläufig nur die Annahme übrig, daß sich im Laufe der Dunkeladaptierung auch bei Hühnern neue Reizempfänger einstellen. Von diesen müssen wir theoretisch - entsprechend den experimentell gefundenen Tatsachen - folgendes verlangen: sie müssen für mittelwelliges Licht maximal empfindlich sein, etwas weniger für kurzwelliges und fast gar nicht für langwelliges Licht.

Einen solchen Reizempfänger stellt aber, nach allem, was wir bisher wissen, der Komplex Stäbchen + Sehpurpur dar. Die Untersuchungen von Köttgen und Abelsdorff (1895), König (1903), Trendelenburg (1904) u. a. haben uns gezeigt, daß wir die Empfindlichkeit dieses Komplexes der von ihm absorbierten strahlenden Energie gleichsetzen dürfen, die natürlich wiederum von der Konzentration bzw. Schichtdicke des Sehpurpurs abhängt. Nach allen bisher ausgeführten Untersuchungen ist der Sehpurpur nun für langwellige Strahlungen so gut wie unempfindlich, sehr empfindlich für mittelwellige (grüne) Strahlen und etwas weniger für kurzwellige Lichter.

Nehmen wir nun an, daß bei Hühnern sich bald nach Beginn des Dunkelaufenthaltes der Sehpurpur zu bilden beginnt. In seiner zuerst dünnen Schicht werden sicher nur geringe Mengen Licht absorbiert und zwar natürlich am ehesten Licht von der Komplementärfarbe des Purpurs, nämlich grünes Licht. Die dadurch entstehende Empfindlichkeit der Stäbchen addiert sich zu der gleichfalls noch wachsenden Empfindlichkeit der Zapfen und bewirkt so das ganz besonders rapide Ansteigen eben der Empfindlichkeit für grüne Strahlungen. Mit zunehmender Konzentration (bzw. Schichtdicke) werden jetzt nicht nur grüne, sondern auch blaugrüne und schließlich auch blaue Strahlungen vom Sehpurpur in steigendem Maße absorbiert. Da hier die hohe Anfangszapfenempfindlichkeit fehlt, so erreicht die Empfindlichkeit für diese Strahlungen erst später Werte, die denjenigen für langwellige Strahlungen gleichkommen.

Sinkt nun aber die Intensität der Strahlungen immer weiter (bis unter die Zapfenschwelle), so gewinnt die Empfindlichkeit für kurzwellige Strahlen sogar die Oberhand über die für langwellige, weil auch bei immer wachsender Konzentration des Sehpurpurs langwellige Strahlen bekanntlich nur sehr wenig, kurzwellige nunmehr aber stark absorbiert werden.

Es ist weiter leicht verständlich, daß bei noch weiterem Ansteigen der'Konzentration des Sehpurpurs nun doch auch langwellige Strahlen etwas mehr absorbiert werden, vor allew gelbe und in geringerem Maße 
und mit bedeutender Verspätung auch gelbrote Lichter - allerdings dann erst, wenn die Absorption mittel- und kurzwelligen Lichtes längst ihr praktisches Maximum erreicht hat.

Betrachten wir nun die absinkēnden Schwellenwerte auf Abb. 8 a und $b$, so finden wir hier in der Tat alles so, wie wir es nach der eben gegebenen theoretischen Auseinandersetzung zu erwarten haben. Ich stehe daher auch nicht an, die hier gegebene Analyse der Adaptierung bei Hühnern als einen neuen Beweis für die Richtigkeit der Duplizitätstheorie zu bezeichnen.

Aus den eben dargestellten Vorgängen können wir noch einen weiteren Schluß ziehen. Wir haben nämlich gesehen, daß auch bei Hühnern im späteren Verlauf der Dunkeladaptierung - etwa in der 2.-10. Stunde des Dunkelaufenthaltes - eine Änderung der Empfindlichkeit vorkommt, die wir als (relatives) umgekehrtes Purkinjesches Phänomen bezeichnet haben. Diese Vorgänge sind nur erklärlich, wenn wir die Stärke der Lichtempfindung der Konzentration des Sehpurpurs im Stäbchenaußengliede proportional setzen. Damit ist aber bewiesen, daß auch im stäbchen- und sehpurpurarmen Auge des Tagvogels der Ort der primären Erregung im Außenglied des Stäbchens gelegen ist.

Durch den Nachweis der Filterwirkung der Ölkugeln - also auf Grund vollkommen anderer Úberlegungen - hatte Hess (1907, II, S. 327) überzeugend bewiesen, daß für die Farbenwahrnehmung in den Augen der Tagvögel der Ort der primären Reizung gleichfalls im Außengliede des Zapfens gelegen ist.

Wir können jetztalso ganz allgemein sagen, daBals Empfänger für Lichtreize lediglich die Außenglieder des Neuro. epithels der Retina in Betracht kommen.

\section{Neue Aufgaben der Forschung.}

Am Ende unserer Untersuchung sei es gestattet, kurz auf die Ziele künftiger Forschungen auf dem Gebiet der vergleichenden physiologischen Optik hinzudeuten.

Wir haben uns hier lediglich mit der Untersuchung des Helligkeitssinnes der Hühner beschäftigt und damit eine feste Grundlage für die Erforschung des Farbensinnes geschaffen. Ob zwei Strahlungen ihrer Farbe nach unterschieden werden, kann eben nur festgestellt werden, wenn eine Unterscheidung ihrer Helligkeit nach ausgeschlossen ist. Wir müssen also vorher ermitteln, wie hell ein Tier die beiden in Betracht kommenden Strahlungen unter allen möglichen Adaptationsbedingungen sieht.

Dann erst kann man, wie schon oben gezeigt wurde, zwei verschiedenfarbige Lichter gleich hell machen und feststellen, ob auch jetzt noch 
für das Tier ein Unterschied besteht, der nunmehr allerdings qualitativer Natur sein muß.

Bei der Auswahl der beiden verschiedenfarbigen Lichter wird man sich aber nicht auf solche beschränken dürfen, die dem Menschen qualitativ verschieden erscheinen, sondern unter anderem wird nötig sein, auch festzustellen, ob nicht dem Tiere vielleicht zwei Lichter verschiedenfarbig erscheinen, die der Mensch in der gleichen Farbe sieht. Theoretisch ist das nämlich ohne weiteres möglich und experimentell wurde bisher in keiner Weise das Gegenteil bewiesen.

Die uns Menschen qualitativ verschieden erscheinenden Strahlungen eines kontinuierlichen Spektrums, die wir als rote, gelbe, grüne, blaue und violette qualitativ voneinander trennen, unterscheiden sich ja objektiv nur durch ihre Brechbarkeit bzw. Wellenlänge, also nur quantitativ. Es ist also von vornherein nicht im geringsten bewiesen, daß sich bei anderen Organismen dieselben qualitativen Unterschiede finden müssen, sondern eher das Gegenteil wahrscheinlich.

Theoretisch sind nun z. B. folgende Fälle möglich: Das Tier kann total farbenblind sein und es kann den gleichen Farbensinn wie ein normaler Mensch besitzen. Es kann aber auch weniger Farben unterscheiden, als dieser: es kann z. B. nur vier, drei oder zwei verschiedene Farben sehen. Nehmen wir etwa an, ein Tier könne nur drei verschiedene Farben $a, b$ und $c$ unterscheiden, so kann dem Tier sowohl unser Rot wie unser Gelb $a$-farbig erscheinen, das Grün $b$-farbig und Blau und Violett $c$-farbig. Ferner besteht die Möglichkeit, daß das Tier Rot und Grün beide $a$-farbig, Gelb und Blau $d$-farbig siehtoder Rot und Rotgelb $a$-farbig, Gelbgrün und Grün $b$-farbig usw. Es ergeben sich schon so sehr zahlreiche theoretische Möglichkeiten, deren experimentelle Erforschung nicht leicht sein wird.

Damit sind aber durchaus nicht alle Möglichkeiten erschöpft. Denn das Tier kann - wie eben angedeutet wurde, auch zwei Strahlungen verschiedenfarbig sehen, die dem normalen farbentüchtigen Menschen nicht verschieden, sondern gleichfarbig erscheinen.

Wie es einerseits möglich ist, daß Hühner Blau und Violett nicht mehr voneinander unterscheiden können - vielleicht nur deshalb, weil die beiden von uns so bezeichneten Lichter für Hühner relativ sehr dunkel sind - so besteht andererseits die Möglichkeit, daß Hühner zwei verschiedene Farben $a$ und $b$ voneinander unterscheiden können, die wir beide als ,,rot" bezeichnen.

Auch diese Möglichkeit wird nur schwer und natürlich nur mit Benutzung spektraler Lichter experimentell zu prüfen sein. Aber jedenfalls haben wir hier ein Problem von grundlegender Bedeutung vor uns, dessen Vorhandensein bei einer künftigen umfassenden Untersuchung des Farbenunterscheidungs vermögens der Tiere nicht vernachlässigt werden darf. - 
Der zweite Punkt, auf den ich noch hinweisen will, bezieht sich auf künftige Untersuchungen der Adaptierung, also des Vorgangs der Empfindlichkeitsänderung des Sehorgans.

Wir haben gesehen, daß diese Änderung nicht eine einfache Funktion der Zeit (bzw. der objektiven Intensität) ist, sondern auch in gesetzmäBiger Weise von der Wellenlänge der benutzten Strahlung abhängt. Künftige Untersuchungen werden deshalb gleichfalls die Änderung der Empfindlichkeit nicht nur für gemischets Licht, wie bisher üblich, sondern auch für verschiedene homogene Lichter festzustellen haben, wobei die Ermittlung der wahren objektiven Intensitätsverhältnisse dieser lichter unbedingt nötig sein wird.

Solche Messungen werden meines Erachtens eine Reihe von Problemen ihrer Iösung zuführen.

Einmal wird so entschieden werden können, ob die aus theoretischen Gründen so interessante Dunkeladaptierung der Schildkröten, deren Retina nach allen bisher vorliegenden Beobachtungen frei von Stäbchen und Sehpurpur ist, sich wirklich qualitativ nicht von der Adaptierungsweise solcher Tierarten unterscheidet, die sowohl Stäbchen wie Zapfen besitzen.

Es ist ja immerhin denkbar, daß bei Schildkröten der Komplex Stäbchen + Sehpurpur anatomisch zwar fehlt, funktionell aber doch in irgend einer Weise ersetzt ist.

Für wahrscheinlicher halte ich aber, daß bei Schildkröten eine reine Zapfenadaptierung vorkommt, und daß die Stäbchenadaptierung wirklich fehlt. In diesem Falle müßte die Empfindlichkeit für alle Farben während des Dunkelaufenthaltes in gleicher Weise ansteigen und sowohl das Purkinjesche Phänomen in der ersten Phase der Dunkeladaptierung, wie auch das relative umgekehrte Purkinjesche Phänomen in der zweiten Phase müßte ausbleiben. Dann entspräche der anatomischen Sonderstellung des Schildkrötenauges auch eine funktionelle Besonderheit.

Jedenfalls wird sich durch entsprechende Messungen der Adaptierung, wie wir sie an Hühnern vorgenommen haben, auch bei Schildkröten diese prinzipiell so wichtige Frage entscheiden lassen. -

Schließlich muß jetzt noch die Forderung erhoben werden, auch bei der Untersuchung der menschlichen Empfindlichkeitsänderung von der bisher üblichen Untersuchungsmethode abzugehen. Statt der früher benutzten Adaptometer mit gemischtem Licht werden wir künftig zur wissenschaftlichen Analyse der Adaptierung Spektraladaptometer anwenden müssen. Es ist hier nicht der Ort, den Entwurf zu einem derartigen Apparat näher zu beschreiben, aber soviel können wir jetzt schon sagen, daß eine genaue Intensitätsmessung der zu benutzenden spektralen Lichter unumgänglich nötig sein wird. 
Ich vermute, daß wir durch Untersuchungen mit einem solchen Apparat ähnliche Gesetzmäßigkeiten im Verlauf der Adaptierung beim Menschen finden werden, wie wir sie beim Huhn festgestellt haben. Weiterhin hoffe ich aber, daß wir auf dem hier eingeschlagenen Wege zu einem tieferen Einblick in die Gesetze des Farbensinnes sowie in das Wesen der verschiedenen Arten von Farbenblindheit gelangen werden.

\section{Zusammenfassung der Ergebnisse.}

1. Durch eine kombinierte Schwellenwerts- und Sehschärfemethode, nämlich das Aufpicken eben sichtbarer Körner, wurde die Lichtempfindlichkeit von Hühnern untersucht. Da die (der Empfindungsstärke äquivalente) Reaktion des Tieres immer gleich blieb, so war die Lichtempfindlichkeit stets gleich dem reziproken Wert der objektiven Intensität der Strahlung.

2. Die Anwendung eines Brettes mit Vertiefungen, aus denen die beleuchteten Körner herausgepickt werden mußten, gab eine Kontrolle dafür, daß die gemessene Intensität der Strahlung wirklich der Reizschwelle entsprach. Mit Hilfe dieser neuen Vorsichtsmaßregel ergaben sich sehr konstante Schwellenwerte.

3. Helladaptierte junge Hühner sehen rotes Licht viel heller als gleichfalls helladaptierte Menschen. Licht von $660 \mu \mu$ Wellenlänge sehen Hühner mindestens 4 mal heller als wir.

4. Während die von Hess gefundene relativ (im Vergleich zum Menschen) geringe Empfindlichkeit der Hühner für kurzwellige Strahlungen durch die Filterwirkung der Ölkugeln ohne weiteres erklärt wird, ist die hier gefundene relative Überempfindlichkeit der Hühner für langwellige Strablungen keinesfalls durch die Filterwirkung, möglicherweise aber zum Teil durch die dioptrische Wirksamkeit der ölkugeln zu erklären.

5. Bald nach Eintreten der Geschlechtsreife ändert sich bei Hühnern die Lichtempfindlichkeit. Die Empfindlichkeit für langwellige Strahlen bleibt zwar bestehen, aber die für kurzwellige Strahlen sinkt erheblich wahrscheinlich infolge stärkerer Absorption durch die roten ölkugeln.

6. Der Vorgang der Adaptierung wurde hier zum ersten Male so gemessen, daß die Empfindlichkeitszunahme nicht für gemischtes Licht, sondern für verschiedene homogene Strahlungen ermittelt wurde.

7. Die Empfindlichkeit für alle verschiedenwelligen Strahlungen steigt in den ersten 15 Minuten der Dunkeladaptierung annähernd gleichmäßig an, von da ab nimmt jedoch die Empfindlichkeit für kurzwellige Strahlungen eine Zeit lang so viel schneller zu, daß sie jetzt größer wird, als die für langwellige Strahlen (,,absolutes" Purkinje sches Phänomen). Diese Tatsache wird dadurch erklärt, daß nunmehr bei Hühnern also viel später als beim Menschen - ein neuer optischer Reizempfänger auftritt, nämlich der Komplex Stäbchen + Sehpurpur. 
8. Das späte Einsetzen des Stäbchenapparates, anatomisch durch die bei Hühnern geringe Anzahl der Stäbchen bedingt, ermöglicht es, die Empfindlichkeitszunahme der Zapfen gesondert von der Empfindlichkeitszunahme der Stäbchen zu untersuchen. Es ergaben sich dabei forgende empirische Gesetzmäßigkeiten:

I. Die Empfindlichkeit bleibt während der ganzen Dunkeladaptierung maximal für Licht von einer bestimmten Wellenlänge $\lambda_{m}$.

II. Die Empfindlichkeit $E$ für Licht von anderer Wellenlänge ist durch folgenden Satz bestimmt:

$$
E \lambda_{m}>E \lambda_{(m \pm x)}>E \lambda_{(m+a x)} .
$$

9. Bei gleichzeitiger Dunkeladaptierung von Mensch und Huhn verschiebt sich das Helligkeitsverhältnis ein- und derselben Strahlung bei Abnahme ihrer objektiven Intensität nicht nur relativ, sondern auch absolut. Für Licht von $620 \mu \mu$ Wellenlänge z. B. ist das helladaptierte Huhn empfindlicher als der gleichfalls helladaptierte Mensch. Dagegen ist das 40 Minuten dunkeladaptierte Huhn für Licht von derselben Wellenlänge weniger empfindlich als der eben so lange dunkeladaptierte Mensch. Diese Tatsache zeigt, daß bei vergleichenden Messungen zwischen Mensch und Tier der Adaptationszustand aufs genaueste berücksichtigt werden muß.

10. Durch den Nachweis eines (relativen) umgekehrten Purkinjeschen Phänomens bei Hühnern während der 2. bis 10. Stunde der Dunkeladaptierung wird bewiesen, daß der Ort der primären Reizung durch Licht im Außengliede des Stäbchens liegen muß.

Tabelle I. Energieverteilung im Normalspektrum eines Nernstbrenners (Modell $\mathrm{H}$ ), der mit 210 Volt Spannung brennt:

\begin{tabular}{|c|c|c|}
\hline & Wellenlänge: & Energie \\
\hline$\lambda=700$ & & $\mathrm{E}=276$ \\
\hline,$=680$ & , &,,$=248$ \\
\hline,$=660$ & , & $"=219$ \\
\hline,$=640$ & $"$ &,$=190$ \\
\hline,$=620$ & " &,$=162$ \\
\hline$\Rightarrow=600$ & , &,$=133$ \\
\hline,$=580$ & , & $"=108$ \\
\hline,$=560$ & ", r n &,$=88$ \\
\hline$\eta=540$ & :" &,$=69$ \\
\hline$s,=520$ & $"$ &,$=53$ \\
\hline$:=500$ & , &,$=41$ \\
\hline$\eta=480$ & ", &, $9=31$ \\
\hline,$=460$ & $"$ &,$=22$ \\
\hline,$y=450$ & , & $"=1$ \\
\hline
\end{tabular}

Tabelle II. Übersicht über die Dis. persion $D$ im benutzten prismatischen Spektrum. $D=15,0$ bei $\lambda=580 \mu \mu$ bedeutet $\mathrm{z}$. B., daß der Abstand der Strahlungen von $570 \mu \mu$ und $590 \mu \mu$ Wellenlänge in der "Ebene des scharfen Spaltbildes" $15,0 \mathrm{~mm}$ betrug.

$$
\begin{aligned}
& \lambda=700 \mu \mu \quad D=8,7 \\
& \text {, }=680,, \quad,=9,2 \\
& \text { "=660 }, \quad,=10,0 \\
& "=640 \quad, \quad,=11,4 \\
& \eta=620 \quad, \quad,=12,0 \\
& \text { " }=600 \quad, \quad,=13,5 \\
& "=580 \quad, \quad,=15,0 \\
& "=560, \quad, \quad,=16,8 \\
& \text {, }=540, \quad, \quad,=19,7 \\
& "=520, ", \quad,=22,3 \\
& ,=500 \quad, \quad,=26,9 \\
& ,=480 \quad, \quad, \quad,=34,1 \\
& ,=460,, \quad,=44,4 \\
& "=450, \% \quad,=48,6
\end{aligned}
$$


Tabelle III. Selektive Reflexion $R$ Tabelle IV. Logarithmen der Intender Reisoberfläche.

$$
\begin{aligned}
& \lambda=700 \mu \mu \quad R=90 \\
& , ;=680 \%, \quad,=96 \\
& ,=660, \quad, \quad,=101 \\
& "=640 \quad, \quad,=104 \\
& ,=620, \quad,=107 \\
& "=600, \quad,=111 \\
& ,=580,, \quad,=113 \\
& ,=560, \quad,=116 \\
& ,=540, \quad, \quad,=117 \\
& "=520, \quad, \quad,=112 \\
& \text { " }=500, \quad, \quad,=106 \\
& \text { "=480 }, \quad,=90 \\
& ,=460, \quad,=71 \\
& ,=450,, \quad,=60
\end{aligned}
$$

\begin{tabular}{|c|c|c|c|}
\hline Wellenlänge & Nicolgrad & Intensität & Empfindlichkeit · 1000 \\
\hline $700 \mu u$ & $90^{\circ}$ & 2800 & 0,4 \\
\hline 680, & $45^{\circ}$ & 1290 & 0,8 \\
\hline $660 "$ & $29^{\circ}$ & 520 & 1,9 \\
\hline 640, & $21^{\circ}$ & 223 & 4,5 \\
\hline $620 \%$ & $19^{\circ}$ & 153 & 6,5 \\
\hline 600, & $20^{\circ}$ & 128 & 7,8 \\
\hline 580, & $22^{\circ}$ & 114 & 8,8 \\
\hline $560 \quad$, & $25^{\circ}$ & 108 & 9,3 \\
\hline 540, & $31^{\circ}$ & 108 & 9,2 \\
\hline 520, & $42^{\circ}$ & 119 & 8,4 \\
\hline 500, & $80^{\circ}$ & 157 & 6,4 \\
\hline
\end{tabular}
sität der „Endstrahlung“. (Kombination der Werte aus Tabelle I-III;

$$
\begin{aligned}
& \left.I=\frac{E \cdot R}{D}\right) \text {. } \\
& \lambda=700 \mu \mu \quad \log I=3,45563 \\
& ,=680,, \quad, \quad=3,41206 \\
& \eta=660 \quad, \quad, \quad,=3,34476 \\
& ,=640, \quad, \quad,=3,23888 \\
& ,=620, \quad, \quad,=3,15905 \\
& ,=600 \quad, \quad, \quad,=3,03884 \\
& ,=580 \quad, \quad, \quad,=2,91041 \\
& ,=560 \quad, \quad, \quad,=2,78116 \\
& \eta=540 \quad, \quad, \quad,=2,61071 \\
& ,=520,, \quad, \quad,=2,42520 \\
& ,=500, \quad, \quad, \quad,=2,20834 \\
& ,=480 \quad, \quad, \quad,=1,91285 \\
& "=460 \quad, \quad, \quad,=1,54 \quad 134 \\
& ,=450 \quad, \quad, \quad,=1,34678
\end{aligned}
$$

Tabelle V. Lichtempfindlichkeit helladaptierter junger Hähne.

Tabelle VI. Lichtempfindlichkeit helladaptierter ausgewachsener Hähne.

$\begin{array}{cccc}\text { Welleniänge } & \text { Nicolgrad } & \text { Intensität } & \text { Empfindlichkeit } \cdot 1000 \\ 700 \mu \mu & 90^{\circ} & 2800 & 0,4 \\ 680, & 45^{\circ} & 1290 & 0,8 \\ 660 ", & 29^{\circ} & 520 & 1,9 \\ 640, & 21^{\circ} & 223 & 4,5 \\ 620 " & 20^{\circ} & 169 & 5,9 \\ 600 " & 22^{\circ} & 154 & 6,5 \\ 580, & 25^{\circ} & 145 & 6,9 \text { Maximum } \\ 560 " & 30^{\circ} & 151 & 6,6 \\ 540, & 40^{\circ} & 169 & 5,9 \\ 520, & 60^{\circ} & 200 & 5,0\end{array}$


Untersuchungen über Lichtempfindlichkeit und Adaptierung des Vogelauges. 65

Tabelle VII. Menschliche Schwellenwerts- und Empfindlichkeitswerte zum Vergleich. Gemessen nach 30 Sekunden Dunkelaufenthalt.

$\begin{array}{cccc}\text { Wellenlänge } & \text { Nicolgrad } & \text { Intensität } & \text { Empfindlichkeit } \cdot 1000 \\ 660 \mu \mu & 76^{\circ} & 2080 & 0,5 \\ 620 " & 28^{\circ} & 318 & 3,1 \\ 580 " & 21^{\circ} & 105 & 9,6 \\ 540 " & 14^{\circ} & 24 & 41,9 \\ 500 " & 24^{\circ} & 27 & 37,4 \\ 480 " & 40^{\circ} & 34 & 29,6\end{array}$

Ta belle VIII. Lichtempfindlichkeit 8 Stunden lang dunkeladaptierter junger Hähne.

Wellenlänge
$700 \mu \mu$
$680 "$,
660,
640,
620,
600,
580,
560,
540,
520,
500,
480,
460,
450,

Intensităt

1915

850

250

75

30

12

6,2

3,5

2,2

1,6

2,3

2,9

3,8

7,3
Empfindlichkeit - 1000

0,5

1,2

4

13

33

84.

161

284

460

610

436

340

260

137

Tabelle IX. Lichtempfindlichkeit 8 Stunden lang dunkeladaptierter ausgewachsener Hähne.

\begin{tabular}{|c|c|c|c|}
\hline \multirow{2}{*}{\multicolumn{2}{|c|}{ Wellenlänge }} & Intensität & Empfindlichkeit · 1000 \\
\hline & & 2800 & 0,4 \\
\hline 680 & , & 1290 & 0,8 \\
\hline 660 & , & 520 & 1,9 \\
\hline 640 & , & 148 & 6,7 \\
\hline 620 & , & 62 & 16 \\
\hline 600 &, & 21 & 47 \\
\hline 580 & , & 12 & 83 \\
\hline 560 & $\because$ & 5,6 & 180 \\
\hline 540 & " & 4,5 & 224 \\
\hline 520 & , & 4,0 & 253 \\
\hline 500 & , & 4,4 & 227 \\
\hline 480 & ," & 5,5 & 183 \\
\hline 460 & , & 7,7 & 130 \\
\hline 450 & ," & 8,8 & 114 \\
\hline
\end{tabular}

Tabelle X. Zunahme der Empfindlichkeit des Huhnes für Licht von $660 \mu \mu$ Wellenlänge während der Dunkeladaptierung.

Dunkelaufenthalt

$\begin{aligned} 0^{\prime} & 29^{\circ} \\ 27^{\prime} & 23^{\circ} \\ 1^{\text {h }} 9^{\prime} & 21^{\circ} \\ 5^{\text {h }} 44^{\prime} & 20^{\circ} \\ 8^{\text {h }} 00^{\prime} & 19^{\circ}\end{aligned}$

Intensität

520

338

284

259

250
Empfindlichkeit • 1000

1,9

3,0

3,5

3,9

4,0

Pflügers Archiv f. d. ges. Physiol. Bd. 189. 
Tabelle XI. Zunahme der Empfindlichkeit des Huhnes für Licht von $620 \mu \mu$ Wellenlänge während der Dunkeladaptierung.

Dunkelaufenthalt

$0^{\prime}$

$17^{\prime}$

$28^{\prime}$

$53^{\prime}$

$4^{\mathrm{h}} 17^{\prime}$

$8^{\text {h }} 30^{\prime}$
Nicolgrad

$19^{\circ}$

$16^{\circ}$

$15^{\circ}$

$14^{\circ}$

$12^{\circ}$

$8^{\circ}$
Intensität

153

110

97

84

62

28
Empfindlichkeit $\cdot 1000$

$$
6,5
$$

9

10

12

16

36

Tabelle XII. Zunahme der Empfindlichkeit des Huhnes für Licht von $580 \mu \mu$ Wellenlänge während der Dunkeladaptierung.

Dunkelaufenthalt

$0^{\prime}$

$13^{\prime}$

$25^{\prime}$

$I^{\text {h }} 16^{\prime}$

$3^{\text {h }} 45^{\prime}$

$8^{\mathrm{h}} 00^{\prime}$

Intensität
114
86
62
35
12
6

Empfindlichkeit $\cdot 1000$

$$
8,8
$$

12

16

28

83

161

Tabelle XIII. Zunahme der Empfindlichkeit des Huhnes für Licht von $560 \mu \mu$ Wellenlänge während der Dunkeladaptierung.

$\begin{array}{cc}\text { Dunkelaufenthalt } & \text { Nicolgrad } \\ 0^{\prime} & 25^{\circ} \\ 22^{\prime} & 15^{\circ} \\ 46^{\prime} & 9^{\circ} \\ 1^{\mathrm{h}} 3^{\prime} & 7^{\circ} \\ 2^{\mathrm{h}} 17^{\prime} & 6^{\circ} \\ 10^{\mathrm{h}} 15^{\prime} & 4^{\circ}\end{array}$

$\begin{array}{cc}\text { Intensität } & \text { Empfindlichkeit } \cdot 1000 \\ 108 & 9,3 \\ 40 & 25 \\ 15 & 68 \\ 9 & 111 \\ 7 & 152 \\ 3 & 340\end{array}$

Tabelle XIV. Zunahme der Empfindlichkeit des Huhnes für Licht von $540 \mu \mu$ Wellenlänge während der Dunkeladaptierung.

Dunkelau
0
9
$19^{\prime}$
$30^{-}$
57
$5^{\text {h }} 00^{\prime}$
$9^{\text {h }} 00$

Nicolgrad
$31^{\circ}$
$22^{\circ}$
$14^{\circ}$
$10^{\circ}$
$7^{\circ}$
$5^{\circ}$
$4^{\circ}$

Intensität
108
57
24
12
6
3
2

Empfindlichkeit $\cdot 1000$

$0^{\prime}$

$9^{\prime}$

$19^{\prime}$

$30^{\prime}$

$57^{\prime}$

$9^{\text {h }} 00^{\prime}$ enthalt

.

Tabelle XV. Zunahme der Empfindlichkeit des Huhnes für Licht von $500 \mu \mu$ Wellenlänge während der Dunkeladaptierung.

$\begin{array}{cc}\text { Dunkelaufenthalt } & \text { Nicolgrad } \\ 0^{\prime} & 80^{\circ} \\ 15^{\prime} & 60^{\circ} \\ 20^{\prime} & 40^{\circ} \\ 23^{\prime} & 30^{\circ} \\ 32^{\prime} & 21^{\circ}\end{array}$

$\begin{array}{cc}\text { Intensität } & \text { Empfindlichkeit } \cdot 1000 \\ 157 & 6,4 \\ 121 & 8 \\ 67 & 15 \\ 40 & 25 \\ 21 & 48\end{array}$


Untersuchungen über Lichtempfindlichkeit und Adaptierung des Vogelauges. $\quad 67$

Tabelle XV. (Fortsetzung).

$\begin{array}{cccc}\text { Dunkelaufenthalt } & \text { Nicolgrad } & \text { Intensität } & \text { Empfindlichkeit } \cdot 1000 \\ 1^{\mathrm{h}} 24^{\prime} & 12^{\circ} & 7 & 143 \\ 1^{\mathrm{h}} 40^{\prime} & 11^{\circ} & 6 & 170 \\ 5^{\mathrm{h}} 30^{\prime} & 8^{\circ} & 3 & 319 \\ 9^{\mathrm{h}} 6^{\prime} & 6,5^{\circ} & 2 & 483\end{array}$

Tabelle XVI. Zunahme der Empfindlichkeit des Huhnes für Iicht von $460 \mu \mu$ Wellenlänge während der Dunkeladaptierung.

$\begin{array}{cccc}\begin{array}{c}\text { Dunkel- } \\ \text { aufenthalt }\end{array} & \text { Nicolgrad } & \text { Intensität } & \begin{array}{c}\text { Empfindlich- } \\ \text { keit } \cdot 1000\end{array} \\ 45^{\prime} & 90^{\circ} & 35 & 29 \\ 1^{\text {h }} 10^{\prime} & 45^{\circ} & 17 & 58 \\ 1^{\text {h }} 25^{\prime} & 39^{\circ} & 14 & 73 \\ 2^{\text {h }} 9^{\prime} & 30^{\circ} & 8,7 & 115 \\ 5^{\text {h }} 53^{\prime} & 20^{\circ} & 4,1 & 246 \\ 9^{\text {h }} 40^{\prime} & 19^{\circ} & 3,7 & 271\end{array}$

Tabelle XVII. Zunahme der Empfindlichkeit des Menschen für Licht von $620 \mu \mu$ Wellenlänge während der Dunkeladaptierung.

$\begin{array}{cccc}\begin{array}{c}\text { Dunkel- } \\ \text { aufenthalt }\end{array} & \text { Nicolgrad } & \text { Intensität } & \begin{array}{c}\text { Empfindlich } \\ \text { keit } \cdot \mathbf{1 0 0 0}\end{array} \\ 0,5^{\prime} & 28^{\circ} & 318 & 3,1 \\ 4^{\prime} & 20^{\circ} & 177 & 5,7 \\ 5^{\prime} & 18^{\circ} & 138 & 7 \\ 15^{\prime} & 15^{\circ} & 97 & 10 \\ 37^{\prime} & 13^{\circ} & 73 & 14 \\ 47^{\prime} & 12^{\circ} & 62 & 16 \\ 54^{\prime} & 12^{\circ} & 62 & 16\end{array}$

Tabelle XVIII. Zunahme der Empfindlichkeit des Menschen für Licht von $540 \mu \mu$ Wellenlänge während der Dunkeladaptierung.

$\begin{array}{cccc}\begin{array}{c}\text { Dunkel- } \\ \text { aufenthalt }\end{array} & \text { Nicolgrad } & \text { Intensität } & \begin{array}{c}\text { Empfindlich- } \\ \text { keit } \cdot 1000\end{array} \\ 0,5^{\prime} & 14^{\circ} & 24 & 41,9 \\ 2^{\prime} & 9^{\circ} & 10 & 100 \\ 5^{\prime} & 7^{\circ} & 6 & 165 \\ 8^{\prime} & 5,5^{\circ} & 3,8 & 267 \\ 12^{\prime} & 5^{\circ} & 3,1 & 323 \\ 16,5^{\prime} & 4^{\circ} & 2,0 & 504 \\ 26^{\prime} & 3^{\circ} & 1,1 & 895 \\ 40^{\prime} & 3^{\circ} & 1,1 & 895\end{array}$

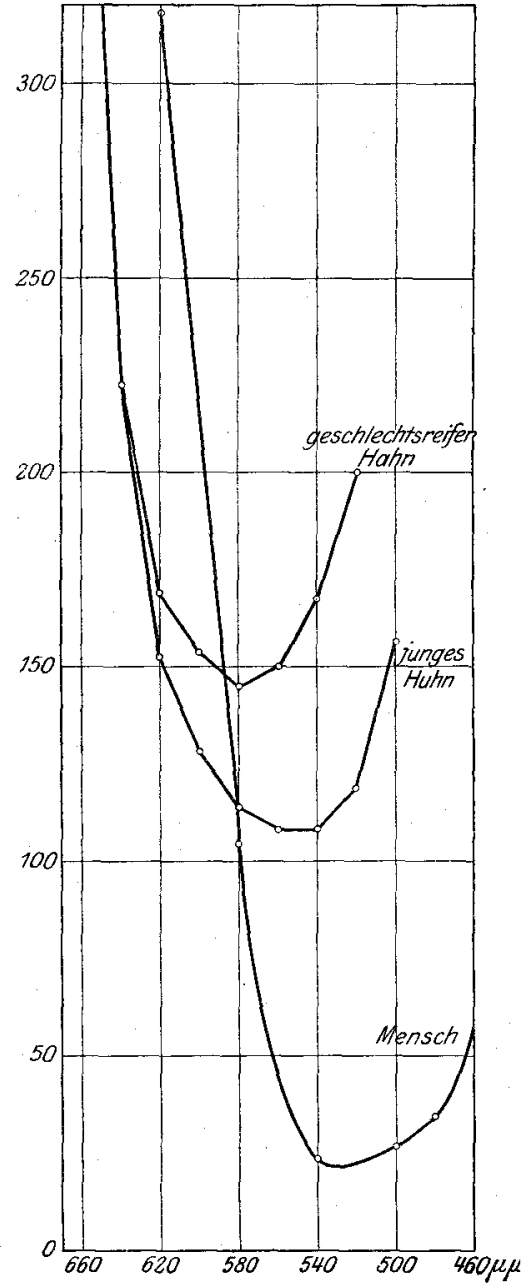

Abb. 4. Schwellenwerte der Intensität für helladaptierte (junge und geschlechtsreife) Hühner und den gleichfalls helladaptierten Menschen. 

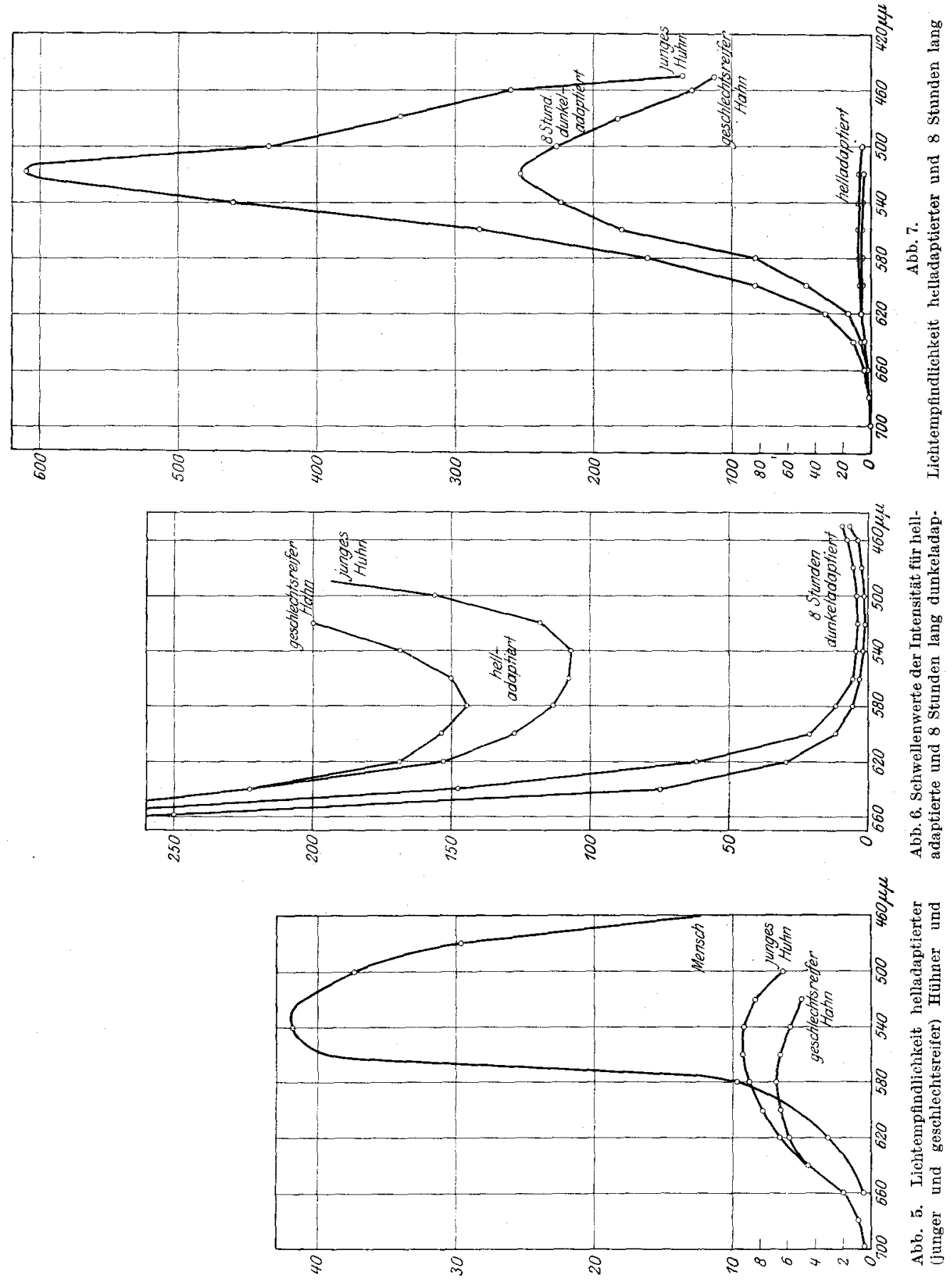


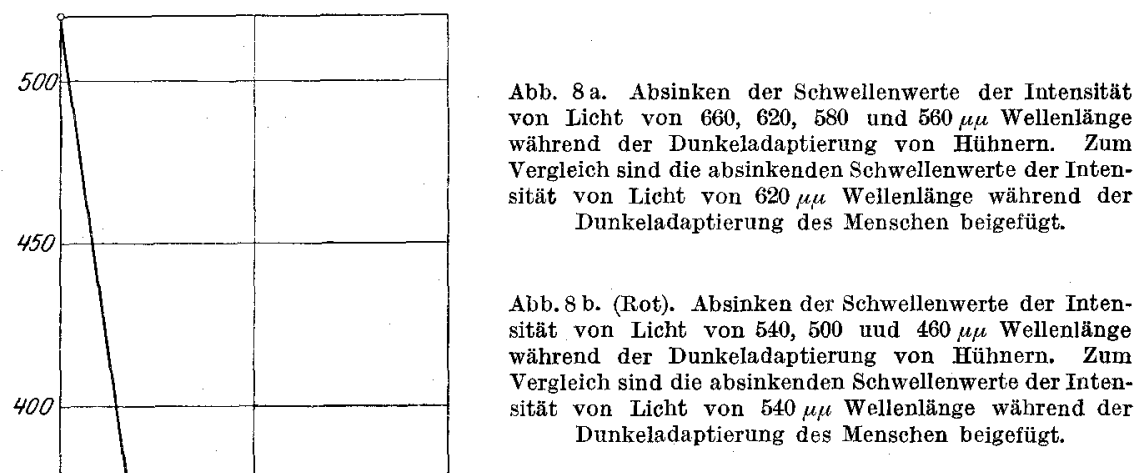

Um Raum zu sparen, ist hier (ebenso auf $\mathrm{Abb}$. 9) der Abszissenmaßstab von der 2. Stunde ab auf die Hälfte verkleinert worden, was zu beachten ist. 


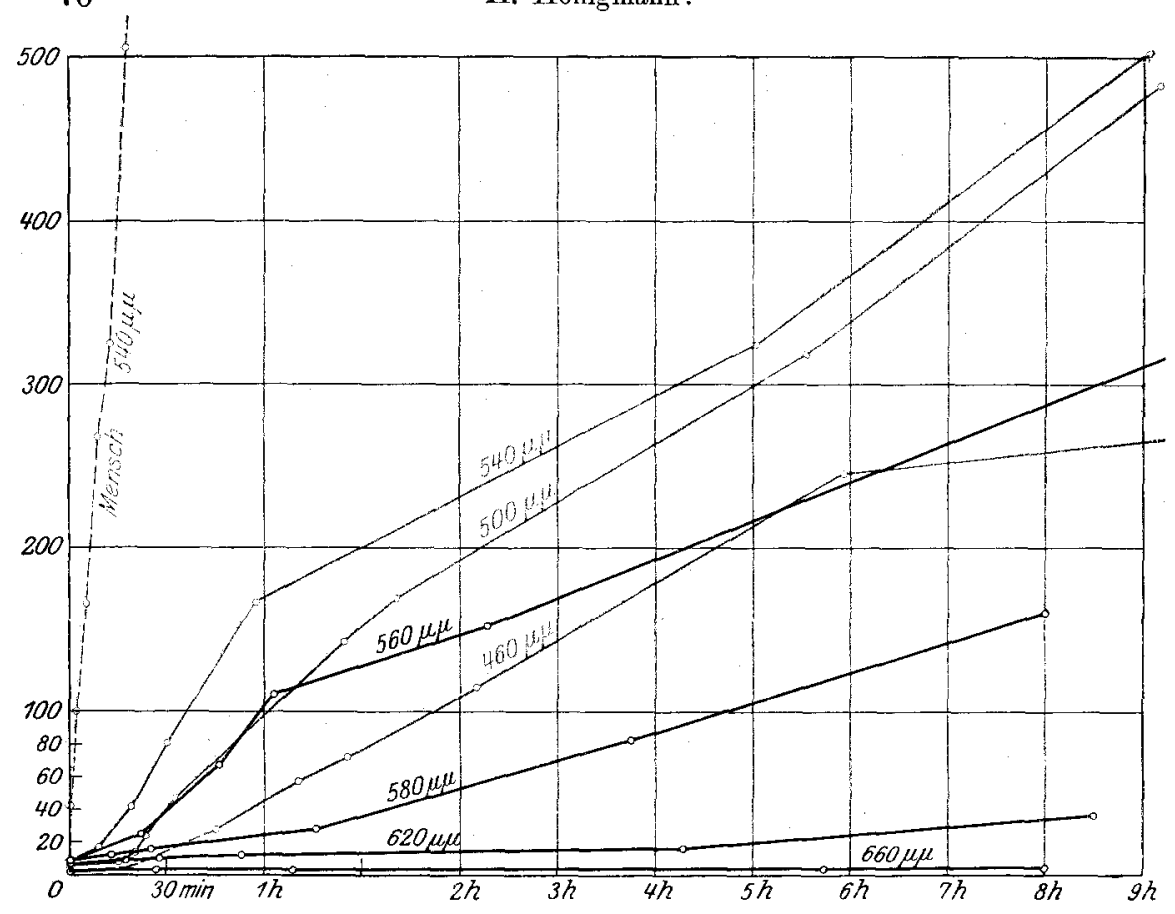

Abb. 9a. Zunahme der Empfindlichkeit für Licht von $660,620,580$ und $560 \mu \omega$. Wellenlänge während der Dunkeladaptierung von Hühnern.

Abb. 9 b. (Rot). Zunahme der Empfindlichkeit für Licht von 540, 500 und 460 Wellenlänge während der Dunkeladaptierung von Hühnern. Zum Vergleich ist die Zunahme der Empfindlichkeit des Menschen für Licht von $540 \mu \mu$ Wellenlänge während der Dunkeladaptierung mit dargestellt.

\section{Literaturverzeichnis.}

Abelsdorff, G., Zur Erforschung des Helligkeits- und Farbensinnes bei Menschen und Tieren. Arch. f. Anat. u. Physiol. 1900. - Abelsdorff, G., Einige Bemerkungen über den Farbensinn der Tag- und Nachtvögel. Areh. f. Augenheilk. 58. 1907. - Aubert, Hermann, Beiträge zur Physiologie der Netzhaut. Abhandlungen der Schles. Gesellsch. f. vaterl. Kultur, Abt. f. Naturwissensch. u. Medizin. Breslau 1861. - Aubert, Hermann, Physiologie der Netzhaut. Breslau 1865. - Babak, Edward, Über den Farbensinn des Frosches, vermittels Atemreaktionen untersucht. Zeitschr. f. Psychol. u. Physiol. d. Sinnesorg. 4\%. 1913. - Bauer, Victor, Über das Farbenunterscheidungsvermögen der Fische. Arch. f. d. ges. Physiol. 133. 1910. - Bender, Hedwig, Untersuchungen am Lummer-Pringsheimschen Spektralflickerphotometer. Inaug.-Diss. Breslau 1913. - Best, F., Über die Dunkeladaptation der Netzhaut. Graefes Archiv 76.1910. - Best, F., Über Nachtblindheit. Graefes Archiv 98. 1918. — Best, F., Untersuchungen über die Dunkelanpassung des Auges mit Leuchtfarben. Zeitschr. f. Biol. 68. 1919. - Boehm, Marie, Über physiologische Methoden zur Prüfung der Zusammensetzung gemischter Lichter. Zeitschr. f. Sinnesphysiol. 42. 1908. - Brücke, E. Th. v. und Garten, S., Zur vergleichenden Physiologie der Netzhautströme, Arch. f. d. ges. Physiol. 120. 1907. - Dittler, Rudolf und Izuo Koike, Über die Adaptationsfähigkeit der Fovea centralis. Zeitschr. f. Sinnesphysiol. 46. 19I2. - Fechner, G. Th., Elemente der Psychophysik. Leipzig 1860. 
- Garten, S., Veränderungen der Netzhaut durch Licht. Graefe-Sämisch Handbuch, Teil I, III. 1908. - Golant, Raissa, Über das Licht der Nernstlampe und seine Verwendung zu physiologisch-optischen Zwecken. Zeitschr. f. Sinnesphysiol. 43. 1909. - Graber, O., Grundlinien zur Erforschung des Helligkeits- und Farbensinnes der Tiere. Prag und Leipzig 1884 - Hahn, Erna, Über den Farbensinn der Tagvögel und die Zapfenölkugeln. Zeitschr. f, wissenschaftl. Zool. 110. 1916. - Helmholtz, H. v., Handbuch der physiologischen Optik. 2. Bd. Die Lehre von den Gesichtsempfindungen. Leipzig und Hamburg 1911. - Henning, Hans, Optische Versuche an Vögeln und Schildkröten über die Bedeutung der roten Ölkugeln im Auge. Arch. f. d. ges. Physiol. 178. 1920. Hertel, E., Experimentelles über die Verengerung der Pupille auf Lichtreize. Bericht über die 33. Verhandl. d. Ophthalmol. Gesellsch. 1906. - Herte1, E., Einiges über die Empfindlichkeit des Auges gegen Tichtstrahlen. Bericht über die 34. Versamml. d. Ophthalmol. Gesellsch. 1907. - Hess, C., Über Dunkeladaptation und Sehpurpur bei Hühnern und Tauben. Arch. f. Augenheilk. 5\%. 1907, I. - Hess, C., Untersuchungen über Lichtsinn und Farbensinn bei Tagvögeln. Arch. f. Augenheilk. 5\%. 1907, II. - Hess, C., Untersuchungen über das Sehen und die Pupillenreaktion von Tag- und Nachtvögeln. Arch. f. Augenheilk. 59. 1908. - Hess, C., Experimentelle Untersuchungen zur vgl. Physiologie des Gesichtssinnes, Arch. f. d. ges. Physiol. 142. 1911. - Hess, C., Gesichtssinn. Handbuch der vgl. Physiologie 4. Jena 1912. - Hess, C., Messende Untersuchungen zur vgl. Physiologie des Pupillenspieles. Graefes Archiv 90. 1915. - Hess, C., Der Farbensinn der Vögel und die Lehre von den Sehmuckfarben. Arch. f. d. ges. Physiol. 166. 1917. - Honigmann, Hans, Methoden zur Erforschung von Licht. und Farbensinn der Tiere. Jahresb. d. Schles. Gesellsch. f. vaterl. Cultur 1916. - Katz, D. und G. R évész, Experimentell-physiologische Untersuchungen an Hühnern. Zeitschr. f. Psychologie 50. 1909. - Koenig, Arth ur, Gesammelte Abhandlungen zur physiologischen Optik. Leipzig 1903. - Kohlrausch, Arnt und Alessandro Brossa, Die Aktionsströme der Netzhaut bei Reizung mit homogenen Lichtern. Arch. f. Anat. u. Physiol. 1913. - Kohlrausch, Arnt und Alessandro Brossa, Die photoelektrische Reaktion der Tag- und Nachtvögelnetzhaut auf Licht verschiedener Wellen]änge. Arch. f. Anat. u. Physiol. 1914. - Kohlrausch, Arnt, Die Netzhautströme der Wirbeltiere in Abhängigkeit von der Wellenlänge des Lichtes und dem Adaptationszustand des Auges. Arch. f. Anat. u. Physiol. 1918. - Koh n, Hedwig, Über das Wesen der Emission der in Flammen leuchtenden Metalldämpfe. Inaug. Diss. Breslau 1913. - Köttgen, Else und Georg Abelsdorff, Absorption und Zersetzung des Sehpurpurs bei den Wirbeltieren. Zeitschr. f. Sinnesphysiol. 12. 1896. - Kries, J. v. und W. Nagel, Weitere Mitteilungen über die funktionelle Sonderstellung des Netzhautzentrums. Zeitschr. f. Sinnesphysiol. 23. 1900. - Kries, J. v., Über die Abhängigkeit der Dämmerungswerte vom Adaptationsgrade. Zeitschr. f. Sinnesphysiol. 25. 190I. - Laurens, Henry, The reactions of amphibians to monochromatic lights of equal intensity. Bull. of the museum of comp. Zoology 1911. Harvard College, Cambridge, Massach. - Lummer, o. und E. Brodhun, Photometrische Untersuchungen. V. Über ein neues Spektralphotometer. Zeitschr. f. Instrumentenkunde 12. 1892. - L u mmer, O. und F. Kurlba u m, Der elektrisch geglühte ,schwarze" Körper. Ann. d. Physik 1901. - Nagel, W, A., Über flüssige Strahlenfilter. Biol. Centralbl. 18. 1898. - Nagel, W. A., und K. L. Schä. fer, Über das Verhalten der Netzhautzapfen bei Dunkeladaptation des Auges. Zeitschr. f. Sinnesphysiol. 34. 1904. - Peschel, Max, Experimentelle Untersuchungen über die Adaptation der Netzhaut für Farben. Arch. f. d. ges. Physiol. 21. 1880. - Pi per, H., Utber Dunkeladaptation. Zeitschr. f. Sinnesphysiol. 31. 1903. - Pi per, H., Untersuchungen über das elektromotorische Verhalten der 
72 H. Honigmann: Lichtempfindlichkeit und Adaptierung des Vogelauges.

Netzhaut bei Warmblütern. Arch. f. Anat. u. Physiol. 1905, Suppl.-Bd. - Purkinje, Johann, Beobachtungen und Versuche zur Physiologie der Sinne. 2. Bändchen: Neue Beiträge zur Kenntnis des Sehens in subjektiver Hinsicht. Berlin 1825. - Sachs, Moritz, Über den Einfluß farbiger Lichter auf die Weite der Pupille. Arch. f. d. ges. Physiol. 52. 1892. - Sachs, Moritz, Eine Methode zur okjektiven Prüfung des Farbensinnes. Graefes Archiv 39. 1893. - Stegmann, Ricardo, Über die Abhängigkeit der Dämmerungswerte vom Adaptationsgrad. Inaug.-Diss. Freiburg 1900. - Trendelenburg, Wilhelm, Quantitative Untersuchungen über die Bleichung des Sehpurpurs im monochromatischen Licht. Zeitschr. f. Sinnespsychiol. 3r. 1904. - Uexküll, J. v., Das Subjekt als Träger des Lebens. Die Neue Rundschan 23, I. 1912. — Waelchi, G., Zur Topographie der gefärbten Kugeln der Vogelnetzhaut. Graefes Archiv 29, III. Abt. 1883. 